Aus der Abteilung Nephrologie und Rheumatologie

(Prof. Dr. med. G. A. Müller)

im Zentrum Innere Medizin

der Medizinischen Fakultät der Universität Göttingen

\title{
Regulation der Nestinexpression bei der epithelial-mesenchymalen Transition
}

\author{
INAUGURAL-DISSERTATION \\ zur Erlangung des Doktorgrades für Zahnheilkunde \\ der Medizinischen Fakultät \\ der Georg-August-Universität zu Göttingen
}

vorgelegt von

Anja Franziska Lotzkat

aus

Hannover

Göttingen 2011 
Dekan: Prof. Dr. med. C. Frömmel

I. Berichterstatter: Prof. Dr. med. F. Strutz

II. Berichterstatter/in: Prof. Dr. med. N. Miosge

III. Berichterstatter/in: /

Tag der mündlichen Prüfung: 28. Februar 2012 


\section{Inhaltsverzeichnis}

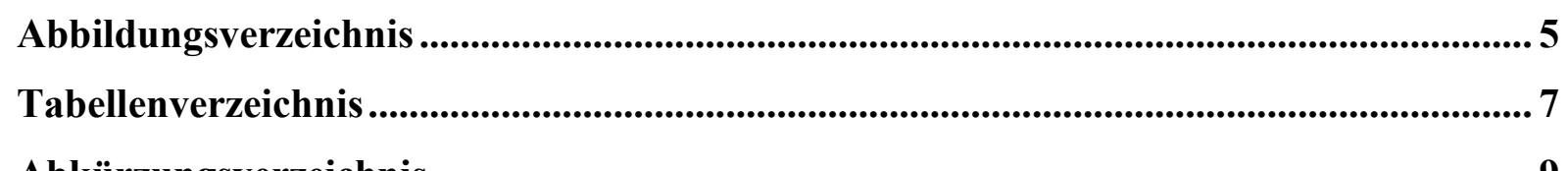

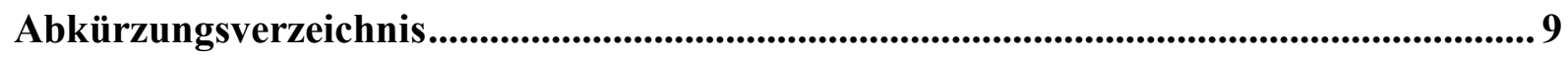

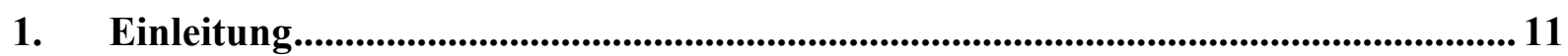

1.1. Allgemeiner Überblick über die Problematik und die Folgen einer chronischen Niereninsuffizienz ....................................................................... 11

1.2. Embryogenese der Niere und der Prozess der MET .............................................. 12

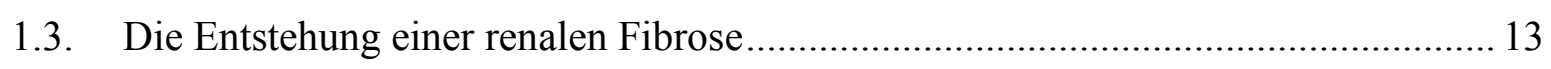

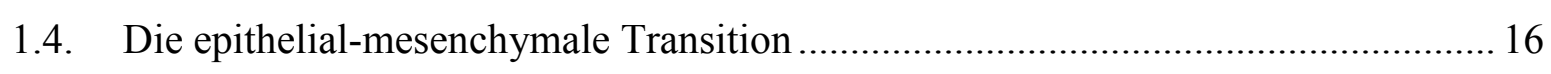

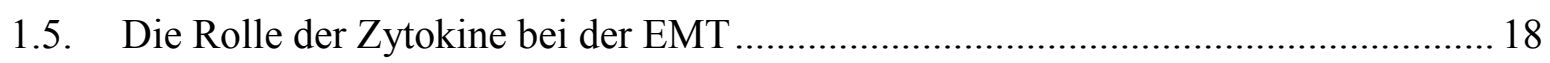

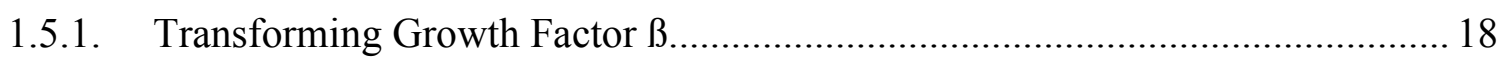

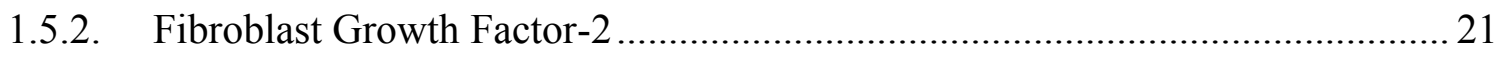

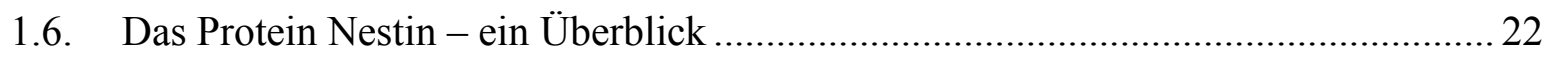

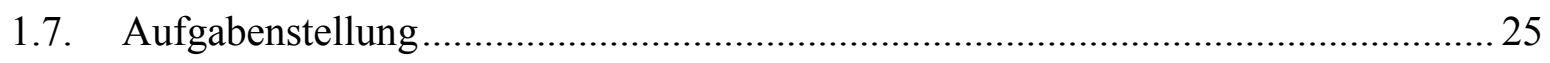

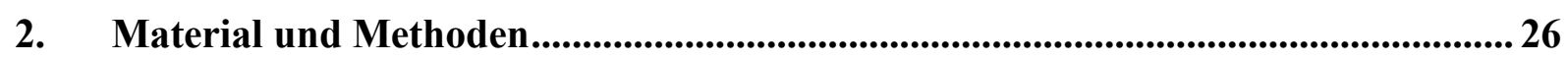

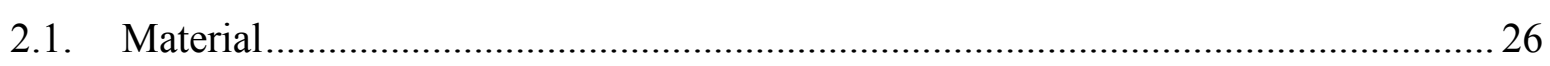

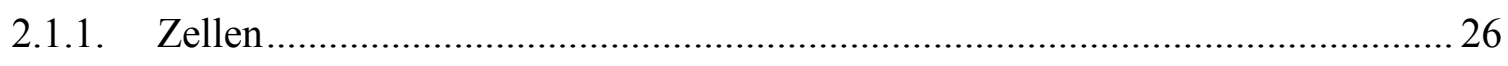

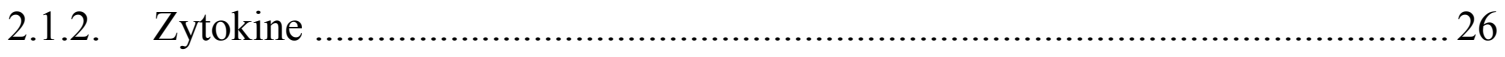

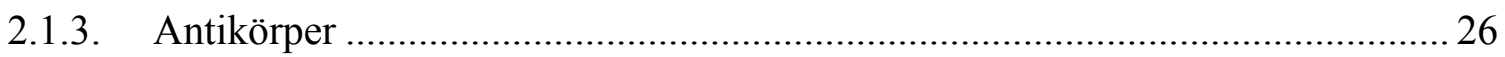

2.1.4. Zusammensetzung verwendeter Reagenzien............................................... 27

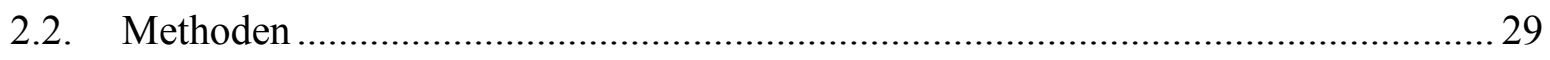

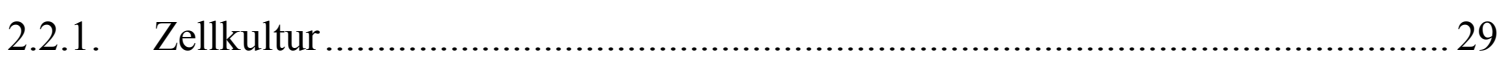

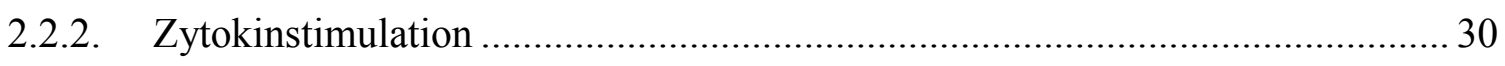

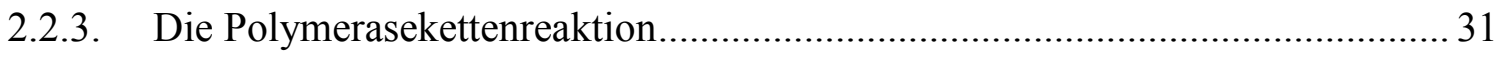

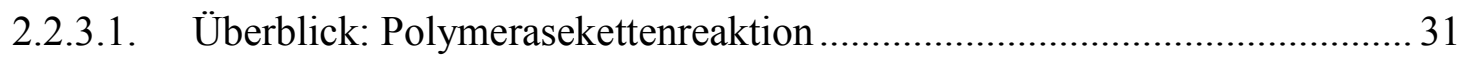

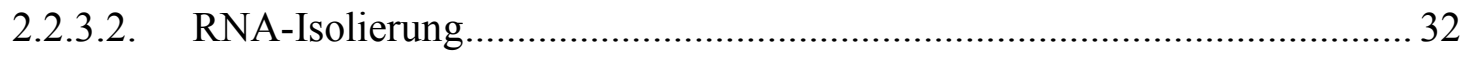

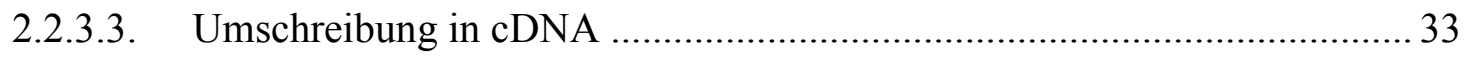

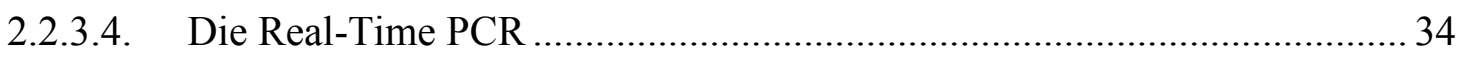

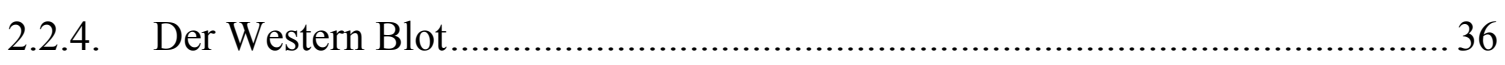

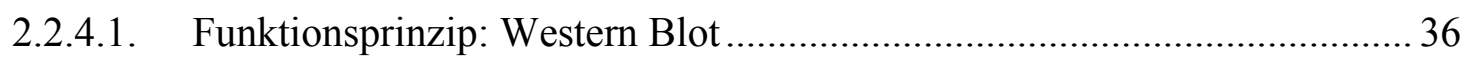

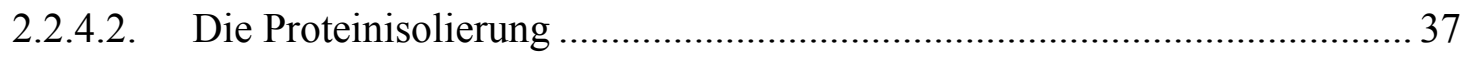


2.2.4.3. Die Messung der Proteinkonzentration.................................................... 37

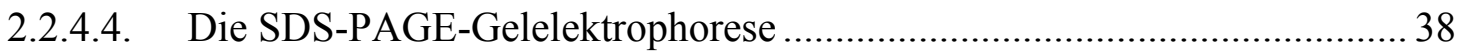

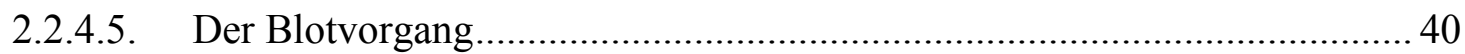

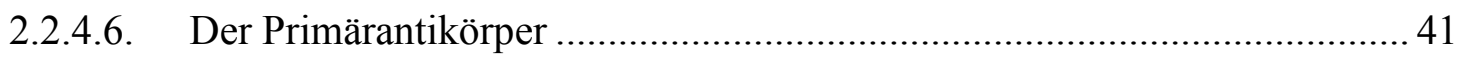

2.2.4.7. Der Sekundärantikörper ..................................................................... 41

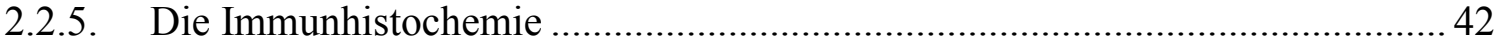

2.2.5.1. Funktionsprinzip: Immunhistochemie ................................................... 42

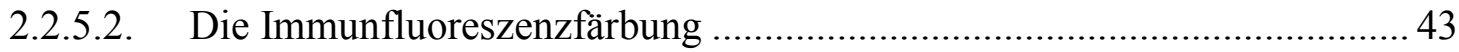

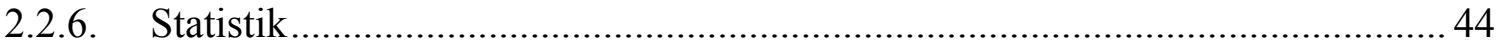

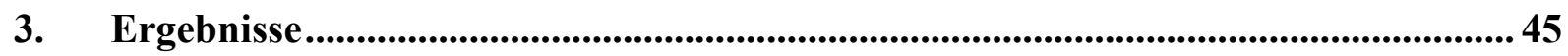

3.1. Ergebnisse der Genexpressionsanalyse für Nestin mittels Real-Time PCR............. 45

3.1.1. Konzentrationsabhängige Untersuchung der Nestinexpression in murinen

Tubulusepithelzellen nach Zytokinstimulation mit TGF-ß und FGF-2 …......... 45

3.1.1.1. Ergebnisse der proximalen Tubulusepithelzellreihe MCT ........................ 45

3.1.1.2. Ergebnisse der distalen Tubulusepithelzellreihe NP-1 ........................... 47

3.1.2. Zeitabhängige Untersuchung der Nestinexpression in murinen

Tubulusepithelzellen nach Zytokinstimulation mit TGF-ß und FGF-2 ............. 49

3.1.2.1. Ergebnisse der proximalen Tubulusepithelzellreihe MCT ........................ 49

3.1.2.2. Ergebnisse der distalen Tubulusepithelzellreihe NP-1 ............................ 51

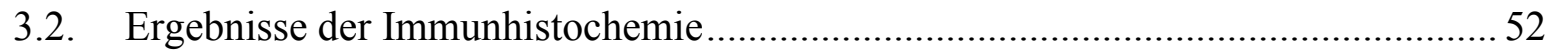

3.2.1. Ergebnisse der Immunfluoreszenzfärbungen bezüglich des Nestingehalts in der Zellreihe MCT nach Stimulation mit TGF- $§$ und FGF-2 _...................... 52

3.2.2. Ergebnisse der Immunfluoreszenzfärbungen bezüglich des Nestingehalts in der Zellreihe NP-1 nach Stimulation mit TGF-ß und FGF-2 …................... 57

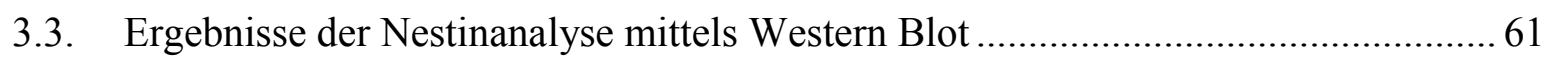

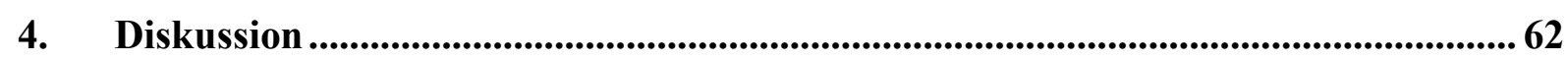

5. Zusammenfassung ….................................................................................................... 77

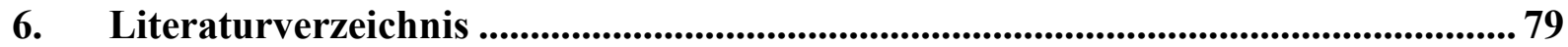




\section{Abbildungsverzeichnis}

Abbildung 1: Mögliche Quellen der Zellen, die an der Produktion der extrazellulären Matrix in der Niere beteiligt sind..

Abbildung 2: Mechanismus der TGF-ß-gesteuerten Signaltransduktion 20

Abbildung 3: Zytokinstimulation mit TGF-ß und FGF-2 von für einen Zeitraum von 8 Stunden. 45

Abbildung 4: Zytokinstimulation mit TGF-ß und FGF-2 von NP-1-Zellen für einen Zeitraum von 8 Stunden. 47

Abbildung 5: Zytokinstimulation von über einen Zeitraum von 4, 8 und 24 Stunden mit der Konzentration $10 \mathrm{ng} / \mathrm{ml}$ der Zytokine TGF-ß und FGF-2.

Abbildung 6: Zytokinstimulation von NP-1-Zellen über einen Zeitraum von 4, 8 und 24 Stunden mit der Konzentration 10 ng/ml der Zytokine TGF- $ß$ und FGF-2 ...... 51

Abbildung 7: Immunhistochemische Färbung an proximalen Tubulusepithelzellen (MCT) auf Nestin. A: Negativkontrolle, Kernfärbung DAPI (400x). B: Zellprobe, die im Versuchsablauf keiner Stimulation mit TGF-ß oder FGF-2 unterlag (400x). .. 53

Abbildung 8: Immunhistochemische Färbung an proximalen Tubulusepithelzellen (MCT) auf Nestin nach TGF-ß-Behandlung. A: Stimulation mit TGF- $\beta$ in der Konzentration $0,1 \mathrm{ng} / \mathrm{ml}$ für $48 \mathrm{~h}(1000 \mathrm{x})$. B: Stimulation mit TGF- $\beta$ in der Konzentration $1 \mathrm{ng} / \mathrm{ml}$ für 48 h (200x). C: Stimulation mit TGF-ß in der Konzentration $10 \mathrm{ng} / \mathrm{ml}$ für $48 \mathrm{~h}$ (1000x).

Abbildung 9: Immunhistochemische Färbung an proximalen Tubulusepithelzellen (MCT) auf Nestin nach FGF-2-Behandlung. A: Stimulation mit FGF-2 in der Konzentration 0,1 ng/ml für $48 \mathrm{~h}(1000 \mathrm{x})$. B: Stimulation mit FGF-2 in der Konzentration $1 \mathrm{ng} / \mathrm{ml}$ für 48 h (200x). C: Stimulation mit FGF-2 in der Konzentration $10 \mathrm{ng} / \mathrm{ml}$ für $48 \mathrm{~h}$ (200x). 
Abbildung 10: Zytokinstimulation von mit TGF- $\beta$ und FGF-2 mit den Konzentrationen 0,1 $\mathrm{ng} / \mathrm{ml}, 1 \mathrm{ng} / \mathrm{ml}$ und $10 \mathrm{ng} / \mathrm{ml}$ für 48 Stunden. . .55

Abbildung 11: Immunhistochemische Färbung an distalen Tubulusepithelzellen (NP-1) auf Nestin. A: Negativkontrolle, Kernfärbung DAPI (400x) B: Zellprobe, die im Versuchsablauf keiner Stimulation mit TGF-ß oder FGF-2 unterlag (1000x) 57

Abbildung 12: Immunhistochemische Färbung an distalen Tubulusepithelzellen (NP-1) auf Nestin nach TGF- $\beta$-Behandlung. A: Stimulation mit TGF- $\beta$ in der Konzentration 0,1 ng/ml für $48 \mathrm{~h}(1000 \mathrm{x})$. B: Stimulation mit TGF-ß in der Konzentration $1 \mathrm{ng} / \mathrm{ml}$ für $48 \mathrm{~h}$ (400x). C: Stimulation mit TGF-ß in der Konzentration $10 \mathrm{ng} / \mathrm{ml}$ für $48 \mathrm{~h}$ (1000x).

Abbildung 13: Immunhistochemische Färbung an distalen Tubulusepithelzellen (NP-1) auf Nestin nach FGF-2-Behandlung. A: Stimulation mit FGF-2 in der Konzentration 0,1 ng/ml für $48 \mathrm{~h}(1000 \mathrm{x})$. B: Stimulation mit FGF-2 in der Konzentration $1 \mathrm{ng} / \mathrm{ml}$ für $48 \mathrm{~h}(1000 \mathrm{x})$. C: Stimulation mit FGF-2 in der Konzentration $10 \mathrm{ng} / \mathrm{ml}$ für $48 \mathrm{~h}(400 \mathrm{x})$.

Abbildung 14: Zytokinstimulation von NP-1-Zellen mit TGF- 3 und FGF-2 mit den Konzentrationen $0,1 \mathrm{ng} / \mathrm{ml}, 1 \mathrm{ng} / \mathrm{ml}$ und $10 \mathrm{ng} / \mathrm{ml}$ für 48 Stunden. 60 


\section{Tabellenverzeichnis}

Tabelle 1: Zytokine für Stimulationen 26

Tabelle 2: Übersicht verwendeter Primärantikörper 26

Tabelle 3: Übersicht verwendeter Sekundärantikörper

Tabelle 4: Zusammensetzung der Reagenzien

Tabelle 5: Übersicht Zellanzahl, Zytokinkonzentrationen und Stimulationsdauer, PCR........ 30

Tabelle 6: Übersicht Zellanzahl, Zytokinkonzentrationen und Stimulationsdauer, Western Blot

Tabelle 7: Übersicht Zellanzahl, Zytokinkonzentrationen und Stimulationsdauer, Immunhistochemie

Tabelle 8: Daten und Fakten der Nestin- und GAPDH-Primer 35

Tabelle 9: Schema der eingesetzten PCR-Zyklen und Temperaturen. 35

Tabelle 10: Statistische Ergebnisse der Nestinexpression bei MCT-Zellen nach konzentrationsabhängiger Zytokinstimulation 46

Tabelle 11: Statistische Ergebnisse der Nestinexpression bei NP-1-Zellen nach konzentrationsabhängiger Zytokinstimulation 48

Tabelle 12: Statistische Ergebnisse der Nestinexpression bei MCT-Zellen nach Zytokinstimulation über einen Zeitraum von 4, 8 und 24 Stunden

Tabelle 13: Statistische Ergebnisse der Nestinexpression bei NP-1-Zellen nach Zytokinstimulation über einen Zeitraum von 4, 8 und 24 Stunden. 
Tabelle 14: Statistische Ergebnisse des Quotienten Flächeninhalt (Nestin)/Zellzahl der Immunfluoreszenzfärbungen von MCT-Zellen nach konzentrationsabhängiger Zytokinstimulation.

Tabelle 15: Statistische Ergebnisse des Quotienten Flächeninhalt (Nestin)/Zellzahl der Immunfluoreszenzfärbungen von NP-1-Zellen nach konzentrationsabhängiger Zytokinstimulation. 60 


\section{Abkürzungsverzeichnis}

$\begin{array}{ll}\text { A/B } & \text { Acrylamid/Bis } \\ \text { Abb. } & \text { Abbildung } \\ \text { AK } & \text { Antikörper } \\ \text { APS } & \text { Ammoniumperoxodisulfat }\end{array}$

BMP Bone Morphogenic Protein

Bp Basenpaare

BSA Bovine Serumalbumin

cDNA complementary DNA

$\mathrm{CO}_{2} \quad$ Kohlenstoffdioxid

DAPI 4,6-Diamin-2-phenylindolhydrochlorid

DEPC Diethylpyrocarbonat

DMEM Dulbecco's Modified Eagle Medium

DNA Deoxyribonucleic acid

DTT Dithiothreitol

ECM Extrazelluläre Matrix

EDTA Ethylenediaminetetraacetic acid

EGF Epidermal Growth Factor

EMT Epithelial-mesenchymale Transition

FCS Fetal Calf Serum

FGF-2 Basic Fibroblast Growth Factor

FSP1 Fibroblast Specific Protein 1

GAPDH Glycerinaldehyd-3-Phosphat-Dehydrogenase

$\begin{array}{ll}\mathrm{h} & \text { Stunde } \\ \mathrm{H}_{2} \mathrm{O} & \text { Wasser } \\ \text { HRP } & \text { Horse Radish Peroxidase }\end{array}$




$\begin{array}{ll}\text { IL-1ß } & \text { Interleukin } 1 \beta \\ \text { IL-18 } & \text { Interleukin } 18\end{array}$

kDa Kilodalton

MET Mesenchymal-epitheliale Transformation

ml Milliliter

MMP Matrixmetalloproteinase

mRNA messenger RNA

$\mathrm{p} \quad$ Irrtumswahrscheinlichkeit

PAGE Polyacrylamid-Gelelektrophorese

PBS Phosphate Buffered Saline

PCR Polymerasekettenreaktion

$\mathrm{pH} \quad$ pondus Hydrogenii (lat.)

rh rekombinant human

RNA Ribonucleic acid

rpm Revolutions per minute/Umdrehungen pro Minute

SDS Sodium Dodecyl Sulfat

$\alpha$-SMA $\alpha$-Glattmuskelaktin

SMAD mothers against decapentaplegic Protein

Tab. Tabelle

TGF- $\beta 1 \quad$ Transforming Growth Factor Beta Eins

TGF-ß2 Transforming Growth Factor Beta Zwei

TGF-ß33 Transforming Growth Factor Beta Drei

TNF- $\alpha \quad$ Tumornekrosefaktor alpha

$\mathrm{U} / \mathrm{min} \quad$ Umdrehungen/Minute

Vergr. Vergrößerung 


\section{1. $\quad$ Einleitung}

\subsection{Allgemeiner Überblick über die Problematik und die Folgen einer chronischen Niereninsuffizienz}

Im Zuge der stetigen Zunahme der an Diabetes mellitus erkrankten Menschen in den Industrienationen weltweit gewinnt auch das Krankheitsbild der chronisch progredienten Niereninsuffizienz in Form einer diabetischen Nephropathie immer mehr an Bedeutung (Jakic et al. 2009). Die chronische Niereninsuffizienz kann des Weiteren auch in Verbindung mit anderen Erkrankungen wie zum Beispiel verschiedenen Glomerulonephritiden, der hypertensiven Nephrosklerose, toxischen sowie infektiösen tubulointerstitiellen Nephritiden und Vaskulitiden auftreten. Die Tatsache, dass Diabetes mellitus die Statistik als Hauptursache einer chronischen Niereninsuffizienz derzeit anführt, unterstreicht die langjährige Befürchtung, dass diese Volkskrankheit mit all ihren Folgeerscheinungen auf dem Vormarsch ist. Noch ca. zehn Jahre zuvor galten die Glomerulonephritiden als primäre Ursache (Frei und Schober-Halstenberg 1999).

Das Fortschreiten einer chronischen Niereninsuffizienz bis hin zum Nierenversagen wird als unaufhaltsamer Prozess angesehen (Liu 2004). Das Nierenparenchym wird nach und nach durch extrazelluläres Matrixgewebe ersetzt, was die Nierenfunktion der erkrankten Menschen erheblich negativ beeinflusst. Bei dieser fibrotischen Veränderung scheint das Ausmaß der Fibrose der Hauptfaktor für den tatsächlichen Funktionsverlust des Organs zu sein (Bohle et al. 1977; van Kooten et al. 1999). Den betroffenen Patienten bleibt häufig nur die Möglichkeit, sich lebenslang einem Dialyseverfahren $\mathrm{zu}$ unterziehen oder auf eine Nierentransplantation zu hoffen (Owen 2003). Laut dem QuaSi Niere Jahresbericht 2006/2007 unterzogen sich 91.718 Patienten einer Nierenersatztherapie (Frei und SchoberHalstenberg 2008). Im Jahre 1995 waren es hingegen mit einer Anzahl von 54.656 noch deutlich weniger Patienten. Somit ließ sich über einen Zeitraum von 11 Jahren eine Steigerung um 68\% feststellen (Frei und Schober-Halstenberg 1999). Die Nierenersatztherapie stellt jedoch kein optimales Behandlungsverfahren dar, da sie aufgrund von Komplikationen bei der Dialysetherapie oder im Rahmen der Transplantation eine recht hohe Mortalitätsrate nach sich zieht (Marshall et al. 2006; Zukowski et al. 2009). Hinzu kommen noch die starke Herabsetzung der Lebensqualität der Betroffenen sowie die finanzielle Belastung des Gesundheitssystems. Es bleibt die Suche nach einem adäquaten Therapieverfahren, welches der Minimierung der Nierenfunktion und den resultierenden, schwerwiegenden Konsequenzen Einhalt gebietet. 


\subsection{Embryogenese der Niere und der Prozess der MET}

Die Niere ist Teil des Urogenitalsystems und entsteht aus dem intermediären Mesoderm. Die zuvor als mesodermale Somiten bezeichneten Gewebsanteile verlieren nach und nach ihre stufenhafte Anordnung und entwickeln sich zu einem Gewebszusammenschluss, dem sogenannten Nephrotom. In zeitlicher und örtlicher Versetzung entstehen die folgenden drei sich überlappenden Nierensysteme: Die Vorniere (Pronephros), die Urniere (Mesonephros) und die Nachniere (Metanephros) (Wallner et al. 1998). Letztere stellt die Anlage der endgültigen Niere dar. Die Vorniere entsteht in der 3.-4. Embryonalwoche im Kopf- und Halsbereich und bildet sich, ohne jemals ihre Entwicklung abzuschließen oder eine Funktion auszuüben, wieder zurück. Allein der Vornierengang, die Verbindung von der Pronephros zur Kloake, bleibt erhalten. Später entwickelt sich dieser zum Urnierengang, der dann auch als Wolff-Gang bezeichnet wird. Aus dem thorakalen intermediären Mesoderm entwickelt sich in der 4.-5. Embryonalwoche die Urniere. Über kugel- und bläschenartige Zwischenstufen kommt es durch eine S-förmige Verbindung der Urniere mit dem ehemaligen Vornierengang zur Bildung des oben erwähnten Wolff'schen Ganges. Ein Teil dieses S-förmigen Kanälchens wird zum Urnierenkörperchen, in dem bereits ein Gefäßknäuel (späterer Glomerulus) und eine äußere Kapsel (Bowman-Kapsel) zu finden sind. Kaudal des Urnierenganges entsteht in der 4. Embryonalwoche die Ureterknospe, die die Entwicklungsvorstufe der Sammelrohre mit Verbindungsstücken zum Tubulussystem darstellt (Lin et al. 2003). Des Weiteren entstehen aus der Ureterknospe (ureteric bud) die Papillengänge, die Nierenkelche, das Nierenbecken sowie die Ureteren. Auf sakraler Ebene entsteht nun die Nachniere über die Vorstufe des metanephrogenen Blastems in der 5. Embryonalwoche (Owen 2003; Solhaug et al. 2004).

Die Epithelien der Niere stammen aus zwei verschiedenen Herkunftsorten. Einerseits bildet sich das Epithel der Sammelrohre durch das Aussprießen und die sich bildenden Verzweigungen der bereits epithelialen Ureterknospe. Das Wachstum wird hierbei durch das umgebende Mesenchym mittels Signaltransduktion beeinflusst (Lechner und Dressler 1997). Eine Isolation der Ureterknospe oder der Versuch, die Knospe mit andersartigem Mesenchym zu umgeben, bewirkt ein Ausbleiben der weiteren Entwicklung (Davies et al. 1999; Lin et al. 2003). Die Epithelien der Nephrone allerdings entstehen durch den Prozess der mesenchymalepithelialen Transition (Zou et al. 2006). Hierunter versteht man die Umwandlung von ursprünglich mesenchymalem in epitheliales Gewebe.

Zu Beginn der MET erhält das metanephritische Mesenchym ein bisher nicht identifiziertes Signal von Seiten der Ureterknospe. Als Reaktion darauf formiert sich ein engmaschiger 
Zellhaufen. Dieser durchwandert den Prozess der mesenchymal-epithelialen Transition. Über kugelartige und komma-förmige Zwischenstufen entsteht letztendlich durch Invagination ein S-förmiger Körper (Davies et al. 1999). Aus dem distalen Anteil dieses Gebildes entwickeln sich verschiedene tubuläre Segmente, die mit den Verzweigungen der Ureterknospe in Verbindung treten. Der proximale Anteil des S-förmigen Körpers stellt die Vorstufe der Glomeruli dar, die nach erfolgter Angio- und Vaskulogenese entstehen (Wallner et al. 1998).

Die epitheliale Differenzierung beinhaltet sowohl die Veränderung des morphologischen Erscheinungsbildes der Zellen als auch die Aktivierung zahlreicher typischer epithelialer Gene, wie zum Beispiel Zytokeratine, desmosomale Komponenten, das Kollagen der Basalmembran und viele mehr. Des Weiteren müssen Gene, die eher einer mesenchymalen Funktion zugeordnet werden können, inaktiviert werden. Hierzu zählen zum Beispiel Vimentin und interstitielles Kollagen (Davies et al. 1999). Die Prozesse der MET werden durch induktive Signale eingeleitet, die eine Kette von intrazellulären Kaskaden und Veränderungen nach sich ziehen, welche letztendlich zu der gewünschten Zellumwandlung führen. Auch wenn sich auf diesem Gebiet in den letzten Jahren viele wissenschaftliche Neuerungen ergeben haben, bleiben noch viele Fragen bezüglich der induktiven Faktoren und deren intrazellulären Folgen ungeklärt (Plisov et al. 2000).

\subsection{Die Entstehung einer renalen Fibrose}

Krankheiten der Niere, die sich in ihrem Endstadium befinden, gehen sehr häufig mit einer tubulointerstitiellen Fibrose einher (Bani-Hani et al. 2008). Fast 90\% des gesamten Nierenvolumens werden vom tubulointerstitiellen Raum gebildet, so dass sich folgenschwere Konsequenzen aus der pathologischen Veränderung dieser Lokalisation ergeben. Eine stetige Abnahme der Nierenfunktion ist bei allen betroffenen Patienten zu beobachten (Hewitson 2009). Zusätzlich ist durch diese Erkenntnis ein guter prädiktiver Wert entstanden, der eine relativ akkurate Vorhersage über die weitere Entwicklung der Nierenfunktion zulässt (Bohle et al. 1992; Healy und Brady 1998). Die Fibrose ist gekennzeichnet durch eine Anhäufung von extrazellulärem Matrixgewebe (ECM). Dazu zählen hauptsächlich Kollagene vom Typ I, III und IV sowie aber auch Fibronectin und Proteoglykane. Über viele Jahre ging man davon aus, dass residente Fibroblasten allein die Produktion der ECM übernehmen. Dieses Bild musste aufgrund von neueren Forschungsergebnissen revidiert werden, da auch periadventitiellen Zellen, mesenchymalen Stammzellen aus dem Knochenmark und tubulären 
Epithelzellen eine Beteiligung an der Matrixproduktion nachgewiesen werden konnte (Strutz und Müller 2006).

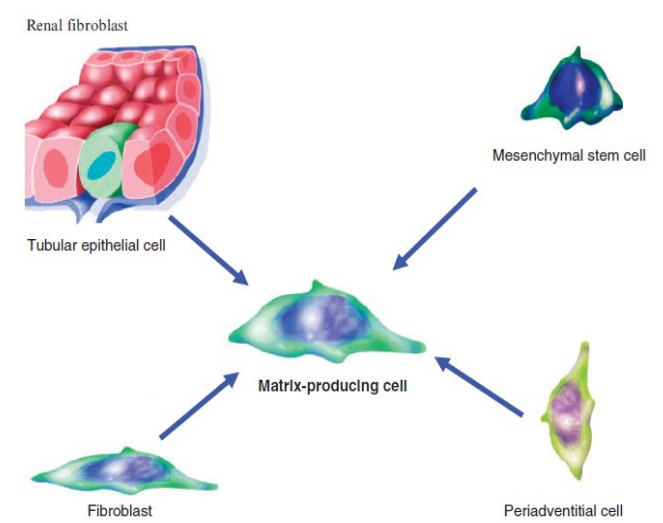

Abbildung 1: Mögliche Quellen der Zellen, die an der Produktion der extrazellulären Matrix in der Niere beteiligt sind. Abbildung entnommen aus der Veröffentlichung von Strutz und Müller (2006), Seite 3369 .

Im Rahmen der Fibrogenese findet eine Umwandlung der Fibroblasten in sogenannte Myofibroblasten statt. Wie der Name schon verrät, handelt es sich hierbei um Fibroblasten, die in ihren Eigenschaften, genauer gesagt in ihrer Kontraktilität, glatten Muskelzellen ähneln. Dies lässt sich darauf zurückführen, dass den Myofibroblasten eine de-novo-Expression von alpha-Glattmuskelaktin ( $\alpha$-SMA) nachzuweisen ist, welches ursprünglich nur im Zusammenhang mit glatten Muskelzellen von Gefäßen bekannt ist (Strutz und Müller 2006). Laut Hewitson ist diese aktivierte Form der Fibroblasten in jeder Art von progressiver Nierenerkrankung zu finden. Die Anhäufung dieser Zellen verhält sich hierbei proportional zum Fortschreiten der Erkrankung (Hewitson 2009).

Doch wie entsteht diese Fibrose? Eine überschießende Produktion von ECM wird häufig mit einer Narbenbildung, wie sie aus der klassischen Wundheilung bei andauerndem inflammatorischen Reiz bekannt ist, in Verbindung gebracht. Zum Teil ist diese Produktion von Gewebe dem Heilungsprozess zuträglich, sie kann aber bei zu starker Ausdehnung auch destruktive Folgen nach sich ziehen. Die Fibroseentstehung lässt sich in Anlehnung an den physiologischen Wundheilungsprozess der Haut erklären. Man unterscheidet hier die folgenden drei Phasen: Die Induktionsphase, die Phase der proinflammatorischen Matrixsynthese sowie die Phase der postinflammatorischen Matrixsynthese. Am Beginn dieser Kette von Ereignissen steht die Zerstörung von spezialisiertem Nierengewebe im Rahmen einer Entzündung. Neu einströmende Blutgefäße ermöglichen Zellen des Immunsystems einen raschen Zutritt zum versehrten Gebiet. Durch diese 
entzündungsmediatorischen Zellen, wie Makrophagen/Monozyten und T-Lymphozyten, wird der Heilungsprozess in Gang gesetzt. Über Zytokine und andere Zellmediatoren kommt es zu einer Proliferation von Fibroblasten, die nun vermehrt Kollagen und weitere Matrixkomponenten bilden. Des Weiteren kommt es zu einer Umwandlung dieser aktivierten Bindegewebszellen in Myofibroblasten, die, wie oben bereits erwähnt, die Eigenschaften von Fibroblasten und glatten Muskelzellen in sich vereinen (Tomasek et al. 2002). Die Quelle dieser Myofibroblasten ist Bestand aktiver Forschung und bis dato nicht vollständig geklärt. Wichtig hervorzuheben ist der in der Niere vorkommende, mittels zahlreicher Studien belegte Prozess bei der Matrixsynthese: Die epithelial-mesenchymale Transition (EMT). Erstmalig wurde der Umwandlungsprozess in dieser Form von der Arbeitsgruppe Strutz und Kollegen im Jahre 1995 beschrieben (Strutz et al. 1995). Eine genaue Auseinandersetzung mit diesem Phänomen folgt im weiteren Verlauf dieser Arbeit. Zusätzlich zu den in Abbildung 1 aufgeführten Entstehungsmöglichkeiten der Matrix-produzierenden Myofibroblasten, ist auch der Prozess der endothelial-mesenchymalen Transition (EndMT) denkbar (Bascands et al. 2007; Zeisberg EM et al. 2008).

Im Wundheilungsprozess folgt nun die Phase der inflammatorischen Matrixsynthese. Sowohl eine vermehrte Bildung von ECM als auch der verminderte Abbau extrazellulären Gewebes sind $\mathrm{zu}$ beobachten (Strutz und Neilson 2003). In der Niere kommt es im Rahmen des Entzündungsprozesses allerdings nie zur kompletten Wiederherstellung der komplexen Architektur des gesamten Nierenparenchyms. Zwar verfügt das Epithel der Niere über gute Heilungseigenschaften durch seine Basalzellschicht, das Interstitium jedoch hat nur die Möglichkeit, verletztes Gewebe zu reparieren, also zu ersetzen, aber nie den Zustand einer restitutio ad integrum zu erlangen (Underwood 1992).

Im Falle der physiologischen Wundheilung einer oberflächlichen Verletzung der Haut folgt nun die Phase der Resolution, die gleichzeitig die Defektheilung und eine Stagnation der Gewebsneubildung der inflammatorischen Phase darstellt. In diesem Punkt unterscheidet sich die Fibrogenese maßgeblich von der Wundheilung, da die Matrixsynthese und -ablagerung häufig losgelöst vom primären Entzündungsstimulus kontinuierlich fortgesetzt wird (Strutz und Neilson 2003). Wie Hewitson 2009 zusammenfasste, scheint es in der Niere eben nicht nur die exzessive Neuentstehung von ECM zu sein, die an dem Krankheitsbild der renalen Fibrose beteiligt ist, sondern zusätzlich auch der Abbau des Nierenparenchyms. Dies zieht eine Kontraktion und damit auch eine Reduktion sowie Beeinträchtigung der ursprünglichen Nierengröße und Funktion nach sich (Hewitson 2009). 


\subsection{Die epithelial-mesenchymale Transition}

Im Jahre 1982 beschrieben Greenburg und Hay erstmals eine mögliche Umwandlung von Epithelzellen in mesenchymale Zellen (Greenburg und Hay 1982). Über zehn Jahre später wurde im Zusammenhang mit der renalen Fibrogenese Ähnliches beobachtet. Es war die Arbeitsgruppe um Strutz und Neilson, die anhand eines murinen Modells durch die Expression von FSP1 die epithelial-mesenchymale Transition (EMT) nachweisen konnte (Strutz et al. 1995). Generell ist eine Transformation zwischen Mesenchym und Epithel aus der embryonalen Entwicklung bekannt; hier dient der Vorgang häufig dazu, komplexere und höher differenzierte Gewebe entstehen zu lassen. Wie oben bereits erwähnt, findet auch in der renalen Entwicklung ein derartiger Umwandlungsprozess statt: Die Tubulusepithelzellen entstehen aus mesenchymalen Vorstufen durch Induktion. Dies lässt es sehr plausibel erscheinen, dass ein Umkehrprozess zurück zum Mesenchym in Zeiten der Regeneration als Antwort auf einen Entzündungsreiz durchaus möglich ist (Okada et al. 2000). Anhand dieser These gelang es, einen weiteren Faktor der renalen Fibrogenese zu identifizieren. Viele Jahre bestand die Annahme, dass die hohe Anzahl an Fibroblasten in der erkrankten Niere aus Stromazellen des Knochenmarks hervorging und die Zellen ihr peripheres Zielorgan über den Blutweg erreichten. Dagegen sprach allerdings, dass nicht sicher nachgewiesen werden konnte, dass diese Zellen nach ihrer Migration zum Zielort auch Teil der Fibrogenese waren (Iwano et al. 2002).

Des Weiteren fiel es mit dieser älteren These schwer zu erklären, warum auch fernab von Blutgefäßen mesenchymales Gewebe in Form von Fibroblasten aufzufinden war. Dies ließ sich jedoch im Rahmen der Hypothese um die EMT in der Niere deutlich nachweisen. Der Arbeitsgruppe Strutz et al. war es möglich, einen weitgehend spezifischen Fibroblastenmarker zu detektieren, ein Protein der S-100 Superfamilie mit dem Namen FSP1. Anhand dessen gelang es erstmals, eine Umwandlung von renalen Tubulusepithelzellen in Zellen mit fibroblastischem, mesenchymalen Charakter mittels FSP1-Expression nachzuweisen. Die murinen Tubulusepithelzellen wiesen unter physiologischen Bedingungen keine Expression des FSP1-Gens auf. Erst als eben diese Zellen mit einem interstitiellen entzündlichen Stimulus in Kontakt kamen, konnte erstaunlicherweise eine de-novo-Expression des Fibroblasten-spezifischen Gens nachgewiesen werden, was eine Transformation von Epithel zu Mesenchym nahe legte. Zusätzlich ließ sich bei diesen Zellen auch phänotypisch das Erscheinungsbild eines Fibroblasten nachweisen, welches die These der renalen Epithelumwandlung noch festigte (Strutz et al. 1995). Zudem ist es naheliegend, dass im Falle 
des Bedarfs an Fibroblasten in einem Organ wie der Niere im Rahmen der Fibrogenese die benötigten Zellen aus dem lokalen Epithel stammen, anstatt eine lange Strecke über den Blutweg zurücklegen zu müssen (Iwano et al. 2002).

Doch wie genau findet diese Transition von Tubulusepithelzellen zu Fibroblasten oder genauer Myofibroblasten statt? Epithelzellen zeichnen sich durch bestimmte Eigenschaften aus. Charakteristisch sind das Aufsitzen sowie die feste Verbindung der Zellen mit einer Basalmembran. So wird eine gewisse Stabilität erreicht, die den typischen Zell-Zell-Verbund zwischen den einzelnen Epithelzellen erst ermöglicht (Iwano et al. 2002). Der durch Zytokine angeregte Vorgang der EMT zeichnet sich dadurch aus, dass die Zellen einen Verlust der apikal-basalen Polarität aufweisen. Zusätzlich verlieren die Epithelzellen ihre typischen zonulae-adhaerentes-Moleküle sowie ihre festen Verbindungen, die sogenannten tight junctions, untereinander. Somit sind nun aus einem ortsständigen Zellverband viele einzelne mobile Zellen entstanden. Auch die intermediären Filamente unterliegen einer Veränderung: Das epitheliale Zytokeratin wird hierbei durch das eher dem Mesenchym zugehörige Intermediärfilament Vimentin ersetzt (Strutz et al. 2002).

Des Weiteren exprimieren diese Zellen nun bereits de novo alpha-Glattmuskelaktin ( $\alpha$-SMA), welches, wie oben erwähnt, ein Charakteristikum von Myofibroblasten darstellt, wohingegen ein typisch epithelialer Marker, das E-Cadherin, nicht mehr vorzufinden ist. Laut Yang und Liu produzieren die veränderten Zellen außerdem verstärkt die Matrixmetalloproteinase-2 (MMP-2) (Yang und Liu 2001). Hierbei handelt es sich um ein Mitglied der Gruppe der Zinkabhängigen Endopeptidasen, die in der Niere für den Abbau der Kollagene zuständig sind. MMP-2 wird in diesem Zusammenhang speziell mit einem Abbau der Basalmembran, also Kollagen vom Typ IV, in Verbindung gebracht. Dies ist von Bedeutung, da durch eine nicht mehr vollständig intakte Basalmembran eine Eintrittspforte in das Interstitium geschaffen wird. Zusätzlich scheinen die nun entstandenen Kollagenfragmente den Prozess der EMT erneut zu aktivieren. Ferner wäre es auch noch denkbar, dass die MMP-2 auf parakrinem Weg durch Zytokinaktivierung die epithelial-mesenchymale Transition ebenfalls fördert (Hewitson 2009).

Der Prozess der EMT unterliegt in der regulären Entwicklung sowohl räumlich als auch zeitlich genau kontrollierten Regulationsmechanismen. Tritt die epithelial-mesenchymale Transition im adulten Organismus auf, geschieht dies meist in Verbindung mit pathologischen Prozessen. Als Beispiele hierfür sind die maßgebliche Beeinflussung der oben bereits erwähnten Organfibrose sowie das Fortschreiten eines malignen Tumorgeschehens zu nennen. In letzterem Zusammenhang stellte man fest, dass epitheliale Tumorzellen nach einer 
epithelial-mesenchymalen Transformation wesentlich invasiver an entlegene Stellen des Primärtumors streuten. Haben die Krebszellen ihren Bestimmungsort erreicht, kommt es nach einer Umwandlung durch MET zur Entstehung von Metastasen (Xu J et al. 2009). Des Weiteren ließ sich nachweisen, dass Tumorzellen häufig ihre Ausschüttung des EMTaktivierenden Zytokins TGF- $\beta$ stark erhöhen, was unter anderem eine verstärkte Gefäßneuentstehung im Tumorgebiet zur Folge hat. Dies führt zur weiteren Verbreitung tumoröser Zellen an vom Primärtumor entfernte Orte des Organismus über den Blutweg (Derynck et al. 2001).

Zusammenfassend lässt sich sagen, dass der Prozess der EMT im Rahmen pathologischer Abläufe im menschlichen Körper eine wichtige Rolle einnimmt, die unter Umständen eine beschleunigte Progression und schwere Folgen im weiteren Krankheitsverlauf nach sich ziehen kann.

\subsection{Die Rolle der Zytokine bei der EMT}

\subsubsection{Transforming Growth Factor $B$}

In menschlichen Geweben herrscht ein Gleichgewicht zwischen den ortsständigen Zellen und der extrazellulären Matrix, welches durch einen komplexen Verständigungsmechanismus der Zellen mit dem umliegenden Gewebe aufrechterhalten wird. Zahlreiche unterschiedliche Zytokine (Zellmediatoren, die durch intrazelluläre Transduktionskaskaden eine Interaktion von Zellen und Umgebung ermöglichen) sind an dieser Homöostase beteiligt. Gerät dieses Verständigungsnetzwerk jedoch außer Kontrolle, kann dies die Ursache für die Entstehung einer Fehlfunktion oder Erkrankung eines Organs sein (Blobe et al. 2000). Des Weiteren werden Zytokinen wichtige Aufgaben in Zusammenhang mit Zellproliferation, Aktivierung und Differenzierung zugeschrieben. Ferner weisen sie eine maßgebliche Beteiligung an Apoptosevorgängen, Zell-Zell-Kontakten, der Angiogenese und an Immunreaktionen im Rahmen von inflammatorischen Prozessen auf (Lechleider und Roberts 1999).

Transforming Growth Factor ß1 (TGF-ß1) nimmt im Rahmen dieser Arbeit eine besondere Stellung unter der Vielzahl von Zytokinen ein, da es in engem Zusammenhang mit dem Prozess der EMT steht. TGF- $\beta$ zählt zur Familie der dimerischen polypeptidalen Wachstumsfaktoren, welcher ebenfalls die bone morphogenic proteins (BMPs) sowie die Aktivine zugeordnet werden. Die Mitglieder dieser Familie zeichnen sich durch Strukturähnlichkeiten aus: Allen gemeinsam ist ein Cystein-Knoten, welcher durch 
intramolekulare Disulfidbrücken stabilisiert wird (Massague 1998). Es existieren drei Isoformen des TGF- $\beta$ : TGF- $\beta 1$, TGF- 32 und TGF- 33 , wobei jede Form sich durch eine eindeutig zuzuordnende Genregion und unterschiedliche Einsatzgebiete und Funktionen auszeichnet. Diese Isoformen entstehen durch proteolytische Spaltung längerer Vorläuferproteine (Misseri et al. 2004). Die Ausführungen und Experimente dieser Arbeit beziehen sich ausschließlich auf die Isoform TGF-ß1. Besonders hervorzuheben ist in Bezug auf TGF- $\beta$, dass jede Zelle im menschlichen Körper die Fähigkeit besitzt, diesen Wachstumsfaktor eigenständig zu produzieren und zusätzlich flächendeckend Rezeptoren für TGF- $\beta$ an allen Körperzellen vorliegen. Ein Produktionsanstieg oder Abfall dieses Zytokins kann direkt mit der Entstehung spezifischer Erkrankungen wie Atherosklerose oder fibrotischen Leiden in Niere, Lunge und Leber in Verbindung gebracht werden (Blobe et al. 2000). Laut Hill et al. konnte bei einer Vielzahl experimentell erzeugter Modelle einer Nephropathie unter anderem auch bei der diabetischen Form eine erhöhte Expression des

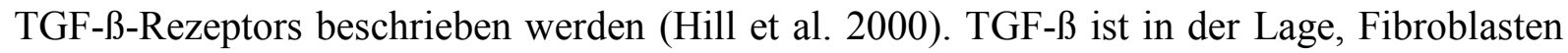
zu stimulieren, was eine erhöhte Produktion extrazellulärer Matrix zur Folge hat. Shull und Kollegen konnten außerdem eine inhibitorische Wirkung auf Zellen des Immunsystems nachweisen (Shull et al. 1992). Diese beiden Aspekte legen nahe, dass eine Beteiligung von TGF- $ß$ an Wundheilungsprozessen sehr wahrscheinlich ist.

Der Signalweg von TGF- $\beta$ wurde bereits in mehreren Studien sowohl in vitro als auch in vivo untersucht (siehe Abbildung 2). Die Signalweiterleitung findet über zwei transmembraneTypI- und zwei Typ-II-Rezeptoren mit Serin-Threonin-Kinase-Aktivität statt. Hierbei reagiert der Typ-II-Rezeptor auf TGF- $\beta$, indem er den Typ-I-Rezeptor phosphoryliert und damit zur Aktivierung der intrazellulären Signalkaskade führt (Xu J et al. 2009). Am häufigsten ist jedoch der TGF-ß-spezifische Typ-III-Rezeptor auf der Zelloberfläche vorzufinden. Dieser unterstützt die Tätigkeit des Typ-II-Rezeptors, indem er ihm bereits gebundenes TGF- $\beta$ präsentiert und zusätzlich den erstgenannten Signalweg aktiviert (Blobe et al. 2000).

Die Phosphorylierung des Typ-I-Rezeptors bewirkt nun, dass durch die integrierte KinaseAktivität der intrazelluläre Transkriptionsfaktor SMAD 2 oder SMAD 3 aktiviert wird. Das phosphorylierte SMAD 2 bzw. SMAD 3 geht daraufhin eine Verbindung mit SMAD 4 ein. Dieser Komplex kann anschließend das Zytoplasma verlassen und in den Nukleus eindringen. Über diesen Weg kann auf Transkriptionsebene in die TGF-ß-Funktion eingegriffen werden, wodurch demnach auch der zelluläre Effekt des Wachstumsfaktors beeinflusst werden kann. SMAD 6 und 7 fehlt die zu phosphorylierende Region. Daher können diese Proteine nur hemmend in diesen Signalweg eingreifen (Schiffer et al. 2000). 


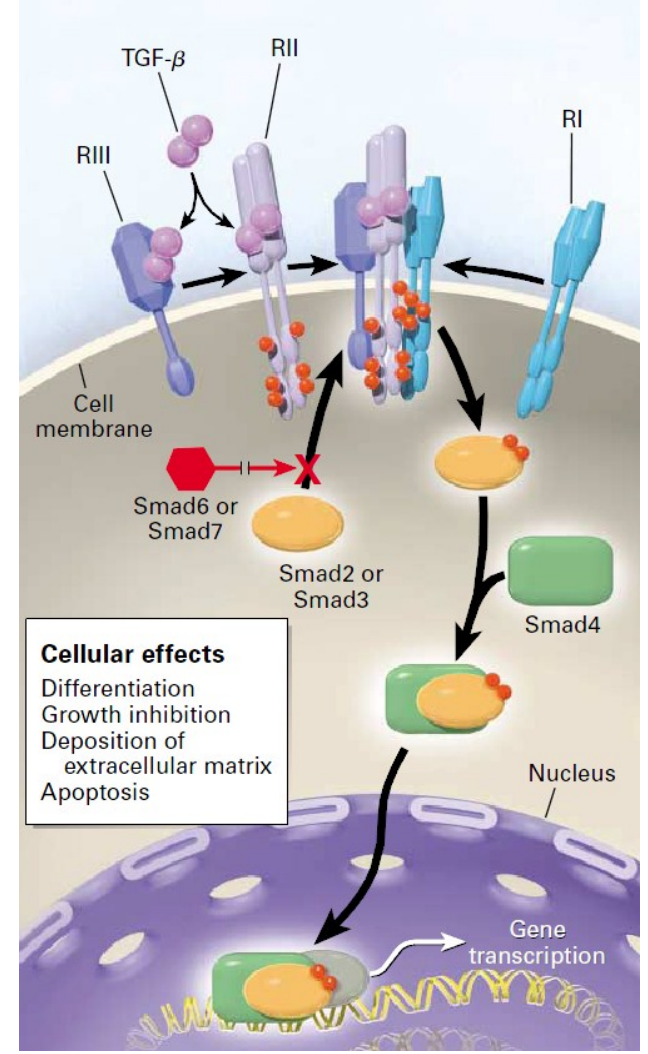

Abbildung 2: Mechanismus der TGF- $\beta$-gesteuerten Signaltransduktion. Abbildung aus der Veröffentlichung von Blobe et al. (2000), Seite 1351.

Neben diesem SMAD-abhängigen Signalweg werden zunehmend auch SMAD-unabhängige Signalmechanismen des TGF- $\beta$ bekannt. Hierbei handelt es sich um Liganden-gesteuerte Rezeptoren, die die zelluläre Antwort auf TGF- $\beta$ verstärken, modulieren oder auch mildern können. So ließen sich auch insbesondere in Zusammenhang mit der EMT Ereignisse wie die phänotypische Verwandlung durch mesenchymale Charakteristika zumindest teilweise auf einen SMAD-unabhängigen Signalweg zurückführen (Zhang 2009).

In den meisten Fällen wird die epithelial-mesenchymale Transition als ein Prozess beschrieben, der nicht autonom abläuft, sondern durch externe Stimuli in Gang gesetzt werden muss (Boyer et al. 2000). Hierbei bildet TGF- $\beta$ den meist untersuchten Mediator. Eine erhöhte TGF-ß-Expression konnte im Nierenkortex bei renaler Obstruktion vorgefunden werden, was die Schlussfolgerung zuließ, dass dieses Zytokin eine bedeutsame regulatorische Rolle in Verbindung mit der Fibrogenese einzunehmen scheint. Diese fibrogenetische Funktion des Zellmediators ist gekennzeichnet durch eine gesteigerte Fibroblastenproliferation, die Synthese von extrazellulärer Matrix und die Inhibition von Kollagenasen (Misseri et al. 2004). Des Weiteren wird die gesteigerte Matrixproduktion auf genetischer Ebene durch TGF-ß zusätzlich beeinflusst und induziert (Reibman et al. 1991). Vielen anderen Wachstumsfaktoren wird im Zusammenhang mit der Matrixproduktion eher 
eine Art Zellverteilungsfunktion (scattering) zugeschrieben, die bewirkt, dass die von ihnen beeinflussten Zellen ihre Zell-Zell-Verbindungen verlieren und ein erhöhtes Maß an Motilität gewinnen. TGF- $\beta$ scheint jedoch eine führende Position in der Induktion der EMT einzunehmen. So gelang es zum Bespiel Fan und Kollegen, mit hohen Dosen von Transforming growth factor $\beta$ den vollständigen Effekt der epithelial-mesenchymalen Transition zu erzielen (Fan et al. 1999).

\subsubsection{Fibroblast Growth Factor-2}

Der Fibroblastenwachstumsfaktor FGF-2 zählt zu den zahlreichen mitogenen Proteinen der FGF-Familie. Insgesamt besteht diese Faktorenfamilie aus 23 Mitgliedern (Yamashita et al. 2000). Unter den Fibroblastenwachstumsfaktoren werden zwei Haupttypen identifiziert, FGF1 und FGF-2, welche sich allerdings in ihrer biologischen Aktivität und Rezeptoraktivität wenig unterscheiden. Die allgemeinen Wirkungen von FGF-2 beinhalten die Proliferationsförderung von Zellen mesodermaler, endodermaler, ektodermaler und neuroektodermaler Herkunft (Ibelgaufts 1992).

FGF-2 wird eine Beteiligung an Wundheilungsprozessen, der Revaskularisierung von Geweben und Entwicklungsprozessen zugeschrieben. Somit vereint dieser Faktor mitogene, chemotaktische und angiogene Eigenschaften. Dies hat zur Folge, dass FGF-2 auch häufig eine Rolle in tumorigenen Prozessen übernimmt (Venkataraman et al. 1999).

In Zusammenhang mit der epithelial-mesenchymalen Transition konnte auch diesem Zytokin eine förderliche Wirkung zugeordnet werden, wenn auch nicht so deutlich wie bei TGF-ß. FGF-2 ist in der Lage, durch Effekte wie die Induktion von alpha-Glattmuskelaktin und die Reduzierung des epithelialen Zytokeratins die Veränderung einer epithelialen Zelle hin zu einer Zelle mit mesenchymalen Charakter zu unterstützen. Das wichtigste Merkmal der FGF2-Beteiligung an der EMT scheint jedoch $\mathrm{zu}$ sein, dass dieses Zytokin es vermag, Matrixmetalloproteinasen zu stimulieren. Diese sind maßgeblich an einem Schlüsselereignis der EMT beteiligt, nämlich der Zerstörung der tubulären Basalmembran (Hewitson 2009). Zudem ließ sich feststellen, dass sich die Effekte des Fibroblastenwachstumsfaktors durch zusätzliche Stimulation mit TGF-ß potenzieren lassen (Strutz et al. 2002) 


\subsection{Das Protein Nestin - ein Überblick}

Bei Nestin handelt es sich um ein intermediäres Filamentprotein der Klasse VI, welches eine Rolle beim Aufbau des Zytoskeletts spielt und sich durch eine sehr hohe molekulare Masse auszeichnet (Bertelli et al. 2007). Erstmals wurde dieses Protein von der Arbeitsgruppe Lendahl et al. im Jahr 1990 definiert. Ihnen war es möglich, ein Gen zu beschreiben, welches es zuließ, neuronale Stammzellen von höher differenzierten Zellen des Neuralrohrs zu unterscheiden. Sie verliehen diesem Gen den Namen Nestin, da es spezifisch von neuroepithelialen Stammzellen exprimiert wurde (Lendahl et al. 1990). Im Gegensatz zu Mikrofilamenten und Mikrotubuli, den anderen zwei Hauptbestandteilen des Zytoskeletts, deren Eigenschaften sich ganz klar einer bestimmten Zellgruppe zuordnen lassen, differieren Intermediärfilamente sehr stark in Häufigkeit und Anordnung in unterschiedlichen Geweben. Im menschlichen Körper sind mehr als sechzig verschiedene Gene bekannt, die für intermediäre Filamente kodieren und ein variierendes Expressionsmuster von Zelle zu Zelle zeigen (Sakairi et al. 2007).

Basierend auf einer Sequenzanalyse der Gene konnten ursprünglich fünf unterschiedliche Klassen an Intermediärfilamenten beschrieben werden (Kishaba et al. 2010). Gruppe I bildeten hierbei die azidischen Keratine, Gruppe II die basischen Keratine. Gruppe III vereinte Desmin, Peripherin, das saure Gliafaserprotein und Vimentin. Das Neurofilament Triplet bildete die Gruppe IV und die nukleären Laminine die Gruppe V (Lendahl et al. 1990). Strukturell kann Nestin durch eine für Intermediärfilamente typische $\alpha$-helikale, zentral gelegene Rod-Domäne beschrieben werden, welche ein sich wiederholendes, hydrophobisches Heptadenmuster (heptad motif) beinhaltet. Im Gegensatz zu den bereits beschriebenen Klassen besitzt Nestin einen verhältnismäßig kurzen N-Terminus bei einem gleichzeitig ungewöhnlich langen C-Terminus. Diese Charakteristika bewirken, dass Nestin es zum einen nicht vermag, sich eigenständig zu formieren, da die Domäne, die für eine Intermediärfilamentformierung nötig wäre, nämlich ein ausgeprägter N-Terminus, hier fehlt. Zum anderen ermöglicht der überlange C-Terminus Nestin eine Interaktion mit Mikrofilamenten und Mikrotubuli. Trotz der fehlenden Selbst-Formierungsfunktion (selfassembly) besitzt Nestin die Fähigkeit, mit anderen Intermediärfilamenten Heterodimere sowie gemischte Polymere zu bilden (Chen J et al. 2006).

Lendahl et al. konnten zeigen, dass eine 16-29\%ige Übereinstimmung der Aminosäuren von Nestin mit denen der übrigen Intermediärfilamente bestand. Dieses Ausmaß an Ähnlichkeit im Aminosäureprofil entspricht dem Anteil an Übereinstimmungen, die auch die anderen 
Intermediärfilamentklassen miteinander teilen. Innerhalb einer Klasse kommt es zu einem Prozentsatz von bis zu 50\% homologer Aminosäuren. Da Nestin allerdings in seinem Profil keiner bereits bestehenden Klasse zugeordnet werden konnte, lag es nahe, eine neue, sechste Klasse der Intermediärfilamente zu kreieren (Lendahl et al. 1990).

Intermediärfilamente bilden ein strukturiertes Netzwerk der Zelle, welches sich von der Zellkernoberfläche bis in die Peripherie ausdehnt. Einerseits tragen sie maßgeblich zur mechanischen Stabilität der Zelle bei, andererseits übernehmen sie eine entscheidende Rolle in vielen zellulären Funktionsabläufen wie zum Beispiel der Festlegung des Phänotyps einer Zelle und ihrer Beweglichkeit. Ebenso besitzen sie eine kontrollierende Funktion im Zellzyklus und in der Signaltransduktion. Es wurde beobachtet, dass eine Gewebsverletzung häufig zu einer Änderung des Expressionsmusters der Intermediärfilamente einer Zelle führt (Zou et al. 2006).

Jahre nach der Entdeckung dieses spezifischen Markers neuronaler und glialer Progenitorzellen wurde Nestin auch in nicht-neuronalen Geweben entdeckt. Berichtet wurde von einer Nestinexpression in sich entwickelnden fetalen Organen wie zum Beispiel Skelettmuskelzellen, Kardiomyozyten, Progenitorzellen des Pankreas und des Gefäßendothels (Wiese et al. 2004). Im Vergleich zu embryonalen Geweben ist das Vorkommen von Nestin in vollständig ausgereiften Geweben eher limitiert. Aufgrund seiner Eigenschaft als Stammzellmarker ist charakteristischerweise ein Rückgang der Nestinexpression zu beobachten, sobald ein Gewebe seinen höchsten Entwicklungsstand erreicht hat (Su et al. 2007).

Interessanterweise wurde jedoch eine Reexpression von Nestin in Verbindung mit Gewebsverletzungen verschiedenster Organe detektiert. Hierzu zählen laut der Arbeitsgruppe um Sakairi das zentrale Nervensystem, der Skelettmuskel, die Leber, das Pankreas, die Zähne und seit wenigen Jahren die Niere (Sakairi et al. 2007). Die Niere nimmt hierbei eine besondere Stellung ein. Nestin konnte in der Niere während der Entwicklungsstadien in Zellen des metanephrischen Mesenchyms gefunden werden, jedoch nie in Strukturen der Uretralknospe ( $\mathrm{Su}$ et al. 2007). Zusätzlich konnte in der Niere eine Nestinexpression in Podozyten nachgewiesen werden, die sich erstaunlicherweise im voll entwickelten Glomerulus zeigte und nach Schädigung eines Podozyten sogar noch ausgeprägter zum Vorschein kam (Perry et al. 2007; Daniel et al. 2008; Su et al. 2008). Des Weiteren gelang es Bertelli et al., noch eine geringe Nestinexpression in Endothelzellen und Mesangialzellen der sich entwickelnden Niere nachzuweisen (Bertelli et al. 2007). Der Arbeitsgruppe um Su et al. war es möglich, die Ergebnisse von Daniel und Kollegen zu bestätigen und zu verifizieren, 
dass das Phänomen der Nestinexpression in adulten Podozyten nicht nur in murinen, sondern auch in humanen Podozyten vorzufinden war. Außerdem stellten sie fest, dass laut ihren Studien Nestin in der ausgereiften Niere selektiv von Podozyten exprimiert wurde, was nahe legte, dass diesem Protein eine gesonderte Rolle in dieser sehr spezialisierten Epithelzelle zukommen könnte (Su et al. 2007; Daniel et al. 2008). Eine weitere Erklärung für das Vorkommen von Nestin in ausgereiften Podozyten lieferte die Arbeitsgruppe um Bertelli: Eine Ähnlichkeit in Struktur, Funktion und Entwicklung ließ sich zwischen Podozyten und Neuronen feststellen. Zum einen sind sowohl Podozyten als auch Nervenzellen postmitotisch ausdifferenzierte Zellen, zum anderen ließ sich ein vergleichbares Expressionsmuster an Zellproteinen detektieren, wodurch ein Vorkommen eines gemeinsamen Intermediärfilaments plausibel erscheint (Bertelli et al. 2007).

Charakteristisch für einen Podozyten ist ein sehr spezieller zytoskelettaler Aufbau. Hierbei ist es wichtig hervorzuheben, dass der Podozyt trotz seines nach klassischen Zelleinteilungen eher epithelialen Zelltyps, der sich durch die Expression von Zytokeratinen auszeichnet, eine verstärkte Expression von Vimentin vorzuweisen hat, welches klassischerweise mesenchymalen Zellen zuzuordnen ist. Ferner konnten Zou und Kollegen Vimentin, Nestin und Desmin als die drei Intermediärfilamentproteine von Podozyten identifizieren, welche je nach Zustand der Zelle und vor allem im Zusammenhang mit einer Gewebsverletzung vermehrt exprimiert werden (Zou et al. 2006). In diesem Zusammenhang muss erwähnt werden, dass Bertelli et al. dieses gleichzeitige Auftreten von Nestin und Vimentin näher untersuchten mit der Erkenntnis, dass Nestin in Podozyten speziell auf die Anwesenheit von einem Intermediärfilament der Gruppe III, in diesem Falle Vimentin, angewiesen ist, um sich formieren zu können. Erstaunlicherweise musste eingeräumt werden, dass Nestin anstatt einer strukturellen Verstärkung des Intermediärfilamentkonstruktes der Podozyten durch Unterstützung des Vimentins eher eine Schwächung des Zellgerüstes hervorruft (Steinert et al. 1999; Bertelli et al. 2007).

Nach wie vor ist relativ wenig bekannt über den Mechanismus der Nestinexpression in Verbindung mit Gewebeverletzungen in der Niere und anschließender Regeneration. Sakairi et al. war es möglich, eine durch einseitige Ureterobstruktion hervorgerufene verstärkte Induktion von Nestin in renalen Myofibroblasten zu detektieren. Hierbei ließ sich eine eindeutige Korrelation zwischen dem Schweregrad der tubulointerstitiellen Fibrose und dem Grad der Nestinexpression zeigen. Infolgedessen ergibt sich die Hoffnung, Nestin in Zukunft als Indikator und Verlaufsmarker für tubulointerstitielle Gewebezerstörung verwenden zu können (Sakairi et al. 2007). 


\subsection{Aufgabenstellung}

Im Rahmen dieser Dissertation sollte untersucht werden, ob dem neuroepithelialen Stammzellprotein Nestin im Rahmen der renalen Fibrogenese eine Bedeutung zukommt und inwiefern ihm eine Beteiligung an dem Prozess der epithelial-mesenchymalen Transition nachgewiesen werden kann.

Ziel der vorliegenden Arbeit war es, die Expression von Nestin speziell in murinen proximalen und distalen Tubulusepithelzellen zu analysieren. Zusätzlich wurde auf zellulärer Ebene die Einflussnahme der Zytokine TGF- $ß$ (Isotyp TGF-ß1) und FGF-2 auf die Nestinexpression untersucht. 


\section{Material und Methoden}

\subsection{Material}

\subsubsection{Zellen}

Die in den Versuchsreihen verwendeten Zellen sind murinen Ursprungs. Es handelt sich um proximale (MCT) und distale (NP-1) Tubulusepithelzellen der Niere (Haverty et al. 1988; Alvarez et al. 1992; Strutz et al. 2002).

\subsubsection{Zytokine}

Folgende Zytokine wurden für die Zellstimulationen verwendet:

\begin{tabular}{|l|l|l|}
\hline Zytokin & $\begin{array}{l}\text { Stocklösung } \\
\text { (Konzentration) }\end{array}$ & Firma \\
\hline $\begin{array}{l}\text { Recombinant Human } \\
\text { TGF- } ß 1\end{array}$ & $10 \mu \mathrm{g} / \mathrm{ml}$ & $\begin{array}{l}\text { R\&D Systems, Inc. } \\
\text { (Katalog Nummer: 240-B) }\end{array}$ \\
\hline $\begin{array}{l}\text { Recombinant Human } \\
\text { FGF basic }\end{array}$ & $25 \mu \mathrm{g} / \mathrm{ml}$ & $\begin{array}{l}\text { R\&D Systems, Inc. } \\
\text { (Katalog Nummer: 233-FB, } \\
\text { Lot Nummer: AU70) }\end{array}$ \\
\hline
\end{tabular}

Tabelle 1: Zytokine für Stimulationen

\subsubsection{Antikörper}

\begin{tabular}{|l|l|l|}
\hline Primärantikörper & Firma & Katalognummer \\
\hline Rabbit Polyclonal anti-Nestin & Novus Biologicals & NB600-876 \\
\hline Nestin (H-85) Antibody & $\begin{array}{l}\text { Santa Cruz Biotechnology, } \\
\text { Inc. }\end{array}$ & sc-20978 \\
\hline
\end{tabular}

Tabelle 2: Übersicht verwendeter Primärantikörper 


\begin{tabular}{|l|l|l|}
\hline Sekundärantikörper & Firma & Katalognummer \\
\hline ECL Rabbit IgG (donkey) & Amersham Biosciences & \# NA 934-1 ml \\
\hline $\begin{array}{l}\text { Alexa Fluor anti-Rabbit IgG } \\
\text { Molecular Probes, Inc. } \\
\text { (InvitroGen) }\end{array}$ & A-11008 \\
\hline
\end{tabular}

Tabelle 3: Übersicht verwendeter Sekundärantikörper

\subsubsection{Zusammensetzung verwendeter Reagenzien}

\begin{tabular}{|c|c|}
\hline Reagenz & Zusammensetzung \\
\hline APS $(10 \%)$ & 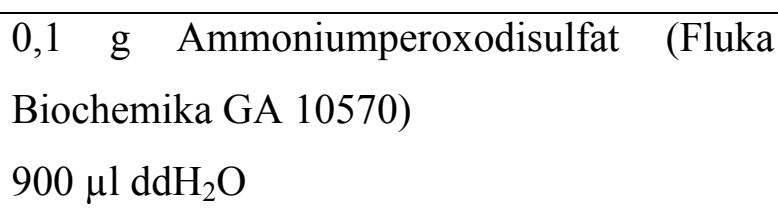 \\
\hline BSA-Lösung & $\begin{array}{l}1 \text { g BSA (Bovine Serum Albumin Fraction } \\
\text { V) (PAA Laboratories GmbH Kat No: K41- } \\
001-500) \\
100 \text { ml PBS (BIOCHROM AG) }\end{array}$ \\
\hline Elektrodenpuffer & 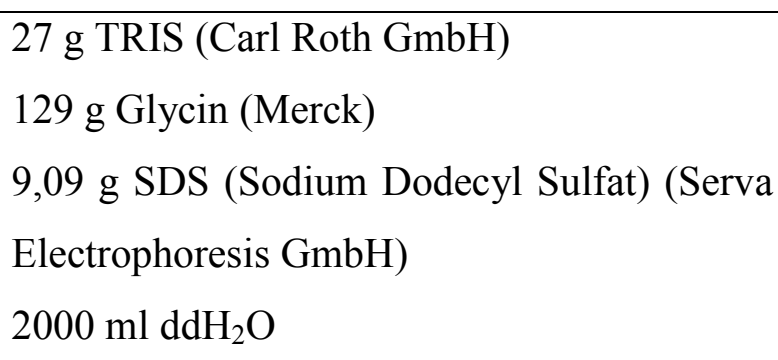 \\
\hline Blocklösung (5\%ige Magermilch) & $\begin{array}{l}15 \text { g Magermilchpulver (Merck) } \\
300 \mathrm{ml} \text { Waschpuffer (Protein) (s.u.) }\end{array}$ \\
\hline Nukleasefreies Wasser & $\begin{array}{l}\text { 1ml DEPC (Diethylpyrocarbonat, approx. } \\
\text { 97\% NMR (Sigma)) } \\
2000 \mathrm{ml} \mathrm{H}_{2} \mathrm{O} \\
\text { bei RT über Nacht inkubiert und autoklaviert }\end{array}$ \\
\hline Loading Buffer & $\begin{array}{l}350 \mu \mathrm{ldd} \mathrm{H}_{2} \mathrm{O} \\
650 \mu 1 \text { Loading Buffer (Sample Buffer, } \\
\text { Laemmli, Sigma, S3401-10VL) }\end{array}$ \\
\hline Lysispuffer (DNA) & $\begin{array}{l}700 \mu 1 \text { RLT-Lysispuffer (RNeasy }{ }^{\circledR} \text { Mini Kit } \\
(250) \text { Cat. No. 74106)) } \\
10 \mu 1 \text { B-Mercaptoethanol (Sigma) }\end{array}$ \\
\hline
\end{tabular}




\begin{tabular}{|c|c|}
\hline Lysispuffer (Protein) & 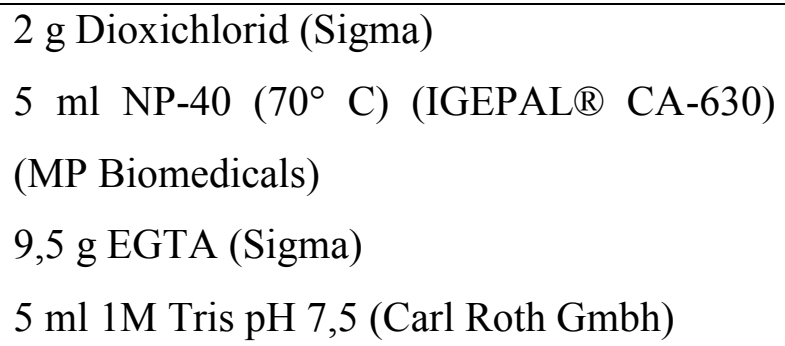 \\
\hline PBS & 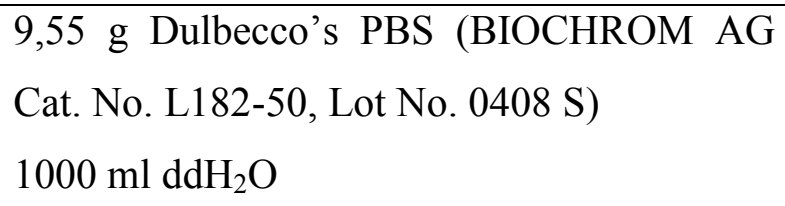 \\
\hline Sammelgel & 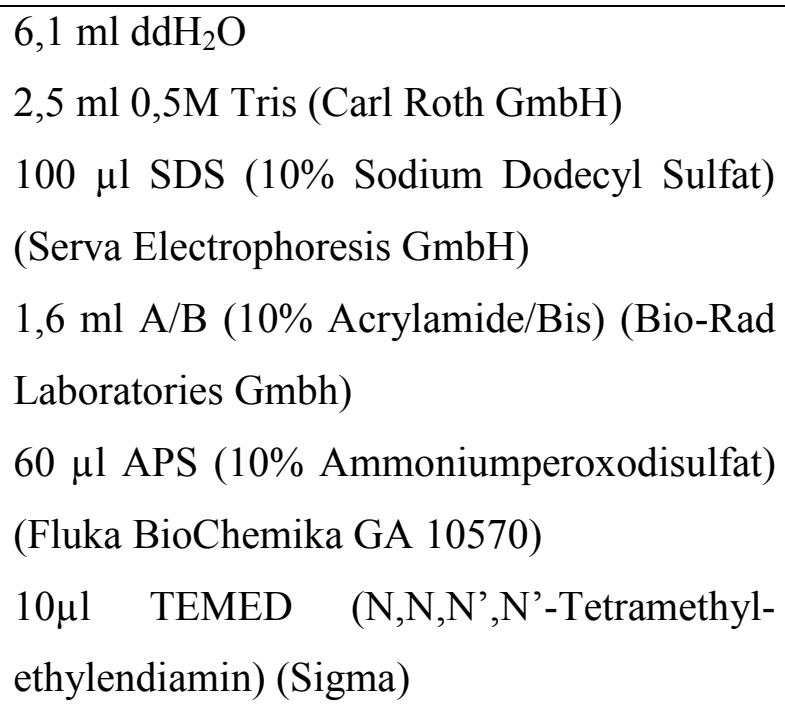 \\
\hline Transferpuffer & 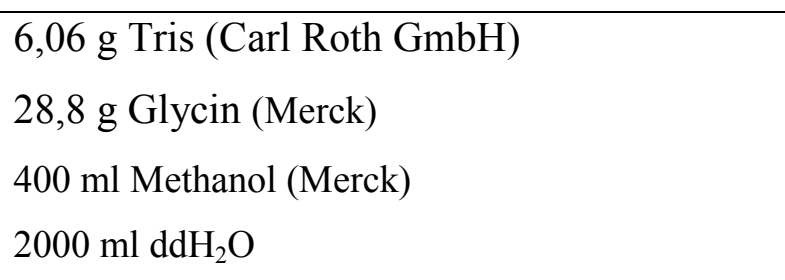 \\
\hline Trenngel $(10 \%)$ & 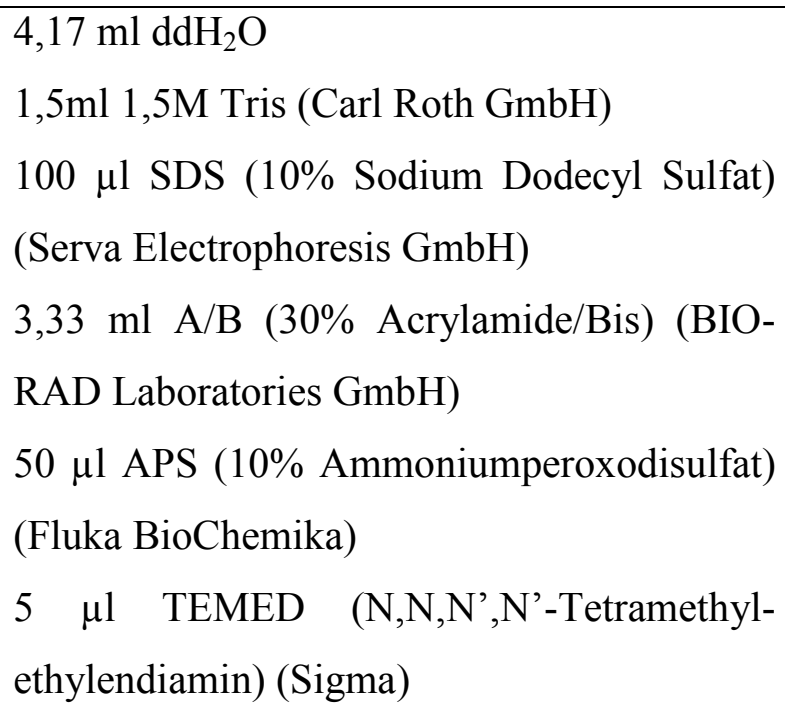 \\
\hline Tris $0,5 \mathrm{M}$ & $\begin{array}{l}\text { 60,57 g Tris (Carl Roth } \mathrm{GmbH}) \\
11 \mathrm{ddH}_{2} \mathrm{O}\end{array}$ \\
\hline
\end{tabular}




\begin{tabular}{|l|l|}
\hline & $\mathrm{pH} \mathrm{5,8}$ \\
\hline Tris 1,5 M & $\begin{array}{l}181,71 \mathrm{~g} \text { Tris (Carl Roth GmbH) } \\
11 \mathrm{dd \textrm {H } _ { 2 } \mathrm { O }} \\
\mathrm{pH} 8,8\end{array}$ \\
\hline Waschpuffer (Protein) & $\begin{array}{l}9,55 \mathrm{~g} \text { Dulbecco's PBS (BIOCHROM AG } \\
\text { Cat. No. L182-50, Lot No. 0408 S) } \\
1 \mathrm{ml} \text { Tween (Merck Lot S4393684) }\end{array}$ \\
\hline
\end{tabular}

Tabelle 4: Zusammensetzung der Reagenzien

\subsection{Methoden}

\subsubsection{Zellkultur}

Die Zellen wurden in dem Kulturmedium DMEM (Dulbecco's modified Eagle medium) der Firma Gibco, InvitroGen mit einem Glucosegehalt von 4,5 g/l ausgesät. Hinzugefügt wurden dem Grundmedium $50 \mathrm{ml}$ Foetal Bovine Serum (FCS 10\%) der Firma GibcoBRL sowie 5ml einer 1\%igen 200 mM L-Glutaminlösung (PAA Laboratories GmbH). Des Weiteren erfolgte die Zugabe von $100 \mu 1$ Plasmocin ${ }^{\mathrm{TM}}$ der Firma InvitroGen.

Einmal wöchentlich wurden die Zellen in neue Kulturflaschen überführt. Hierzu wurden die adhärenten Zellen mit $10 \mathrm{ml}$ Dulbecco's PBS (PAA Laboratories GmbH) pro Kulturflasche gewaschen und durch eine Zugabe von $3 \mathrm{ml}$ Trypsin-EDTA (PAA Laboratories GmbH) mit anschließender fünfminütiger Inkubation in einem $\mathrm{CO}_{2}$-Inkubator $\left(37^{\circ} \mathrm{C}\right.$ bei $100 \%$ relativer Luftfeuchtigkeit und $5 \% \mathrm{CO}_{2}$ in der Begasungsluft) vom Kulturflaschenboden abgelöst. Durch Zugabe von $5 \mathrm{ml}$ des oben erwähnten Vollmediums wurde die Zellablösung unterbrochen. Nach Überführung des Zellgemisches in ein 50-ml-Falcon (Greiner Bio-One $\mathrm{GmbH})$ pro Zelllinie wurde dies für 10 Minuten bei $1250 \mathrm{rpm}$ zentrifugiert. Im Anschluss wurde das Zellpellet in $10 \mathrm{ml}$ frischem Vollmedium aufgelöst und in neuen 250-mlCELLSTAR $^{\circledR}$ Kulturflaschen (Greiner Bio-One $\mathrm{GmbH}$ ) ausgesät. Anschließend wurden die Kulturflaschen in dem $\mathrm{CO}_{2}$-Inkubator aufbewahrt. 


\subsubsection{Zytokinstimulation}

Um die MCT- und NP-1-Zellen auf die Stimulation vorzubereiten, wurde mittels Zellzählung eine Zellzahl von 1.000.000 (für RT-PCR und Western Blot) bzw. 50.000 (für Immunhistochemie) bestimmt. Für jede geplante Stimulation sowie für eine unstimulierte Probe (Positivkontrolle) und eine zweite unstimulierte Probe im Falle der Immunfluoreszenz (Negativkontrolle) wurde die gewünschte Zellzahl nun in 250-ml-Kulturflaschen in $10 \mathrm{ml}$ Vollmedium bzw. in Culture Slides (BD Falcon ${ }^{\mathrm{TM}}$ REF 354104) in $1 \mathrm{ml}$ Vollmedium ausgesät und für 24 Stunden in den Inkubator gestellt. Nachdem die gewünschte Konfluenz von $80 \%$ erreicht war, wurde das Vollmedium entfernt und durch $5 \mathrm{ml}$ bzw. $1 \mathrm{ml}$ eines Mediums ohne Zusätze, dem sogenannten Hungermedium (Dulbecco's DMEM 4,5 g/l Glucose), ersetzt. Nach erneuter 24-stündiger Inkubation im $\mathrm{CO}_{2}$-Inkubator waren die Zellen bereit für die Stimulation. Um die für die Versuchsreihen erwünschten Konzentrationen der Zytokine zu erlangen, wurde eine Verdünnungsreihe für das jeweilige Zytokin aufgestellt, mittels derer jeweils die Endkonzentration $10 \mathrm{ng} / \mathrm{ml}, 1 \mathrm{ng} / \mathrm{ml}$ und 0,1 ng/ml von TGF- $\beta$ und FGF-2 hergestellt wurden. Nun wurden jeweils $5 \mathrm{ml}$ bzw. $1 \mathrm{ml}$ des in Hungermedium verdünnten Zytokins auf die dafür vorgesehene Kulturflasche gegeben. Die unstimulierte Negativprobe wurde erneut mit $5 \mathrm{ml}$ bzw. $1 \mathrm{ml}$ Hungermedium versehen.

Die MCT- und NP-1-Zellen wurden abhängig von der durchgeführten Methode für folgende Stimulationszeiten inkubiert:

\section{PCR}

\begin{tabular}{|l|l|l|}
\hline Zellen & $\begin{array}{l}\text { Zytokinkonzentrationen } \\
\text { von TGF-ß und FGF-2 }\end{array}$ & Stimulationsdauer \\
\hline $\begin{array}{l}1.000 .000 \mathrm{MCT}-Z e l l e n \\
1.000 .000 \mathrm{NP}-1-Z e l l e n\end{array}$ & $10 \mathrm{ng} / \mathrm{ml}, 1 \mathrm{ng} / \mathrm{ml}, 0,1 \mathrm{ng} / \mathrm{ml}$ & $8 \mathrm{~h}$ \\
\hline $10 \mathrm{ng} / \mathrm{ml}, 1 \mathrm{ng} / \mathrm{ml}, 0,1 \mathrm{ng} / \mathrm{ml}$ & $8 \mathrm{~h}$ \\
$1.000 .000 \mathrm{MCT}-Z$ ellen & $10 \mathrm{ng} / \mathrm{ml}$ & $4 \mathrm{~h}, 8 \mathrm{~h}, 24 \mathrm{~h}$ \\
$1.000 .000 \mathrm{NP}-1-Z e l l e n$ & $10 \mathrm{ng} / \mathrm{ml}$ & $4 \mathrm{~h}, 8 \mathrm{~h}, 24 \mathrm{~h}$ \\
\hline
\end{tabular}

Tabelle 5: Übersicht Zellanzahl, Zytokinkonzentrationen und Stimulationsdauer, PCR 
Western Blot

\begin{tabular}{|l|l|l|}
\hline Zellen & $\begin{array}{l}\text { Zytokinkonzentrationen } \\
\text { von TGF-ß und FGF-2 }\end{array}$ & Stimulationsdauer \\
\hline $\begin{array}{l}1.000 .000 \text { MCT-Zellen } \\
1.000 .000 \mathrm{NP}-1-Z e l l e n\end{array}$ & $10 \mathrm{ng} / \mathrm{ml}, 1 \mathrm{ng} / \mathrm{ml}, 0,1 \mathrm{ng} / \mathrm{ml}$ & $48 \mathrm{~h}$ \\
\hline $1.000 .000 \mathrm{ml}, 1 \mathrm{ng} / \mathrm{ml}, 0,1 \mathrm{ng} / \mathrm{ml}$ & $48 \mathrm{~h}$ \\
$1.000 .000 \mathrm{NP}-1-Z$-Zellen & $10 \mathrm{ng} / \mathrm{ml}$ & $24 \mathrm{~h}, 48 \mathrm{~h}, 72 \mathrm{~h}$ \\
\end{tabular}

Tabelle 6: Übersicht Zellanzahl, Zytokinkonzentrationen und Stimulationsdauer, Western Blot

\section{Immunhistochemie}

\begin{tabular}{|l|l|l|}
\hline Zellen & $\begin{array}{l}\text { Zytokinkonzentrationen } \\
\text { von TGF-ß und FGF-2 }\end{array}$ & Stimulationsdauer \\
\hline $50.000 \mathrm{MCT}-Z e l l e n$ & $10 \mathrm{ng} / \mathrm{ml}, 1 \mathrm{ng} / \mathrm{ml}, 0,1 \mathrm{ng} / \mathrm{ml}$ & $48 \mathrm{~h}$ \\
$50.000 \mathrm{NP}-1-Z e l l e n$ & $10 \mathrm{ng} / \mathrm{ml}, 1 \mathrm{ng} / \mathrm{ml}, 0,1 \mathrm{ng} / \mathrm{ml}$ & $48 \mathrm{~h}$ \\
\hline
\end{tabular}

Tabelle 7: Übersicht Zellanzahl, Zytokinkonzentrationen und Stimulationsdauer, Immunhistochemie

\subsubsection{Die Polymerasekettenreaktion}

\subsubsection{1. Überblick: Polymerasekettenreaktion}

Die Polymerasekettenreaktion (PCR) ist eine Methode, die eine exponentielle Amplifizierung kleinster DNA-Sequenzen innerhalb eines doppelsträngigen DNA-Moleküls ermöglicht. Hierzu benötigt man Primer, die in ihrer Sequenz komplementär zu den speziell definierten Bereichen auf den zwei jeweiligen DNA-Strängen sind. Zusätzlich wird eine DNAPolymerase beigefügt, um die gewünschten Sequenzen zu kopieren. Hiernach können die Primer ebenfalls an diese Kopie binden, so dass nun nicht nur die Ausgangs-DNA, sondern auch das neu entstandene kurzsträngige Molekül kopiert werden kann. Durch einen zyklusartigen Ablauf der PCR ergibt sich somit eine logarithmische Amplifizierung der gewünschten DNA.

Um diesen Prozess in Gang zu setzen, muss jedoch zuerst die Doppelstrang-DNA in Einzelstränge überführt werden. Hierzu werden Temperaturen von bis $\mathrm{zu} 95^{\circ} \mathrm{C}$ benötigt. Früher war es nötig, jedem Zyklus erneut eine Polymerase hinzuzufügen, da diese derart hohen Temperaturen nicht standhalten konnte. Mit der Entdeckung der hitzestabilen Taq- 
Polymerase aus dem Bakterium Thermus aquaticus jedoch kann auf ein erneutes Hinzugeben von DNA-Polymerase verzichtet werden.

Nach einer gewissen Anzahl von Amplifikationszyklen kann das Produkt auf einem Agarosegel mittels einer Ethidium-Bromid-Farbgebung dargestellt werden. Problematisch hierbei ist, dass diese Methode der PCR nur das Vorhanden- bzw. Nichtvorhandensein einer bestimmten DNA-Sequenz zeigt. Zusätzlich besteht auch noch die Möglichkeit, durch das Einsetzten einer reversen Transkriptase den Gehalt an messenger RNA (mRNA) in einer Probe zu ermitteln. Hierbei ermöglicht das genannte Enzym die Umschreibung von mRNA in cDNA, welche dann mittels PCR und Agarosegelauswertung bestimmt wird (auch genannt: RT-PCR). Doch auch dieses Verfahren lässt nur wenig quantitative Aussagen zu. Um aus der PCR ein quantitatives Ergebnis abzuleiten, kam es zum Einsatz der Real-Time PCR. Diese Methode beruht auf der direkten Fluoreszenzmessung eines hinzugefügten Fluoreszenzfarbstoffs während eines Amplifikationszyklus (daher: real time), wobei die entstandene Menge an DNA sich proportional zur Fluoreszenz verhält. Letztendlich wird die Quantifizierung der Ergebnisse nur in der exponentiellen Phase durchgeführt, da hier die optimalen Reaktionsbedingungen herrschen. Die auch im Rahmen dieser Arbeit angewandte Real-Time PCR stellt somit eine Möglichkeit dar, auch kleinste Mengen DNA amplifizieren und die Menge an exprimierter mRNA vergleichen zu können.

\subsubsection{RNA-Isolierung}

Um die gewünschte Stimulationsdauer zu beenden, wurden die Zellen mit Dulbecco's PBS (PAA Laboratories GmbH) gewaschen und mit Trypsin (PAA Laboratories GmbH) vom Kulturflaschenboden abgelöst. Nach Deaktivierung der Wirkung des Trypsins durch erneute PBS-Zugabe wurden die Zellsuspensionen in 50-ml-Falcons (Greiner, Art. No. 210270) bei 1250 rpm für 10 Minuten zentrifugiert. Der resultierende Überstand wurde abgesaugt und pro Falcon $700 \mu \mathrm{l}$ des vorher angesetzten Lysispuffers (Ansatz: 700 $\mu 1$ RLT Lysispuffer $\left(\right.$ RNeasy ${ }^{\circledR}$ Mini Kit (250) Cat. No. 74106) + $10 \mu \mathrm{l}$ ß-Mercaptoethanol (Sigma)) hinzugegeben. Nun folgte ein Einfrieren der lysierten Zellen bei $-20^{\circ} \mathrm{C}$ oder die direkt anschließende RNA-Isolation mit Hilfe des RNeasy® Mini Kits der Firma Qiagen (Cat. No. 74106).

Die Proben wurden in zwei Schritten auf Schreddersäulen (QIAshredder ${ }^{\mathrm{TM}}$ Mini Spin Column Qiagen Cat. No. 79656) pipettiert und anschließend bei $14.000 \mathrm{U} / \mathrm{min}$ für 2 Minuten 
zentrifugiert. Anschließend erfolgte die Zugabe von $700 \mu 1$ 70\%-Ethanol zu jeder Probe. Dieses Ethanol-Zell-Lysat wurde auf eine filterhaltige Säule (RNeasy® Mini Spin Column Qiagen Cat. No. 79656) pipettiert und bei $10.000 \mathrm{U} / \mathrm{min}$ für 15 Sekunden zentrifugiert. Dieser Vorgang wurde mit weiteren $700 \mu$ Ethanol pro Probe wiederholt. Nun wurden $350 \mu 1$ des RWI Waschpuffers (RNeasy® Mini Kit (250) Cat. No. 74106) hinzugefügt und bei 10.000 U/min für 15 Sekunden zentrifugiert. Anschließend folgte der Ansatz des DNase-Verdaus: 10 $\mu 1$ RNase-freie DNase (RNase-Free DNase Set (50) Qiagen Cat. No. 79254) pro Probe wurden mit $70 \mu \mathrm{l}$ RDD-Puffer (RNase-Free DNase Set (50) Qiagen Cat. No. 79254) vermischt. $80 \mu 1$ dieses Ansatzes wurden direkt auf jede Probe appliziert und für 45 Minuten bei Raumtemperatur inkubiert.

Nach hinreichender Inkubation wurde ein Waschvorgang angeschlossen: $350 \mu \mathrm{l}$ RWIWaschpuffer (RNeasy ${ }^{\circledR}$ Mini Kit (250) Cat. No. 74106) pro Probe mit anschließender Zentrifugation bei $10.000 \mathrm{U} / \mathrm{min}$ für 20 Sekunden. Der Filter der Schreddersäule wurde erneuert und die Proben zweifach mit je $350 \mu 1$ RPE-Waschpuffer (RNeasy® Mini Kit (250) Cat. No. 74106) gespült und bei $10.000 \mathrm{U} / \mathrm{min}$ für 15 Sekunden bzw. abschließend 2 Minuten zentrifugiert. Zuletzt wurde die RNA für 5 Minuten trocken zentrifugiert $(10.000 \mathrm{U} / \mathrm{min})$ und in $30 \mu \mathrm{l}$ nukleasefreiem $\mathrm{H}_{2} \mathrm{O}$ aufgelöst, welches vorher auf $43^{\circ} \mathrm{C}$ erwärmt wurde. Nun wurden die Proben selbst für 5 Minuten auf $43^{\circ} \mathrm{C}$ erhitzt, noch einmal bei $14.000 \mathrm{U} / \mathrm{min}$ für 1 Minute zentrifugiert und bei $-20^{\circ} \mathrm{C}$ eingefroren oder gegebenenfalls anschließend direkt umgeschrieben.

\subsubsection{Umschreibung in cDNA}

Nachdem die Konzentration der isolierten RNA mit dem Photometer bestimmt wurde, konnte für jede Probe berechnet werden, wie viel RNA eingesetzt werden musste, um eine Verdünnungskonzentration von $3 \mu \mathrm{g} / \mathrm{ml}$ zu erreichen. Um die mRNA in cDNA umzuschreiben, wurden $1 \mu 1$ Oligo dt (InvitroGen), $1 \quad \mu l \quad$ dNTP-Mix (Desoxynukleotidtriphosphat der Firma InvitroGen) und $5 \mu$ l nukleasefreies $\mathrm{H}_{2} \mathrm{O}$ angesetzt und mit $5 \mu 1$ der RNA-Verdünnung $(3 \mu \mathrm{g} / \mathrm{ml}$ ) versehen. Durch die Zugabe des Oligo dt Primers wurde hierbei gewährleistet, dass die reverse Transkriptase einen ersten Angriffspunkt findet. Zusätzlich wurde eine Negativkontrolle (NoRT) angefertigt, die in der PCR als Indikator dient, ob eine Spezifität des Ergebnisses und eine sichere Umschreibungstechnik den Versuchen zu Grunde liegen. Im Cycler (Mastercycler Personal, 
Eppendorf) wurden diese Proben nun für 10 Minuten bei $70^{\circ} \mathrm{C}$ und anschließend für 3 Minuten bei $4^{\circ} \mathrm{C}$ inkubiert.

Nun erfolgte die Zugabe von $4 \mu$ First Strand Puffer (InvitroGen), $1 \mu 1$ DTT (Dithiothreitol der Firma InvitroGen) sowie 0,5 $\mu \mathrm{l}$ des RNaseOut ${ }^{\mathrm{TM}}$-Inhibitors (InvitroGen), welcher die Ansätze vor Zerstörung durch RNasen schützen soll. Eine weitere Inkubation der Proben bei $42^{\circ} \mathrm{C}$ für 5 Minuten schloss sich an. Im Folgenden wurde der entscheidende Schritt der Umschreibung durch Zugabe von $1 \mu \mathrm{l}$ des Reverse-Transkriptase-Enzyms Superskript ${ }^{\mathrm{TM}}$ II (InvitroGen) durchgeführt. Die Negativkontrolle wurde hierbei ausgespart und lediglich mit 1 $\mu 1$ nukleasefreiem Wasser versehen. Hierauf folgten eine 50 -minütige Inkubation bei $42^{\circ} \mathrm{C}$ sowie eine 15 -minütige bei $70^{\circ} \mathrm{C}$.

Als letzter Schritt wurde allen Proben jeweils $1 \mu$ des Enzyms RNase H (InvitroGen) zugefügt und eine Inkubation bei $37^{\circ} \mathrm{C}$ für 20 Minuten durchgeführt, um die reverse Transkriptase in ihrer Syntheseaktivität zu stoppen. Hierauf wurden die Proben für eine weitere Stunde bei $4^{\circ} \mathrm{C}$ inkubiert. Abschließend wurden die Ansätze mit $160 \mu 1$ nukleasefreiem Wasser aufgefüllt und bei $-20^{\circ} \mathrm{C}$ eingefroren oder direkt für die PCR eingesetzt.

\subsubsection{Die Real-Time PCR}

Nachdem die benötigten Primer für die Sequenz von Nestin und dem ausgewählten housekeeping-Gen GAPDH in entsprechender Verdünnung angesetzt wurden, konnte ein PCR-Programm erstellt werden, in dem die Annealing Temperaturen der Primer berücksichtigt wurden (siehe Tabelle 8). Die Annealing Temperatur beschreibt die maximale Temperatur, bei der es dem Primer noch möglich ist, an die gewünschte Einzelstrang-DNASequenz zu binden, also zu hybridisieren. Die richtig gewählte Temperatur ist von großer Bedeutung, da sie für die Spezifität der Ergebnisse spricht. Wählt man die Gradzahl zu niedrig, riskiert man das Entstehen unspezifischer Bindungen, wählt man sie zu hoch, könnte unter Umständen das Ausbleiben eines Produktes die Folge sein. 


\begin{tabular}{|l|l|l|}
\hline Primer & Sequenz & Annealing Temperatur \\
\hline Nestin (Maus) & & \\
forward & 5'-CTGTTCACCCATCCCAATC-3' & $56,7^{\circ} \mathrm{C}$ \\
reverse & $5^{\prime}$-TCATCTGCCTCGCTTTCTTC-3' & $57,3^{\circ} \mathrm{C}$ \\
\hline GAPDH (Maus) & & \\
forward & 5'-GCCTCCCGTGTTCCTACC-3' & $60,5^{\circ} \mathrm{C}$ \\
reverse & $5^{\prime}$-GCCTGCTTCACCACCTCC-3' & $60,5^{\circ} \mathrm{C}$ \\
\hline
\end{tabular}

Tabelle 8: Daten und Fakten der Nestin- und GAPDH-Primer

Insgesamt wurde für die PCR ein Volumen von $25 \mu 1$ pro Tube (Optical Tube, Stratagene ${ }^{\circledR}$, Cat. No. 401428) verwendet. Dies setzte sich aus $3 \mu 1$ der verdünnten cDNA bzw. der NoRTProbe und $22 \mu 1$ eines vorher angesetzten Mastermixes für den jeweiligen Primer zusammen. Dieser Mastermix beinhaltete folgendes für eine Probe: $11 \mu$ nukleasefreies Wasser, 0,5 $\mu 1$ des gewünschten forward Primers, $0,5 \mu 1$ des entsprechenden reverse Primers sowie $13 \mu 1$ des SYBR Green Supermixes (IQ ${ }^{\mathrm{TM}}$ SYBR GRN SUPERMIX, 1000x50 $\mu 1$, BIO-RAD, Art. No. 170-8884). Dieser wurde zuvor mit 3,3 $\mu$ d des SYBR-Green-Fluoreszenzfarbstoffs (ROX Passive Reference Dye, BIO-RAD, Art. No. 170-8858) versehen, anhand dessen in der RealTime PCR die Fluoreszenz gemessen wird.

Nachdem die Tubes (Optical Cap, Stratagene ${ }^{\circledR}$, Cat. No. 401425) dicht verschlossen wurden, konnten die Proben der PCR-Maschine Mx3000PTM der Firma Stratagene ${ }^{\circledR}$ zugeführt und das vorher programmierte PCR-Zyklus- und Temperaturmuster gestartet werden. Nach Beendigung des Durchlaufs wurden die Proben verworfen.

Die Zyklusdauer und -anzahl sowie das Temperaturschema der durchgeführten PCR sind in Tabelle 9 zusammengefasst.

\begin{tabular}{|l|l|l|l|}
\hline Segment & Temperatur & Zeit & Zyklus \\
\hline 1 & $95^{\circ} \mathrm{C}$ & $10.00 \mathrm{~min}$ & $1 \mathrm{x}$ \\
\hline 2 & $95^{\circ} \mathrm{C}$ & $30 \mathrm{sec}$ & $40 \mathrm{x}$ \\
& $57^{\circ} \mathrm{C}$ & $1.00 \mathrm{~min}$ & \\
& $72^{\circ} \mathrm{C}$ & $30 \mathrm{sec}$ & \\
\hline 3 & $95^{\circ} \mathrm{C}$ & $30 \mathrm{sec}$ & $1 \mathrm{x}$ \\
& $57^{\circ} \mathrm{C}$ & $1.00 \mathrm{~min}$ & \\
\hline & $95^{\circ} \mathrm{C}$ & $30 \mathrm{sec}$ & \\
\hline
\end{tabular}

Tabelle 9: Schema der eingesetzten PCR-Zyklen und Temperaturen 


\subsubsection{Der Western Blot}

\subsubsection{Funktionsprinzip: Western Blot}

Der Western Blot stellt eine sehr sensitive und schnelle Methode dar, mit der es möglich ist, gezielt bestimmte Proteine einer Zelle nachzuweisen. Hierbei ist hervorzuheben, dass selbst kleine Mengen an Protein sich mittels Western Blot zeigen lassen, obwohl große Anteile anderer Proteine in der Zelle vorhanden sind. Der Western Blot ermöglicht es, Aussagen über die Größe eines Proteins in Kilodalton $(\mathrm{kDa}) \mathrm{zu}$ treffen. Ebenso bietet diese Methode die Möglichkeit, die Expressionsmenge eines Proteins im Vergleich zu anderen Proben darzustellen.

Das Prinzip des Western Blots ist die Übertragung, das sogenannte Blotten, zahlreicher Proteine von einem SDS-Polyacrylamid-Gel auf eine hierfür geeignete Membran (meist Nitrocellulose oder PVDF), um danach mittels Antigen-Antikörper-Reaktionen das gewünschte Protein nachweisen zu können. Als erstes müssen jedoch die zuvor aus Zellen isolierten Proteine mittels Gelelektrophorese ihrer Größe entsprechend aufgetrennt werden, damit die Möglichkeit besteht, später einzelne Banden unterschiedlicher Proteingrößen zu detektieren. Mit Hilfe von Elektrizität findet das Blotting der Proteine von dem Gel auf die Nitrocellulosemembran statt. Dies geschieht, um einen besseren Angriffspunkt für die Reaktion mit dem ausgewählten Antikörper zu ermöglichen.

Nun wird ein Primärantikörper appliziert, der spezifisch ein bestimmtes Antigen, in diesem Fall das zu detektierende Protein, bindet. Dies schafft die Möglichkeit, das gewünschte Protein neben bis zu 30.000 anderen Proteinen der Zelle zu identifizieren. Nach erfolgter Antigen-Antikörper-Komplex-Bildung kann nun ein Sekundärantikörper eingesetzt werden. Dieser richtet sich gegen die Quelle (z.B. anti-goat) des eingesetzten Erstantikörpers, um wiederum eine Antigen-Antikörper-Komplex-Reaktion hervorzurufen. Zusätzlich ist der zum Einsatz gebrachte Zweitantikörper zum Beispiel mit Biotin oder einem Enzym wie der alkalischen Phosphatase oder der horseradish peroxidase (HRP) gekoppelt. Werden diese Stoffe nun mit einem chemilumineszenten Reagens in Verbindung gebracht, kommt es auf einem photosensitiven Film zur Detektion der gebundenen Antikörper durch die bei der Reaktion entstandene Lumineszenz. 


\subsubsection{Die Proteinisolierung}

Die Einwirkungszeit der Zytokine auf die MCT- und NP-1-Zellen wurde durch Entfernung der Stimulanzien nach Ablauf der gewünschten Dauer beendet. Anschließend erfolgte eine zweifach durchgeführte Waschung der Zellen mit Dulbecco's PBS (PAA Laboratories $\mathrm{GmbH}$ ). Nun wurden die Zellen mit $2 \mathrm{ml}$ pro 250-ml-Kulturflasche des vorher angesetzten Lysispuffers (Protein) versehen. Zusätzlich wurden jeder Kulturflasche $2 \mu 1$ PMSF (Phenylmethansulfonylfluorid der Firma Sigma) zugeführt. Hierbei handelt es sich um einen Serin-Proteasen Inhibitor, der einem endogenen Proteinzerfall entgegen wirken soll, um so das Entstehen von fälschlicherweise zu hohen Proteinkonzentrationen zu verhindern. Im Anschluss wurden die Zellen für 10 Minuten auf Eis gelagert und darauf folgend mechanisch mit Hilfe eines Zellschabers (Sarstedt, Inc., Cat. No. 83.1830) vom Kulturflaschenboden abgelöst.

Das Zell-Lysat wurde anschließend in Eppendorf Cups (Safe-Lock Tubes 2,0 ml, Eppendorf AG, Order No. 0030 120.094) überführt und erneut für 20 Minuten auf Eis gestellt. Anschließend erfolgte eine Zentrifugation der Proben bei $14.000 \mathrm{U} / \mathrm{min}$ für 10 Minuten bei $4^{\circ}$ C (Centrifuge 5402, Eppendorf AG). Der nun entstandene Überstand enthielt die Proteine der lysierten Zelle und konnte in frischen Eppendorf Cups bei $-20^{\circ} \mathrm{C}$ eingefroren oder direkt der Proteinmessung zugeführt werden.

\subsubsection{Die Messung der Proteinkonzentration}

Zum Bestimmen der vorliegenden Proteinkonzentrationen der Proben wurde die Methode nach Bradford angewandt. Hierzu musste die benötigte Bradfordlösung angesetzt werden. Dafür wurde eine 1:4 Verdünnung aus einem Farbstoffkonzentrat (BIO-RAD Protein Assay, Cat. No. 500-0006) und zweifach destilliertem Wasser hergestellt, welche anschließend mit Hilfe eines Faltenfilters (Schleicher \& Schuell MicroScience GmbH, Ref. No. 10311 845) einmal filtriert wurde. In jede Messküvette (Sarstedt, REF 67.742) wurden 1,225 ml der filtrierten Bradfordlösung und $25 \mu 1$ der jeweiligen Proteinprobe pipettiert. Zusätzlich musste eine Leerwertprobe erstellt werden. $\mathrm{Zu}$ diesem Zweck wurde eine mit 1,225 ml Bradfordlösung befüllte Messküvette mit $25 \mu$ Lysispuffer (Protein) und einem Zusatz aus PMSF (Phenylmethansulfonylfluorid der Firma Sigma) versehen. 
Anschließend wurde der Inhalt der Messküvetten ausreichend vermengt und für 10 Minuten bei Raumtemperatur inkubiert. Die Konzentrationsmessung nach Bradford sieht eine Doppelmessung vor. Daher wurden jeweils zwei Messküvetten mit dem Inhalt einer identischen Probe vorbereitet.

In Bezug zum angefertigten Leerwert konnten nun die Messungen der einzelnen Proben durchgeführt und die Proteinkonzentrationen in $\mathrm{mg} / \mathrm{ml}$ abgeleitet werden.

\subsubsection{Die SDS-PAGE-Gelelektrophorese}

Um die Proteine einer Zelle aufzutrennen, ist es nötig, eine Gelelektrophorese durchzuführen. Abhängig vom gewählten Verfahren besteht die Möglichkeit, die Proteine nach ihrem isoelektrischen Punkt, ihrer Ladung, ihrer molekularen Größe oder einer Kombination aus diesen $\mathrm{zu}$ separieren. In diesem Fall wurde eine SDS-PAGE (NatriumdodecylsulfatPolyacrylamid-Gelelektrophorese) durchgeführt, die eine Auftrennung der Proteine im elektrischen Feld nach ihrer Molekülgröße ermöglicht. Die Gelmatrix des sogenannten Trenngels wird aus einem Gemisch von Acrylamid und Bisacrylamid hergestellt. Das Acrylamid hat die Fähigkeit, lange Polymerketten im Rahmen einer Kettenreaktion mit vorliegenden freien Radikalen zu bilden. Dem Bisacrylamid wird die Aufgabe zuteil, diese Ketten zu vernetzen. Hinzugefügt wird außerdem ein Katalysator für diese Reaktion, TEMED (N,N,N',N'-Tetramethylethylendiamin der Firma Sigma), sowie ein Radikalbildner in Form von Ammoniumperoxodisulfat (10\% APS). Von entscheidender Bedeutung ist das zusätzlich beigefügte 10\%ige SDS, welches sich an die Proteinkomplexe anlagert und zu einer Denaturierung führt. Durch die neu gebundenen Sulfatgruppen erhalten die Proteine alle eine gleichmäßig verteilte Negativladung, welche sicherstellt, dass die Laufgeschwindigkeit der Proteine nunmehr vollständig von der relativen Molekülmasse abhängig ist. So kommt es nachfolgend $\mathrm{zu}$ einer Bewegung der negativ geladenen Proteine in Richtung positiver Elektrode innerhalb des Acrylamidgels. Kleinere Proteine durchwandern dieses Gel bedeutend schneller als große Moleküle, wodurch eine stufenhafte Trennung nach der Größe erfolgt.

Durch die Konzentration des Gels kann die Auflösung der Proteine beeinflusst werden. Ist eine deutliche Auflösung kleinmolekularer Proteine erwünscht, ist es nötig, ein hochprozentiges Gel anzusetzen et vice versa. Da Nestin mit einem molekularen Gewicht von 176 kDa (laut Datasheet, Novus Biologicals) ein verhältnismäßig großes Protein ist, wurde 
hierfür ein 10\%iges Trenngel angefertigt. Eine Bande, die Nestin repräsentiert, ist bei 200 kDa zu erwarten. Das Gel wurde im Zwischenraum zweier Glasplatten der Firma BIO-RAD (Short Plates (5) Mini Protean 3, BIO-RAD, Cat. No. 1653308 und Glass Plates Mini Protean 3 System, BIO-RAD, Cat. No. 1653312) angesetzt, die zuvor dicht abschließend in einer BIO-RAD-Halteapparatur eingespannt wurden. Die beim Gießen des Gels entstandenen Blasen wurden durch die Zugabe einer geringen Menge Isopropanol beseitigt, welches nach Erhärtung des Gels wieder entfernt wurde. Um eine schärfere Trennung der Banden zu erreichen, wurde oberhalb des Trenngels ein Sammelgel gegossen. Dieses besitzt wesentlich größere Poren, so dass die Proteine geschlossen mit relativ hoher Geschwindigkeit gemeinsam das Gel durchwandern bis es an der Grenzlinie zum Trenngel zu den gewünschten unterschiedlichen Laufgeschwindigkeiten kommt. Beim Gießen des Sammelgels wurden die späteren Kammern für die einzelnen Proben vorbereitet, indem in das noch flüssige Gel Trennkämme (BIO-RAD) eingesetzt wurden.

Die zu untersuchenden Proteine wurden zeitgleich zur Anfertigung der Gele für den Western Blot vorbereitet. Hierzu wurden aus der mit Bradford bestimmten Konzentration für jede Probe berechnet, welches Volumen über $50 \mu \mathrm{g}$ Proteingehalt verfügte. Zur Fällung des Proteins wurde die berechnete Menge der jeweiligen Probe mit der dreifachen Menge Aceton versetzt und für 20 Minuten auf Eis inkubiert. Anschließend wurden die Proben bei $4^{\circ} \mathrm{C}$ für 10 Minuten bei $14.000 \mathrm{U} / \mathrm{min}$ zentrifugiert, um das ausgefällte Protein als Pellet am Boden der Eppendorf Cups zu erhalten. Der Überstand wurde verworfen und das Proteingemisch anschließend an der Raumluft für 10 Minuten getrocknet. Währenddessen wurde der Loading Buffer (Sample Buffer, Laemmli, Sigma, S3401-10VL) angesetzt sowie der Rainbow Marker (Full Range Rainbow Molecular Weight Markers, Amersham Biosciences, Cat. No. RPN800E) (15 $\mu 1$ Loading Buffer $+10 \mu 1$ Rainbow Marker) vorbereitet. Im Folgenden diente der Rainbow Marker zur Bestimmung der Proteingrößen durch die ihm beigefügten an Farbstoff gekoppelten Referenzproteine. Jede Proteinprobe wurde nun mit $25 \mu \mathrm{l}$ des $\beta$ Mercaptoethanol-haltigen Loading Buffers versehen. Anschließend wurden alle Proben einschließlich des Rainbow Markers bei $93^{\circ} \mathrm{C}$ für 5 Minuten im Heizblock inkubiert.

Die Glasplatten mit den erhärteten Gelen wurden nun in eine Elektrodenhalterung (MiniPROTEAN ${ }^{\circ} 3$ Cell, BIO-RAD) eingespannt. Anschließend wurde der Zwischenraum der Halterung mit 1-fachem Elektrodenpuffer (100 ml Elektrodenpuffer $\left.+400 \mathrm{ml} \mathrm{dd} \mathrm{H}_{2} \mathrm{O}\right)$ geflutet, so dass Puffer auch in die Bereiche außerhalb der Glasplatten gelangte. Nach Entfernung der Kämme konnten die im erhärteten Sammelgel entstandenen Kammern mit Hilfe einer Pipettiernadel (Mikroliterspritze 705N, Hamilton, Cat. No. 80500) mit $25 \mu 1$ des 
Protein/Loading Buffer-Gemisches befüllt werden. Die erste Kammer auf jedem Gel wurde hierbei mit $25 \mu 1$ des angesetzten Rainbow Markers versehen. Auf Eis gelagert und verschlossen wurde die Elektrodenapparatur nun mit der Spannungsquelle (BIO-RAD Power Pac 1000) verbunden. Für die ersten 10-15 Minuten wurde eine Spannung von 80 V angelegt, die anschließend in langsamen Schritten bis auf $140 \mathrm{~V}$ gesteigert wurde. Die Gelelektrophorese gilt als beendet, wenn die voranschreitenden Proteine, die aufgrund eines im Loading Buffer enthaltenen Farbstoffes sichtbar sind, die untere Begrenzung des Trenngels erreicht haben.

\subsubsection{Der Blotvorgang}

Um die durch die Gelelektrophorese erlangte Auftrennung der Proteine beizubehalten und die Moleküle für die Aufnahme des Primärantikörpers vorzubereiten, mussten die Proteine vom Gel auf eine Nitrocellulosemembran (PROTRAN Nitrocellulose Transfer Membrane, Whatman GmbH, Cat. No. 10401 396) übertragen werden. Der hier durchgeführte Vorgang wird auch als electroblotting bezeichnet. Vorbereitend wurde zu diesem Zweck eine Membran mit den Abmessungen 8,5 cm in der Länge und $7 \mathrm{~cm}$ in der Breite zurechtgeschnitten. Pro Gel wurden je eine Membran, zwei Filterpapiere und zwei Schwämme für 15-20 Minuten in Transferpuffer getränkt. Der gewünschte Transfer fand auf elektrophoretischem Wege in die Protein-bindende Membran statt. Hierfür wurde eine Blotkassette schichtartig befüllt. Mittig befand sich das vorsichtig platzierte Trenngel, bedeckt von der Nitrocellulosemembran. Zu beiden Seiten folgten in der nächsten Schicht getränkte Filterpapiere sowie je ein Schwamm pro Seite als Deckschicht. Nun konnten die Blotkassetten dicht verschlossen in die mit Transferpuffer befüllte und mit einem zusätzlichen Kühlelement versehene Elektrophoresekammer eingebracht werden.

Anschließend wurde die Kammer an eine Spannung von $30 \mathrm{~V}$ bei einer Temperatur von $4^{\circ} \mathrm{C}$ über Nacht angeschlossen. Das elektrische Feld wurde hierbei senkrecht zur ursprünglichen Laufrichtung angelegt. Dies bewirkte, dass die Proteine das Gel verlassen und auf der Membran gebunden werden konnten, wobei die Transferpuffer getränkten Deckschichten als Ionen-Reservoir dienen sollten. 


\subsubsection{Der Primärantikörper}

Bevor der Erstantikörper hinzugegeben werden konnte, mussten die Membranen mit einer Blocklösung vorbehandelt werden, um das Entstehen unspezifischer Bindungen so gering wie möglich zu halten. Hierzu wurde 5\%ige Magermilch mit PBS und Tween angesetzt (siehe Tabelle 4). Für 2 bis 3 Stunden wurden die Membranen in mit Magermilch befüllten Glasküvetten auf der Wippe bei Raumtemperatur inkubiert.

Der Erstantikörper Rabbit Polyclonal anti-Nestin (Novus Biologicals, siehe Tabelle 2) wurde in einer Verdünnung von 1:500 (laut Datasheet) in 5\%iger Magermilchlösung angesetzt (14 $\mu 1$ Antikörper $+6,986 \mathrm{ml}$ Magermilch). Die Membranen wurden nun in frischen Glasküvetten mit jeweils $7 \mathrm{ml}$ der Antikörperverdünnung benetzt und bei $4^{\circ} \mathrm{C}$ über Nacht auf der Wippe inkubiert.

Nach Beendigung der Inkubation wurden die Membranen mit dem angesetzten Waschpuffer (Protein) (siehe Tabelle 4) dreifach für je 10 Minuten gereinigt und so von eventuellen Überresten nicht gebundenen Primärantikörpers befreit.

\subsubsection{Der Sekundärantikörper}

Anschließend konnte der Sekundärantikörper, ein ECL-Antikörper, der mit Meerrettichperoxidase (HRP) gekoppelt ist und selbst vom Esel stammt, eingesetzt werden (Amersham Biosciences, siehe Tabelle 3). Dieser bewirkte eine Immunreaktion auf die im ersten Antikörper enthaltenen Hasengene, wodurch eine gezielte Markierung aller gebundenen Erstantikörper durchgeführt werden konnte. Hier wurde eine Verdünnung von 1:3000 gewählt, was bei $7 \mathrm{ml}$ Gesamtvolumen $3 \mu \mathrm{l}$ Sekundärantikörper und $9 \mathrm{ml}$ Magermilchlösung entsprach. Die mit dieser Verdünnung benetzten Membranen wurden für 1 Stunde bei Raumtemperatur auf der Wippe inkubiert. Anschließend erfolgte wieder die dreifache Säuberung der Membranen in Waschpuffer (Protein) für je 10 Minuten.

Um die gewünschte Lumineszenz, die zur Detektion der Proteine notwendig ist, zu erreichen, wurde der Western Lightning ${ }^{\text {TM }}$ Chemiluminescence Reagent Plus (PerkinElmer LAS, Inc., Boston, Cat. No. NEL104) Enhanced Luminol Reagent im Verhältnis 1:1 mit dem Oxidizing Reagent angesetzt. Die Membranen wurden mit diesem Ansatz benetzt und für 1 Minute unter ständigem Schwenken bei Raumtemperatur inkubiert. Anschließend konnten die Membranen in die Entwicklungskassette eingelegt werden und in der Dunkelkammer bei Rotlicht 
entwickelt werden. Hierzu wurde für variable Entwicklungszeiten (1 Sekunde bis zu mehreren Minuten) je ein photosensitiver Film (FUJI Medical X-RAY Film 13x18, Fujifilm) in die Entwicklungskassette eingelegt und im Folgenden der Entwicklungsmaschine zugeführt, um das Ergebnis des Western Blots zu erhalten. Letztendlich wurde die Skalierung des Rainbow Markers von der Membran auf den Film übertragen, um die entstandenen Banden ihrer Größe in Kilodalton zuordnen zu können.

\subsubsection{Die Immunhistochemie}

\subsubsection{Funktionsprinzip: Immunhistochemie}

Das immunhistochemische Verfahren stellt eine Methode dar, durch die eine gezielte Lokalisation von Antigenen in Gewebe- oder Zellproben ermöglicht wird. Das gesuchte Antigen wird über eine spezifische Bindung eines Primärantikörpers durch eine Bildung von Antigen-Antikörper-Komplexen markiert und mit Hilfe eines Detektionssystems visualisiert. Zur Detektion kommen verschieden Möglichkeiten in Frage: Die direkte Methode verwendet einen markierten Erstantikörper, der es ermöglicht, in einem Schritt eine Darstellung des gewünschten Antigens zu erhalten. Obgleich diese Methode schnell durchzuführen ist, führt ihre schwache Signalstärke häufig eher zu der Verwendung der indirekten Methode. Hierbei besteht das Detektionssystem zumeist aus einem Farbstoff-gekoppelten Sekundärantikörper, wobei der eingesetzte Erstantikörper unmarkiert bleibt. Ebenso kommt zur Detektion eine Kopplung an Enzyme, radioaktive Elemente oder kolloidales Gold infrage. Die indirekte Methode resultiert in einer deutlichen Signalverstärkung, da der Sekundärantikörper mehrere Immunkomplexreaktionen mit jedem bereits gebundenen Erstantikörper eingehen kann.

Bei den eingesetzten Farbstoffen handelt es sich um eine Fluorochrommarkierung. Nach Anregung mit Licht einer bestimmten Wellenlänge emittiert dieser Fluoreszenzfarbstoff Licht in einem für ihn charakteristischen Wellenlängenbereich. Hierbei kommt es häufig zur Anwendung des Fluoreszenzmikroskops, welches ultraviolette Strahlung verwendet und durch den Einsatz bestimmter Filter die selektive Darstellung der Fluorochrome ermöglicht. Heutzutage existieren eine Reihe Fluoreszenzfarbstoffe, die zum Einsatz kommen, wie zum Beispiel Fluoresceinisothiocyanat (FITC), Phycoerythrin (PE), Cyan-Farbstoffe und Allophycocyanin (APC). 


\subsubsection{Die Immunfluoreszenzfärbung}

Nach Beendigung der Stimulation der Zellen nach 48 Stunden konnten die zelltragenden Anteile der speziell für diesen Versuch eingesetzten Kulturflaschen, der Chamber Slides, abgenommen werden und anschließend einmal in 1x PBS (siehe Tabelle 4) gewaschen werden. Anschließend wurden die Zellen einem $-20^{\circ} \mathrm{C}$ kalten 1:1 Methanol/Aceton-Gemisch (Merck) für 20 Minuten zugeführt, um die adhärenten Zellen auf dem Objektträger zu fixieren. Die Fixierung wurde durch eine ausgiebige Trocknung der Objektträger an der Raumluft beendet. Nach erneuter dreimaliger Waschung der Zellen mit 1x PBS wurde ein Blockvorgang mittels 15 minütiger Inkubation in 1\%igem BSA (siehe Tabelle 4) durchgeführt, um ein unspezifisches Binden des Antikörpers zu verhindern.

Im Anschluss konnte nun der Primärantikörper Rabbit Anti-Nestin (Novus Biologicals) in einer 1:75 Verdünnung in 1\%igem BSA appliziert werden $(10,6 \mu 1$ Erstantikörper $+789,4 \mu 1$ 1\%iges BSA). Wichtig hierbei ist das Anfertigen einer Negativkontrolle (eine Zellkammer, die mit reinem 1\%igem BSA ohne Erstantikörper inkubiert wird), um im Versuchsablauf ein unspezifisches Binden des Zweitantikörpers ausschließen zu können. Nach einer Inkubation des Primärantikörpers für 1 Stunde bei Raumtemperatur erfolgte dreimal eine Waschung mit 1x PBS für je 2 Minuten, um eventuell nicht gebundene Erstantikörpermoleküle zu entfernen. Nun erfolgte die Zugabe des mit Fluoresceinisothiocyanat (FITC) markierten Zweitantikörpers (siehe Tabelle 3) in einem 1:250 verdünnten Ansatz $(4 \mu 1$ Sekundärantikörper + 996 1x PBS). Hierbei musste die sich anschließende einstündige Inkubation der Zellen zwingend in einer Dunkelkammer stattfinden, da das Fluorochrom höchst lichtsensibel ist. Anschließend wurden die Zellen erneut dreimal für je zwei Minuten mit PBS gewaschen.

Um die Zellkerne der fixierten Zellen ebenfalls zu visualisieren, wurde im Anschluss eine DAPI-Färbung (4',6'- Diamidin-2-phenylinoledihyrdochlorid) durchgeführt. Hierfür wurde eine 1:1000 Verdünnung der DAPI-Stocklösung (Roche, Cat. No. 84898129) in 1x PBS angesetzt. Die Zellen wurden für 10 Minuten in einer Dunkelkammer mit der DAPI-Lösung inkubiert und anschließend kurz in $1 \mathrm{x}$ PBS gewaschen. Im Folgenden wurden die Objektträger mit Eindeckmedium (DAKO Fluorescent Mounting Medium, Cat. No. 3023) versehen und mit einer Glasplatte abgedeckt. Nun konnten die Zellen mit den detektierten Proteinen mit Hilfe des Fluoreszenzmikroskops (Axiovert S $100^{\text {TV }}$, Zeiss) begutachtet werden. Hierzu wurden unterschiedliche Vergrößerungen verwendet, um verschiedene Fragestellungen zu beantworten. 


\subsubsection{Statistik}

Sowohl die Ergebnisse der RT-PCR als auch die der Immunfluoreszenz der beiden Zellreihen MCT und NP-1 wurden statistisch mit Hilfe der Abteilung für medizinische Statistik der Universität Göttingen ausgewertet. Die Einflüsse der Zytokine TGF- $ß$ und FGF-2 auf die Nestinexpression bei der Real-Time PCR wurden im Vergleich zum unstimulierten Calibrator mittels eines Einstichproben-t-Tests ausgewertet. Der Effekt der Konzentration bzw. der Zeit auf die Nestinexpression wurden mit Zweistichprobentests in Form von gepaarten t-Tests zum Vergleich der unterschiedlichen Konzentrationen bzw. Stimulationszeiten untereinander evaluiert. Im Fall der Versuchsreihe der Immunfluoreszenz wurde jede Stimulationskonzentration des einzelnen Zytokins mit Hilfe eines abhängigen t-Tests im Vergleich zur unstimulierten Probe ausgewertet.

Als Signifikanzniveau wurde für alle Tests $\alpha=5 \%$ festgelegt. Die Analysen wurden mit der Datenanalysesoftware STATISTICA 9 der Firma Statsoft ausgeführt. 


\section{Ergebnisse}

\subsection{Ergebnisse der Genexpressionsanalyse für Nestin mittels Real-Time PCR}

\subsubsection{Konzentrationsabhängige Untersuchung der Nestinexpression in} murinen Tubulusepithelzellen nach Zytokinstimulation mit TGF-ß3 und FGF-2

\subsubsection{Ergebnisse der proximalen Tubulusepithelzellreihe MCT}

\section{Konzentrationsversuch MCT Zellen}

(TGFß \& FGF-2)

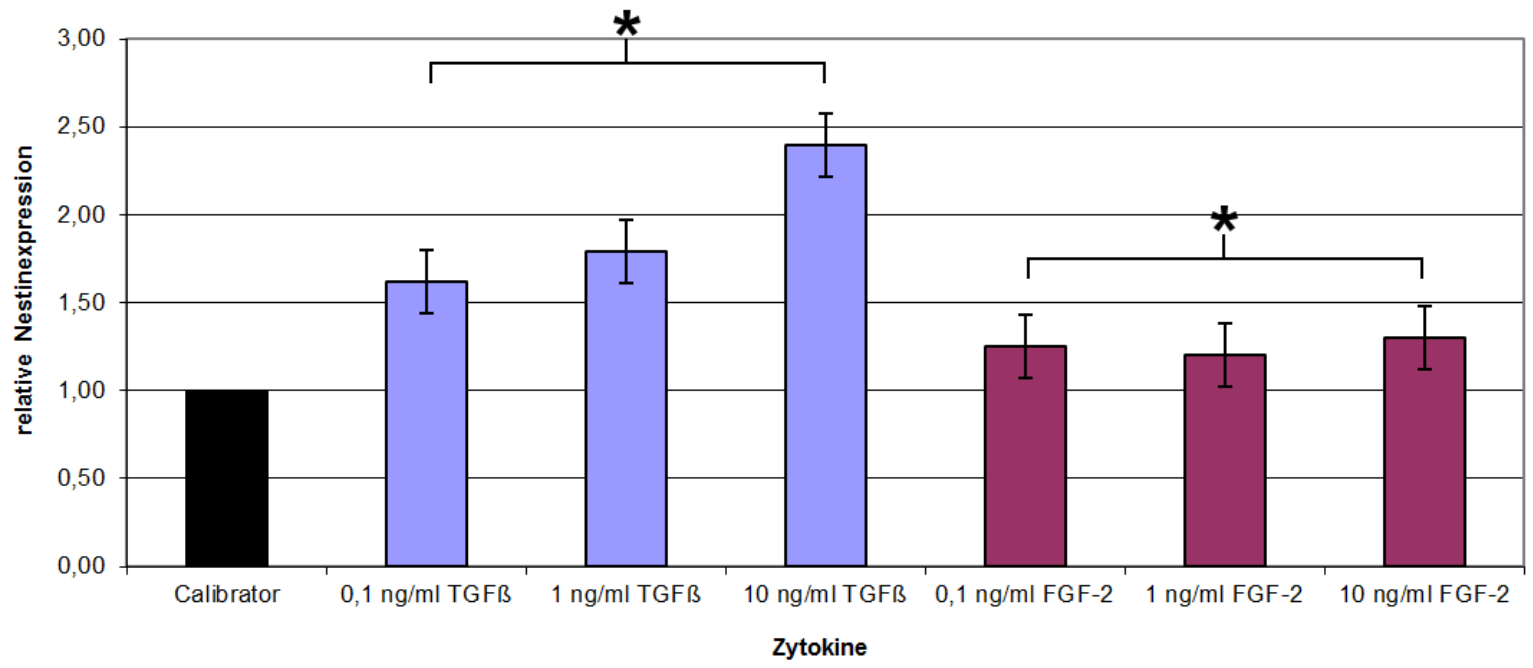

Abbildung 3: Zytokinstimulation mit TGF- $\beta$ und FGF-2 von MCT-Zellen für einen Zeitraum von 8 Stunden. In dieser Grafik sind jeweils die Mittelwerte der relativen Nestinexpression bei den Konzentrationen $0,1 \mathrm{ng} / \mathrm{ml}, 1 \mathrm{ng} / \mathrm{ml}$ und $10 \mathrm{ng} / \mathrm{ml}$ von TGF- $\beta$ und FGF-2 sowie der Standardfehler dargestellt. Signifikanzniveau $*=p<0,05$. Anmerkung: $*$ bezieht sich in dieser Abbildung auf den Effekt der drei verwendeten Stimulationskonzentrationen auf die relative Nestinexpression im Vergleich zur unstimulierten Probe.

\begin{tabular}{|c|c|c|c|}
\hline TGF-B & p-Wert & FGF-2 & p-Wert \\
\hline $\begin{array}{l}\text { Effekt der } \\
\text { Zytokinbehandlung auf die } \\
\text { relative Nestinexpression im } \\
\text { Vergleich zur unstimulierten } \\
\text { Probe }\end{array}$ & $0,0114 *$ & $\begin{array}{l}\text { Effekt der } \\
\text { Zytokinbehandlung auf die } \\
\text { relative Nestinexpression im } \\
\text { Vergleich zur unstimulierten } \\
\text { Probe }\end{array}$ & $0,0398 *$ \\
\hline
\end{tabular}




\begin{tabular}{|l|l|l|l|}
\hline $\begin{array}{l}\text { TGF-ß3- } \\
\text { Konzentrationsvergleich }\end{array}$ & p-Wert & $\begin{array}{l}\text { FGF-2- } \\
\text { Konzentrationsvergleich }\end{array}$ & p-Wert \\
\hline $0,1 \mathrm{ng} / \mathrm{ml}: 1 \mathrm{ng} / \mathrm{ml}$ & 0,4112 & $0,1 \mathrm{ng} / \mathrm{ml}: 1 \mathrm{ng} / \mathrm{ml}$ & 0,3356 \\
\hline $0,1 \mathrm{ng} / \mathrm{ml}: 10 \mathrm{ng} / \mathrm{ml}$ & 0,0505 & $0,1 \mathrm{ng} / \mathrm{ml}: 10 \mathrm{ng} / \mathrm{ml}$ & 0,1770 \\
\hline $1 \mathrm{ng} / \mathrm{ml}: 10 \mathrm{ng} / \mathrm{ml}$ & 0,0631 & $1 \mathrm{ng} / \mathrm{ml}: 10 \mathrm{ng} / \mathrm{ml}$ & 0,2390 \\
\hline
\end{tabular}

Tabelle 10: Statistische Ergebnisse der Nestinexpression bei MCT-Zellen nach konzentrationsabhängiger Zytokinstimulation

Mit Hilfe der Real-Time PCR konnte die Nestinexpression nach Stimulation mit den Zytokinen TGF- $\beta$ und FGF-2 im proximalen Anteil des murinen Tubulusepithels (MCTZellen) analysiert werden (siehe Abbildung 3). Hierbei ist es interessant zu sehen, dass sich nicht nur die zwei eingesetzten Zytokine in ihrem Effekt unterscheiden, sondern zusätzlich auch eine von der Zytokinkonzentration abhängige Steigerung der Nestinexpression festzustellen ist. Bei TGF- $\beta$ lassen sich beide eben genannten Effekte bestätigen. Zum einen liegt eine klare Expressionssteigerung von Nestin unter Einfluss dieses Zytokins vor. Zum anderen lässt sich auch zwischen den Konzentration $0,1 \mathrm{ng} / \mathrm{ml}, 1 \mathrm{ng} / \mathrm{ml}$ und $10 \mathrm{ng} / \mathrm{ml}$ eine deutliche Tendenz hin zur verstärkten Nestinexpression bei höherer Zytokinkonzentration erkennen.

Im Gegensatz dazu lässt sich bei FGF-2-Stimulation keine klare Steigerung der Nestinexpression und auch keine deutliche Veränderung des Expressionsmusters in Abhängigkeit von der Konzentration in MCT-Zellen finden. Graphisch ist eine leichte Steigerung des exprimierten Nestins zu verzeichnen, die jedoch nur knapp das Niveau des Calibrators übersteigt. Die Stimulationsdauer der unterschiedlich konzentrierten Zytokinansätze wurde in diesem Versuch mit 8 Stunden konstant gehalten, um allein die Auswirkung des Zytokins und der veränderten Konzentrationen beurteilen zu können. Bei der vorliegenden Versuchsreihe wurde eine dreimalige Wiederholung durchgeführt. Um den Effekt der Zytokine auf den Nestingehalt zu verdeutlichen, wurde eine Zellprobe ohne Zytokinbehandlung als Calibrator der Real-Time PCR beigefügt.

Statistisch konnte sowohl für TGF-ß als auch für FGF-2 eine eindeutige Signifikanz des Effektes der Zytokinbehandlung auf die Nestinexpression bei MCT-Zellen festgestellt werden (gebündelte Analyse der drei jeweils verwendeten Stimulationskonzentrationen im Vergleich zur unstimulierten Probe: p-Wert $($ TGF- $\beta)=0,0114$, p-Wert $($ FGF-2) $=0,0398$, siehe Tabelle 10). Eine statistische Signifikanz für die einzelnen Konzentrationen im Vergleich zur unstimulierten Probe konnte dabei nicht belegt werden ( $p$-Werte nicht aufgeführt). Der Vergleich der Stimulationskonzentration $0,1 \mathrm{ng} / \mathrm{ml}$ TGF- $\beta$ mit der Konzentration $10 \mathrm{ng} / \mathrm{ml}$ TGF- $ß$ verfehlte das Signifikanzniveau von 5\% nur knapp ( $\mathrm{p}$-Wert $=0,0505$, siehe Tabelle 10). Wie auch graphisch zu erwarten war, konnte kein signifikanter Unterschied im Einfluss 
verschiedener Konzentrationen von FGF-2 auf die Nestinexpression festgestellt werden. Hierbei ist hinzuzufügen, dass eine etwaige Signifikanz der Konzentrationsunterschiede bei beiden Zytokinstimulationen durch eine höhere Anzahl an Versuchsdurchläufen deutlicher zum Vorschein gebracht werden könnte.

\subsubsection{Ergebnisse der distalen Tubulusepithelzellreihe NP-1}

\section{Konzentrationsversuch NP-1 Zellen \\ (TGFß \& FGF-2)}

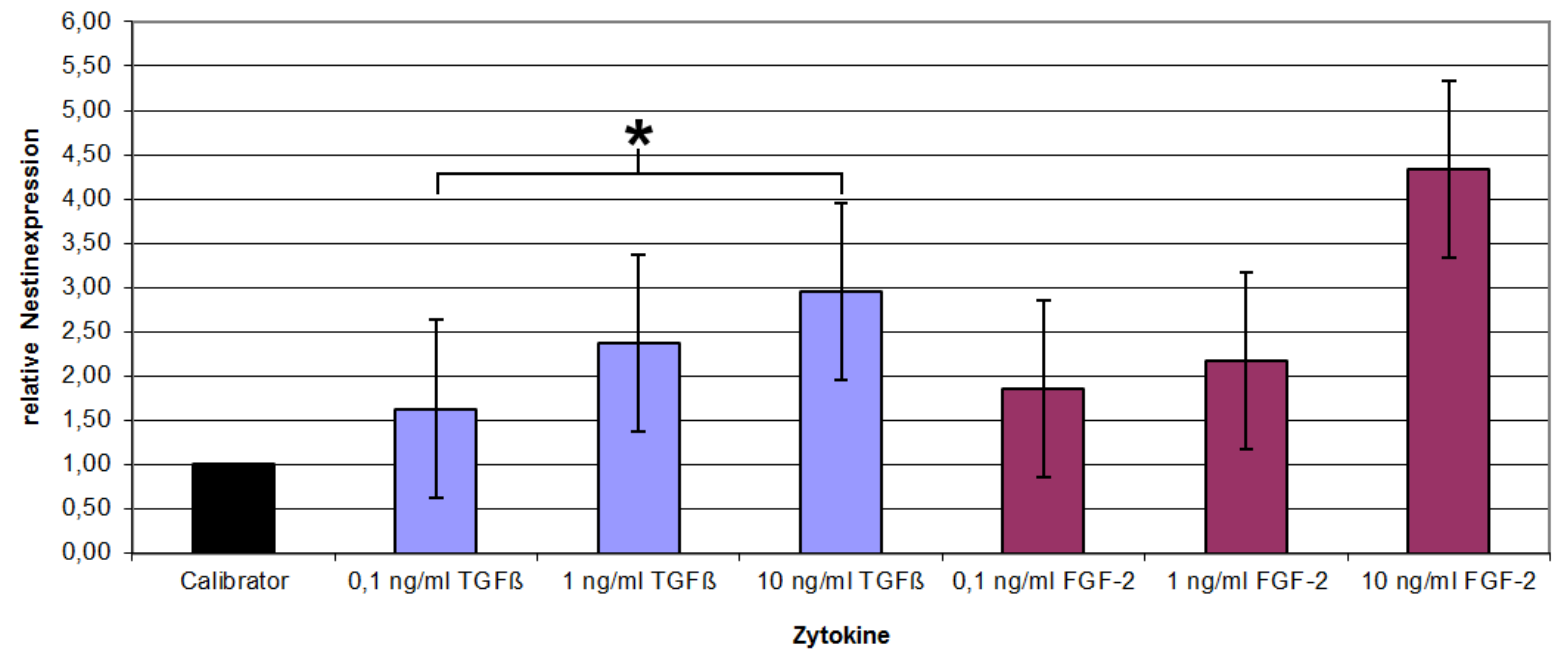

Abbildung 4: Zytokinstimulation mit TGF- 3 und FGF-2 von NP-1-Zellen für einen Zeitraum von 8 Stunden. In dieser Grafik sind jeweils die Mittelwerte der relativen Nestinexpression bei den Konzentrationen $0,1 \mathrm{ng} / \mathrm{ml}, 1 \mathrm{ng} / \mathrm{ml}$ und $10 \mathrm{ng} / \mathrm{ml}$ von TGF- $\beta$ und FGF-2 sowie der Standardfehler dargestellt. Signifikanzniveau $*=p<0,05$. Anmerkung: * bezieht sich in dieser Abbildung auf den Effekt der drei verwendeten Stimulationskonzentrationen auf die relative Nestinexpression im Vergleich zur unstimulierten Probe.

\begin{tabular}{|c|c|c|c|}
\hline TGF-B & p-Wert & FGF-2 & p-Wert \\
\hline $\begin{array}{l}\text { Effekt der } \\
\text { Zytokinbehandlung auf die } \\
\text { relative Nestinexpression im } \\
\text { Vergleich zur unstimulierten } \\
\text { Probe }\end{array}$ & $0,0417 *$ & $\begin{array}{l}\text { Effekt der } \\
\text { Zytokinbehandlung auf die } \\
\text { relative Nestinexpression im } \\
\text { Vergleich zur unstimulierten } \\
\text { Probe }\end{array}$ & 0,1276 \\
\hline
\end{tabular}




\begin{tabular}{|l|l|l|l|}
\hline $\begin{array}{l}\text { TGF-8- } \\
\text { Konzentrationsvergleich }\end{array}$ & p-Wert & $\begin{array}{l}\text { FGF-2- } \\
\text { Konzentrationsvergleich }\end{array}$ & p-Wert \\
\hline $0,1 \mathrm{ng} / \mathrm{ml}: 1 \mathrm{ng} / \mathrm{ml}$ & 0,3455 & $0,1 \mathrm{ng} / \mathrm{ml}: 1 \mathrm{ng} / \mathrm{ml}$ & 0,3833 \\
\hline $0,1 \mathrm{ng} / \mathrm{ml}: 10 \mathrm{ng} / \mathrm{ml}$ & 0,3060 & $0,1 \mathrm{ng} / \mathrm{ml}: 10 \mathrm{ng} / \mathrm{ml}$ & 0,4318 \\
\hline $1 \mathrm{ng} / \mathrm{ml}: 10 \mathrm{ng} / \mathrm{ml}$ & 0,3231 & $1 \mathrm{ng} / \mathrm{ml}: 10 \mathrm{ng} / \mathrm{ml}$ & 0,4462 \\
\hline
\end{tabular}

Tabelle 11: Statistische Ergebnisse der Nestinexpression bei NP-1-Zellen nach konzentrationsabhängiger Zytokinstimulation

Die Abbildung 4 zeigt die durch Real-Time PCR ermittelte relative Nestinexpression nach Zytokinbehandlung in den distalen Tubulusepithelzellen NP-1. In dieser Versuchsreihe wurde ebenfalls eine Stimulation für einen Zeitraum von 8 Stunden mit den Zytokinen TGF- $\beta$ und FGF-2 durchgeführt. Nach dreifacher Wiederholung des Versuchsablaufes zeigte sich, dass die Expression von Nestin bei den zwei eingesetzten Zytokinen leicht über dem Niveau der unstimulierten Probe (Calibrator) liegt. Statistisch ist der Zytokinbehandlung mit TGF- $\beta$ eine Signifikanz zuzuordnen (gebündelte Analyse der drei verwendeten Stimulationskonzentrationen von TGF- $\beta$ im Vergleich zur unstimulierten Probe: $p$-Wert = 0,0417, siehe Tabelle 11), wohingegen die FGF-2-Behandlung keinen signifikanten Unterschied ergab ( $\mathrm{p}$-Wert $=0,1276$, siehe Tabelle 11). Dies ist mit der sehr starken Schwankungsbreite innerhalb der Werte der drei durchgeführten Versuchsreihen mit FGF-2 zu erklären. Auch hier wäre eine höhere Anzahl an Versuchsdurchführungen hilfreich, um derartige Schwankungen ausgleichen zu können, damit diese in der statistischen Erfassung nicht derartig ins Gewicht fallen.

Die statistische Untersuchung des Effektes der verschiedenen Konzentrationen ergab weder in der Stimulationsreihe mit TGF- $\beta$ noch mit FGF-2 eine relevante Information. Rein graphisch betrachtet, lässt sich eine kontinuierliche Steigerung der Nestinexpression mit zunehmender Zytokinkonzentration in beiden Gruppen feststellen. 


\subsubsection{Zeitabhängige Untersuchung der Nestinexpression in murinen} Tubulusepithelzellen nach Zytokinstimulation mit TGF-ß und FGF-2

\subsubsection{Ergebnisse der proximalen Tubulusepithelzellreihe MCT}

\section{Zeitversuch MCT Zellen}

(TGFß \& FGF-2)

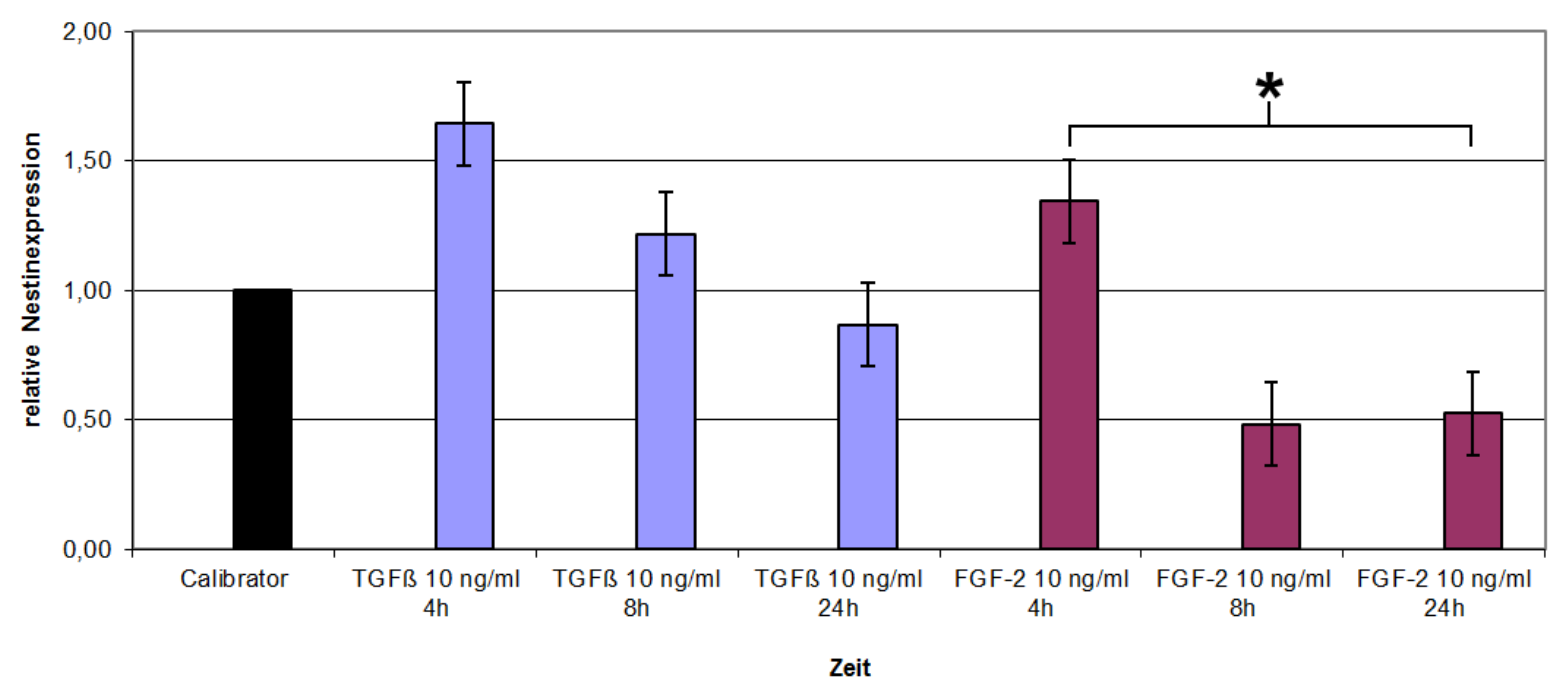

Abbildung 5: Zytokinstimulation von MCT-Zellen über einen Zeitraum von 4, 8 und 24 Stunden mit der Konzentration $10 \mathrm{ng} / \mathrm{ml}$ der Zytokine TGF- $\beta$ und FGF-2. In dieser Grafik sind jeweils die Mittelwerte der relativen Nestinexpression sowie der Standardfehler dargestellt. Signifikanzniveau * = $\mathrm{p}<0,05$. Anmerkung: * bezieht sich in dieser Abbildung auf den statistischen Vergleich der Stimulationszeiten $4 \mathrm{~h}: 24 \mathrm{~h}$.

\begin{tabular}{|l|l|l|l|}
\hline $\begin{array}{l}\text { TGF-ß- } \\
\text { Stimulationszeitvergleich }\end{array}$ & p-Wert & $\begin{array}{l}\text { FGF-2- } \\
\text { Stimulationszeitvergleich }\end{array}$ & p-Wert \\
\hline $4 \mathrm{~h}: 8 \mathrm{~h}$ & 0,3514 & $4 \mathrm{~h}: 8 \mathrm{~h}$ & 0,0511 \\
\hline $4 \mathrm{~h}: 24 \mathrm{~h}$ & 0,0545 & $4 \mathrm{~h}: 24 \mathrm{~h}$ & $\mathbf{0 , 0 2 3 0} *$ \\
\hline $8 \mathrm{~h}: 24 \mathrm{~h}$ & 0,2324 & $8 \mathrm{~h}: 24 \mathrm{~h}$ & 0,9059 \\
\hline
\end{tabular}

Tabelle 12:Statistische Ergebnisse der Nestinexpression bei MCT-Zellen nach Zytokinstimulation über einen Zeitraum von 4, 8 und 24 Stunden.

In Abbildung 5 erkennt man die Versuchsergebnisse zu einem Zytokinstimulationsversuch an MCT-Zellen, welche mit einer konstanten Konzentration $(10 \mathrm{ng} / \mathrm{ml})$ von jeweils zwei unterschiedlichen Zytokinen (TGF- 3 und FGF-2) für drei verschiedene Zeitperioden ( $4 \mathrm{~h}, 8 \mathrm{~h}$ und $24 \mathrm{~h}$ ) stimuliert wurden. Hierbei wurde sich in Bezugnahme auf die Ergebnisse der konzentrationsabhängigen Versuche für die Konzentration, mit der in beiden Versuchsmodellen der höchste Effekt auf die Nestinexpression erzielt wurde, entschieden, um 
sich auf die Ereignisse bezüglich der Zeit zu konzentrieren. Als unterschiedliche Stimulationszeiträume wurden 4,8 und 24 Stunden gewählt, um zu erkennen, ob eine Zeitabhängigkeit der Nestinexpression besteht und bei welcher Stimulationsdauer diese am deutlichsten ist. Als Calibrator wurde in diesem Versuchsmodell ebenfalls eine Zellprobe ohne Zytokinstimulation mitgeführt. Um eine höhere Aussagekraft der Ergebnisse zu erzielen, wurde die Versuchsreihe in dreifacher Wiederholung mit jeweils neuen Versuchsansätzen durchgeführt.

Graphisch lässt sich erkennen, dass bei einer vierstündigen Stimulation mit TGF- $\beta$ an MCTZellen der deutlichste Effekt zu erzielen ist. Die Nestinexpression nimmt mit zunehmender Stimulationsdauer ab. Bei einer 24-stündigen Stimulation mit TGF- $\beta$ zeigt sich sogar ein Rückgang der Nestinexpression unterhalb des Calibratorniveaus, was auf eine mögliche Inhibition der Expression dieses Proteins oder einen vorliegenden zytotoxischen Effekt schließen lässt.

Bei der Zytokinbehandlung mit FGF-2 zeigt sich der Effektverlauf auf die Nestinexpression in einem ähnlichen Muster wie bei TGF- $\beta$. Allerdings lässt sich graphisch sowohl bei einer Stimulationsdauer von 8 als auch von 24 Stunden eine hemmende Auswirkung auf die Nestinexpression feststellen. Auch hierbei ist die Möglichkeit eines toxischen Effektes nicht auszuschließen. Kritisch zu sehen ist der toxische Effekt bei einer FGF-2-Stimulationsdauer von 8 Stunden, da dies auch die in den konzentrationsabhängigen Versuchen eingesetzte Stimulationsperiode darstellt, welche eine, wenn auch geringe, Steigerung der Nestinexpression über das Calibratorniveau zur Folge hatte. Auch in dieser Versuchsreihe ist dieses etwas widersprüchliche Ergebnis der hohen Spannbreite der Werte der drei Versuchsdurchläufe geschuldet.

Statistisch konnte ein maßgeblicher Unterschied im Effekt zwischen einer Stimulationsdauer von 4 und 24 Stunden für TGF- $\beta$ und FGF-2 in MCT-Zellen ermittelt werden (p-Wert (TGF$\beta)=0,0545, \mathrm{p}$-Wert $(\mathrm{FGF}-2)=0,0230$, siehe Tabelle 12$)$, wobei der $\mathrm{p}$-Wert für TGF- $\beta$ hier das Signifikanzniveau von $5 \%$ knapp überschreitet. 


\subsubsection{2. $\quad$ Ergebnisse der distalen Tubulusepithelzellreihe NP-1}

\section{Zeitversuch NP-1}

(TGFß \& FGF-2)

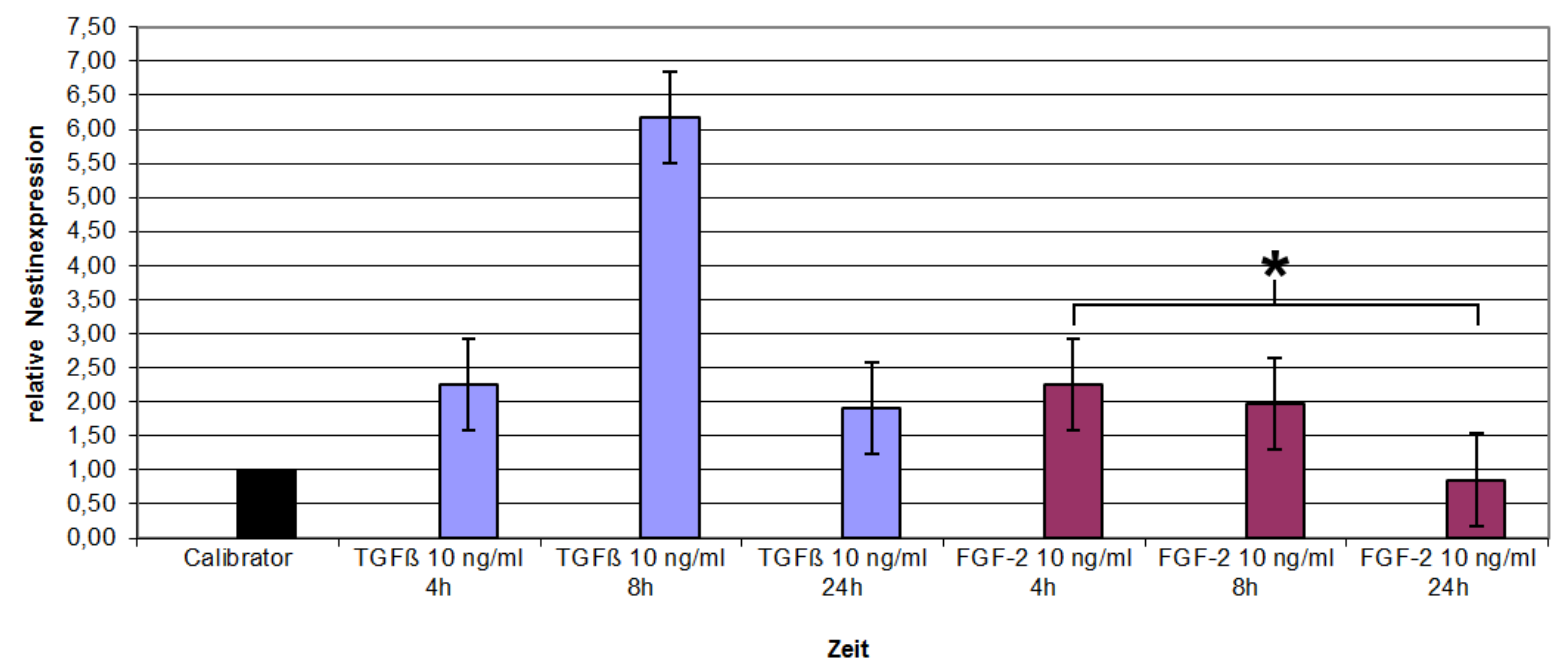

Abbildung 6: Zytokinstimulation von NP-1-Zellen über einen Zeitraum von 4, 8 und 24 Stunden mit der Konzentration $10 \mathrm{ng} / \mathrm{ml}$ der Zytokine TGF- $\beta$ und FGF-2. In dieser Grafik sind jeweils die Mittelwerte der relativen Nestinexpression sowie der Standardfehler dargestellt. Signifikanzniveau * = $\mathrm{p}<0,05$. Anmerkung: * bezieht sich in dieser Abbildung auf den statistischen Vergleich der Stimulationszeiten $4 \mathrm{~h}: 24 \mathrm{~h}$.

\begin{tabular}{|l|l|l|l|}
\hline $\begin{array}{l}\text { TGF-B- } \\
\text { Stimulationszeitvergleich }\end{array}$ & p-Wert & $\begin{array}{l}\text { FGF-2- } \\
\text { Stimulationszeitvergleich }\end{array}$ & p-Wert \\
\hline $4 \mathrm{~h}: 8 \mathrm{~h}$ & 0,0757 & $4 \mathrm{~h}: 8 \mathrm{~h}$ & 0,6506 \\
\hline $4 \mathrm{~h}: 24 \mathrm{~h}$ & 0,4847 & $4 \mathrm{~h}: 24 \mathrm{~h}$ & $\mathbf{0 , 0 0 1 5} *$ \\
\hline $8 \mathrm{~h}: 24 \mathrm{~h}$ & 0,1030 & $8 \mathrm{~h}: 24 \mathrm{~h}$ & 0,0908 \\
\hline
\end{tabular}

Tabelle 13: Statistische Ergebnisse der Nestinexpression bei NP-1-Zellen nach Zytokinstimulation über einen Zeitraum von 4, 8 und 24 Stunden.

Die Grafik 6 stellt den Verlauf der Nestinexpression nach Zytokinstimulation mit einer konstanten Konzentration von TGF- $\beta$ und FGF-2 in distalen Tubulusepithelzellen über drei unterschiedliche Zeiträume (4, 8, 24 Stunden) dar. Interessanterweise lässt sich in diesem Zeitversuch graphisch eine Abhängigkeit der Zeit für die Behandlung mit dem Zytokin TGF- $\beta$ erkennen. Dabei lässt sich feststellen, dass mit einer Stimulationsdauer von 8 Stunden in NP1-Zellen ein scheinbar deutlicher induktiver Effekt auf die Nestinexpression durch TGF-ß (10 $\mathrm{ng} / \mathrm{ml}$ ) auszulösen ist. Bei vierstündiger Stimulation mit TGF- $ß$ kann ebenfalls, wenn auch ein weitaus schwächerer, induktiver Effekt verzeichnet werden. Bei einer Einwirkungsdauer des Zytokins für 24 Stunden ist der induktive Effekt des TGF-ß ebenfalls vorzufinden, jedoch in 
noch geringerer Ausprägung. Statistisch lassen sich diese Beobachtungen bezüglich des Zeiteinflusses von TGF- $\beta$ aufgrund hoher Varianz in den gemessenen Werten nicht bestätigen.

Bei der Stimulation mit dem Zytokin FGF-2 ist graphisch eine absteigende Tendenz in der relativen Expression von Nestin mit zunehmender Stimulationsdauer zu verzeichnen. Bei 24stündiger Stimulation fällt das Expressionsniveau sogar in Bereiche unterhalb des Calibrators, wodurch auch hier die Annahme eines toxischen Effektes auf die Zellen nahe liegt. Statistisch aussagekräftig ist hierbei der Unterschied der Stimulationsdauer von 4 Stunden im Vergleich zu 24 Stunden (p-Wert =0,0015, siehe Tabelle 13) der FGF-2-Stimulation.

\subsection{Ergebnisse der Immunhistochemie}

\subsection{1. $\quad$ Ergebnisse der Immunfluoreszenzfärbungen bezüglich des Nestingehalts in der Zellreihe MCT nach Stimulation mit TGF-ß und FGF-2}

In dieser Versuchsreihe wurde der Nestingehalt der proximalen Tubulusepithelzellen nach Stimulation mit TGF- $\beta$ und FGF-2 mittels indirekter Immunfluoreszenz untersucht. Die Stimulation der Zellen erfolgte für 48 Stunden mit den Konzentrationen 0,1 ng/ml, 1 ng/ml und $10 \mathrm{ng} / \mathrm{ml}$ von TGF- $\beta$ und FGF-2. Die Versuchsreihe wurde zweifach durchgeführt. Es wurde jeweils eine Negativprobe, die mit dem Primärantikörper im Rahmen des Versuches keinen Kontakt hatte, mitgeführt, um eventuelle unspezifische Bindungen des Zweitantikörpers aufzudecken sowie eine unstimulierte Zellprobe, um den Einfluss der Zytokine auf den Nestingehalt der Zellen im Vergleich darzustellen. 

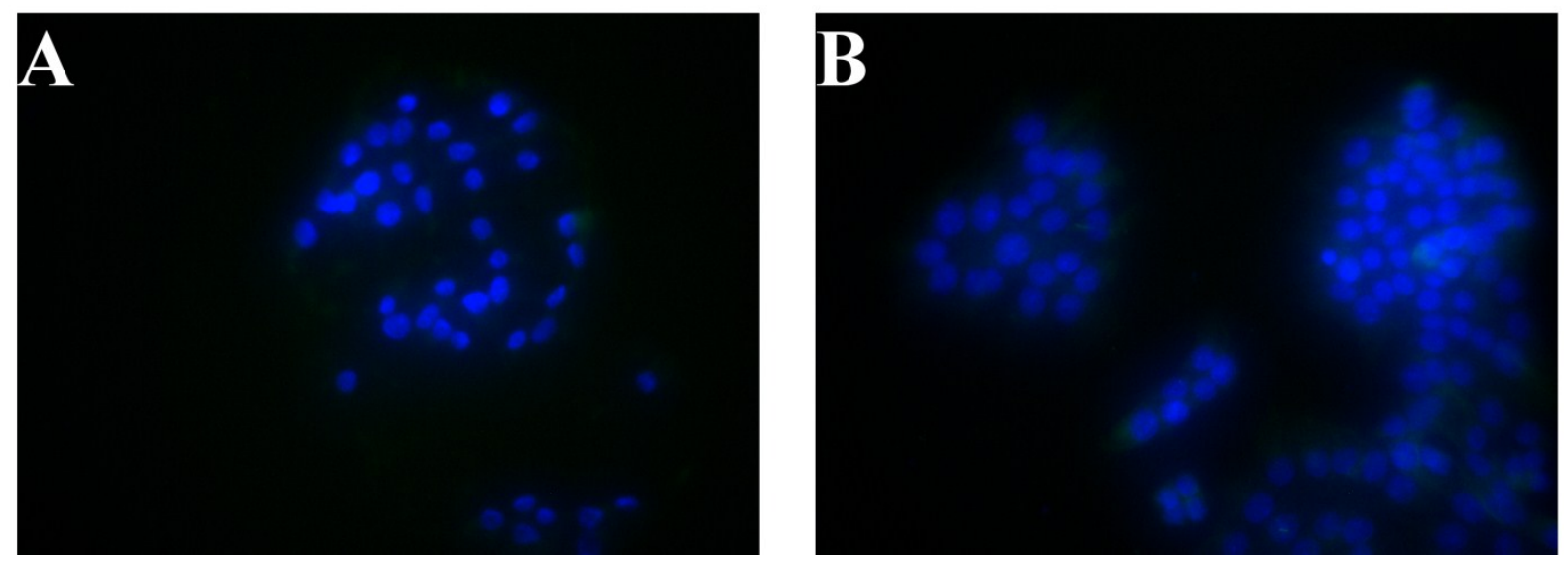

Abbildung 7: Immunhistochemische Färbung an proximalen Tubulusepithelzellen (MCT) auf Nestin. A: Negativkontrolle, Kernfärbung DAPI (400x). B: Zellprobe, die im Versuchsablauf keiner Stimulation mit TGF-ß oder FGF-2 unterlag (400x).
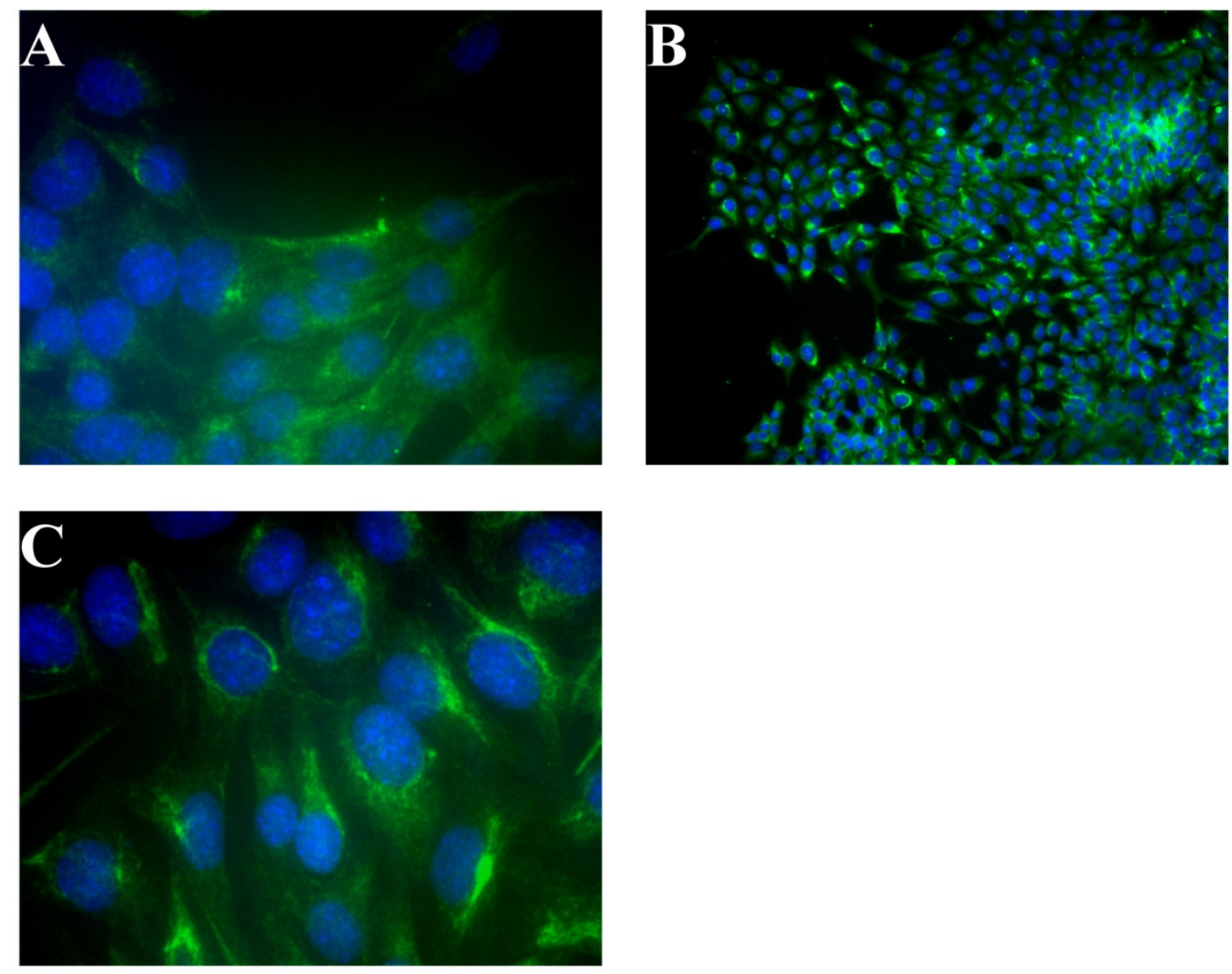

Abbildung 8: Immunhistochemische Färbung an proximalen Tubulusepithelzellen (MCT) auf Nestin nach TGF- $\beta$-Behandlung. A: Stimulation mit TGF- $\beta$ in der Konzentration 0,1 ng/ml für 48 h (1000x). B: Stimulation mit TGF- $\beta$ in der Konzentration $1 \mathrm{ng} / \mathrm{ml}$ für $48 \mathrm{~h}$ (200x). C: Stimulation mit TGF- $\beta$ in der Konzentration $10 \mathrm{ng} / \mathrm{ml}$ für $48 \mathrm{~h}$ (1000x). 

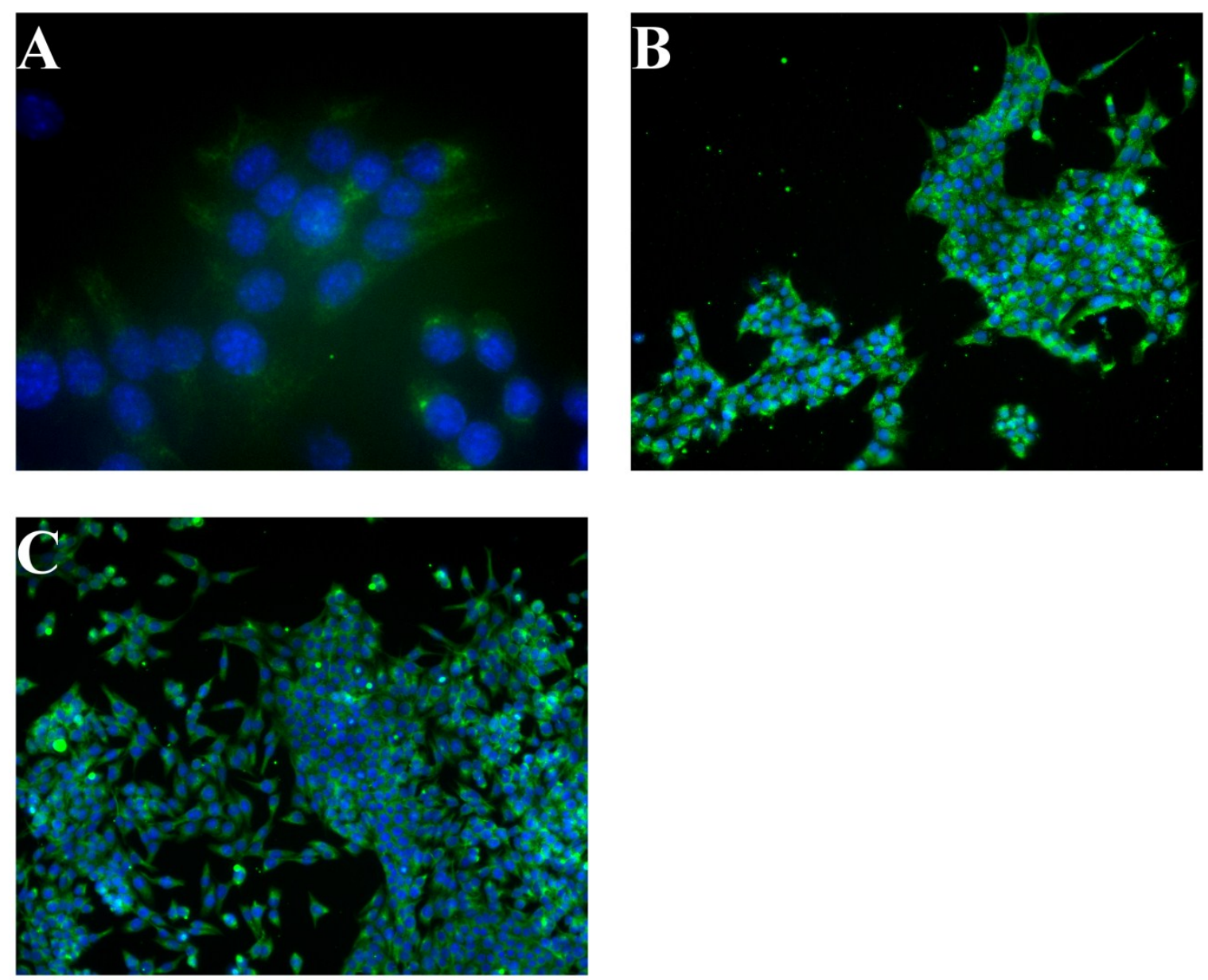

Abbildung 9: Immunhistochemische Färbung an proximalen Tubulusepithelzellen (MCT) auf Nestin nach FGF-2-Behandlung. A: Stimulation mit FGF-2 in der Konzentration 0,1 ng/ml für $48 \mathrm{~h}(1000 \mathrm{x})$. B: Stimulation mit FGF-2 in der Konzentration $1 \mathrm{ng} / \mathrm{ml}$ für $48 \mathrm{~h}$ (200x). C: Stimulation mit FGF-2 in der Konzentration $10 \mathrm{ng} / \mathrm{ml}$ für $48 \mathrm{~h}(200 \mathrm{x})$.

Sowohl in der Versuchsreihe mit dem Stimulans TGF- $\beta$ als auch mit FGF-2 lässt sich an proximalen Tubulusepithelzellen (MCT-Zellen) mittels Markierung durch das Fluorochrom FITC das Vorhandensein von Nestin nachweisen. Die hier gezeigten Abbildungen sind als exemplarische Beispiele zur Darstellung der Nestinverteilung zu betrachten. Es wurden unterschiedliche Vergrößerungen gewählt, um unterschiedliche Aspekte der Färbungen darzustellen. Man erkennt besonders in den stark vergrößerten Aufnahmen (1000x), dass das Protein Nestin den Zellkern einer jeden Zellen umgibt, im Zellkern selbst jedoch nicht vorzufinden ist. Außerdem wird in den Übersichtsbildern (200x) deutlich, dass die Nestindichte nach Zytokinstimulation deutlich erhöht ist im Vergleich zu der Negativkontrolle und der unstimulierten Zellprobe. Aufgrund der teilweise sehr hohen 
Zelldichte lässt sich die Zellform in dieser Stimulationsreihe nur bedingt beurteilen. Vereinzelt lässt sich eine etwas länglichere, spindelförmige Zellform erkennen.

Um die mit Hilfe der Färbungen veranschaulichten Ergebnisse auch numerisch einschätzen und bewerten zu können, wurden jeweils drei Ausschnitte einer Probe im Detail analysiert. Hierbei war es wichtig, dass die mikroskopischen Aufnahmen für diese Auswertungen allesamt mit einheitlicher Belichtungszeit (FITC: 1 s) und Vergrößerung (400x) aufgenommen wurden. Im Anschluss war es möglich mittels Phasenanalyse festzustellen, mit welchem Anteil die Proteinfärbung am Gesamtflächeninhalt des Objektträgerauschnittes beteiligt war. Dieser Flächeninhalt wurde anschließend durch die Zellzahl des jeweiligen Ausschnittes dividiert, um einen vergleichbaren Parameter $\mathrm{zu}$ erhalten. Bei diesem Auswertungsverfahren muss kritisch hervorgehoben werden, dass die unterschiedliche Zellgröße sowie die Abstufungen in der Färbungsintensität des Fluoreszenzfarbstoffs FITC nicht mit in Betracht gezogen wurden.

Diagramm zum Nestingehalt der Immunfluoreszenzfärbung von MCT Zellen

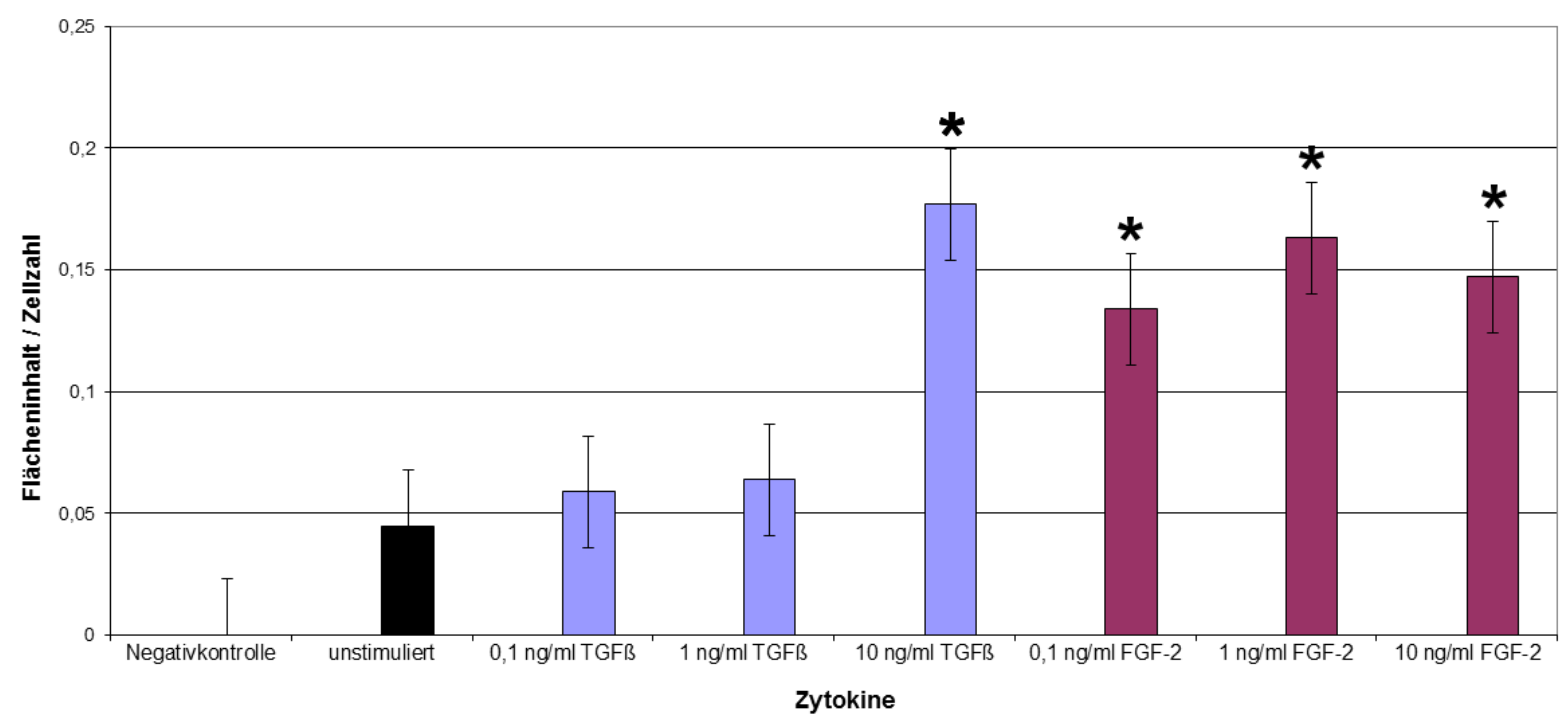

Abbildung 10: Zytokinstimulation von MCT-Zellen mit TGF-ß und FGF-2 mit den Konzentrationen 0,1 ng/ml, $1 \mathrm{ng} / \mathrm{ml}$ und $10 \mathrm{ng} / \mathrm{ml}$ für 48 Stunden. Dargestellt sind die Mittelwerte des Quotienten Flächeninhalt (Nestin)/Zellzahl des jeweiligen Ausschnittes der Färbung sowie der Standardfehler. Signifikanzniveau $*=\mathrm{p}<0,05$. Anmerkung: * bezieht sich in dieser Abbildung auf den statistischen Vergleich der einzelnen Stimulationskonzentrationen mit der unstimulierten Probe.

\begin{tabular}{|l|l|l|l|}
\hline $\begin{array}{l}\text { TGF-ß - } \\
\text { Zytokinbehandlung }\end{array}$ & p-Wert & $\begin{array}{l}\text { FGF-2- } \\
\text { Zytokinbehandlung }\end{array}$ & p-Wert \\
\hline Unstimuliert : $0,1 \mathrm{ng} / \mathrm{ml}$ & 0,2320 & Unstimuliert : $0,1 \mathrm{ng} / \mathrm{ml}$ & $\mathbf{0 , 0 0 4 5} *$ \\
\hline Unstimuliert : $1 \mathrm{ng} / \mathrm{ml}$ & 0,2151 & Unstimuliert : $1 \mathrm{ng} / \mathrm{ml}$ & $\mathbf{0 , 0 0 0 5} *$ \\
\hline Unstimuliert : $10 \mathrm{ng} / \mathrm{ml}$ & $\mathbf{0 , 0 0 9 5} *$ & Unstimuliert : $10 \mathrm{ng} / \mathrm{ml}$ & $\mathbf{0 , 0 0 0 6} *$ \\
\hline
\end{tabular}




\begin{tabular}{|l|l|l|l|}
\hline $\begin{array}{l}\text { TGF-ß- } \\
\text { Konzentrationsvergleich }\end{array}$ & p-Wert & $\begin{array}{l}\text { FGF-2- } \\
\text { Konzentrationsvergleich }\end{array}$ & p-Wert \\
\hline $0,1 \mathrm{ng} / \mathrm{ml}: 1 \mathrm{ng} / \mathrm{ml}$ & 0,8488 & $0,1 \mathrm{ng} / \mathrm{ml}: 1 \mathrm{ng} / \mathrm{ml}$ & 0,1628 \\
\hline $0,1 \mathrm{ng} / \mathrm{ml}: 10 \mathrm{ng} / \mathrm{ml}$ & 0,0903 & $0,1 \mathrm{ng} / \mathrm{ml}: 10 \mathrm{ng} / \mathrm{ml}$ & 0,7321 \\
\hline $1 \mathrm{ng} / \mathrm{ml}: 10 \mathrm{ng} / \mathrm{ml}$ & 0,1074 & $1 \mathrm{ng} / \mathrm{ml}: 10 \mathrm{ng} / \mathrm{ml}$ & 0,6470 \\
\hline
\end{tabular}

Tabelle 14: Statistische Ergebnisse des Quotienten Flächeninhalt (Nestin)/Zellzahl der Immunfluoreszenzfärbungen von MCT-Zellen nach konzentrationsabhängiger Zytokinstimulation.

Die Abbildung 10 zeigt den Effekt der unterschiedlichen Zytokinkonzentrationen der Faktoren TGF- $\beta$ und FGF-2 auf den durch den Fluoreszenzfarbstoff FITC detektierbaren Gehalt an Nestin einer Zellprobe. In dieser Versuchsreihe wurde eine Zellprobe, die während des Versuchsablaufes nicht in Kontakt mit Zytokinen gekommen ist, mitgeführt, so dass man hier sehen kann, dass auch ohne Stimulans ein gewisser Nestingrundgehalt der MCT Zelle vorhanden $\mathrm{zu}$ sein scheint. Dies muss kritisch gesehen werden, da auch eine gewisse Unspezifität im Bindungsverhalten des Antikörpers in Frage kommt, so dass nicht eindeutig geklärt ist, ob es sich hier ausschließlich um die Anfärbung von Nestin handelt. Nach 48stündiger Zytokinbehandlung ist zu erkennen, dass bei TGF- $ß$ eine eindeutige Zunahme des Proteingehaltes bei der Konzentration $10 \mathrm{ng} / \mathrm{ml}$ vorzufinden ist. Dem gegenüber steht die eher geringfügige Steigerung des Nestingehalts unter dem Einfluss der niedriger konzentrierten TGF-ß Ansätze $(0,1 \mathrm{ng} / \mathrm{ml}$ und $1 \mathrm{ng} / \mathrm{ml})$, welche das Niveau der unstimulierten MCT Zellprobe nur unwesentlich überragen. Dies lässt sich auch statistisch feststellen (p-Wert = 0,0095, siehe Tabelle 14). Der Nestingehalt der proximalen Tubulusepithelzellen nach Behandlung mit FGF-2 erscheint in dieser Graphik insgesamt hochreguliert. Hierbei lässt sich nicht eindeutig trennen, bei welcher Konzentration der stärkste Effekt vorherrscht. $1 \mathrm{ng} / \mathrm{ml}$ FGF-2 scheint eine minimal stärkere Auswirkung auf die Nestinproduktion zu haben als die Konzentrationen $0,1 \mathrm{ng} / \mathrm{ml}$ und $10 \mathrm{ng} / \mathrm{ml}$. Statistisch ist bei jeder Konzentration im Vergleich zur unstimulierten Probe eine signifikante Steigerung der Nestinexpression festzustellen, wie auch auf den immunhistochemischen Abbildungen deutlich wird (siehe Tabelle 14).

Statistisch ist es sehr interessant zu sehen, dass eine Parallelität zwischen den Ergebnissen der Real-Time PCR und der Immunfluoreszenz besteht. In der immunhistochemischen Versuchsreihe konnte eine detailliertere statistische Auswertung der einzelnen Konzentrationen mit der unstimulierten Probe stattfinden, da es sich hier anders als bei der Real-Time PCR nicht um einen auf das Niveau 1 festgelegten Calibrator handelt. Diese Detailanalyse ergab, dass bei der Stimulationsreihe mit TGF- $\beta$ einzig und allein die Diskrepanz der Nestinexpression in MCT-Zellen zwischen der unstimulierten Probe und der 
Konzentration $10 \mathrm{ng} / \mathrm{ml}$ als statistisch relevant einzustufen ist. Dies stimmt mit den Ergebnissen der Real-Time PCR überein, da auch hier graphisch bei der Konzentration 10 ng/ml TGF- $ß$ die deutlichste Steigerung der Nestinexpression zu erkennen ist. In der statistischen Betrachtung der einzelnen Konzentrationen untereinander zeichnet sich hier eine ähnliche Tendenz wie bei der Real-Time PCR ab. Allein der Effektunterschied im Vergleich der Konzentrationen 0,1 ng/ml und $10 \mathrm{ng} / \mathrm{ml}$ liegt mit 9\% in der Nähe des Signifikanzniveaus, wobei die Vergleiche der anderen Konzentrationen statistisch gänzlich zu vernachlässigen sind. Bei der Real-Time PCR fiel der statistische Test der Konzentrationen 0,1 ng/ml und 10 ng/ml TGF- $ß$ ebenso als einzig statistisch relevanter aus.

Die Behandlung mit FGF-2 führte sowohl in der Real-Time PCR als auch in der immunhistochemischen Versuchsreihe zu signifikanten Ergebnissen. Hierbei ließ sich des Weiteren analog zu den Ergebnissen der Real-Time PCR keine Signifikanz im Effekt der verschiedenen Konzentrationen auf die Nestinexpression feststellen.

\subsubsection{Ergebnisse der Immunfluoreszenzfärbungen bezüglich des}

\section{Nestingehalts in der Zellreihe NP-1 nach Stimulation mit TGF-B und FGF-2}

Die distale Tubulusepithelzellreihe NP-1 wurde ebenfalls nach Zytokinstimulation immunhistochemisch auf ihren Nestingehalt untersucht. Die Bedingungen dieser $\begin{array}{lllll}\text { Versuchsreihe } & \text { sind } & \text { identisch } & \text { mit }\end{array}$ beschriebenen.
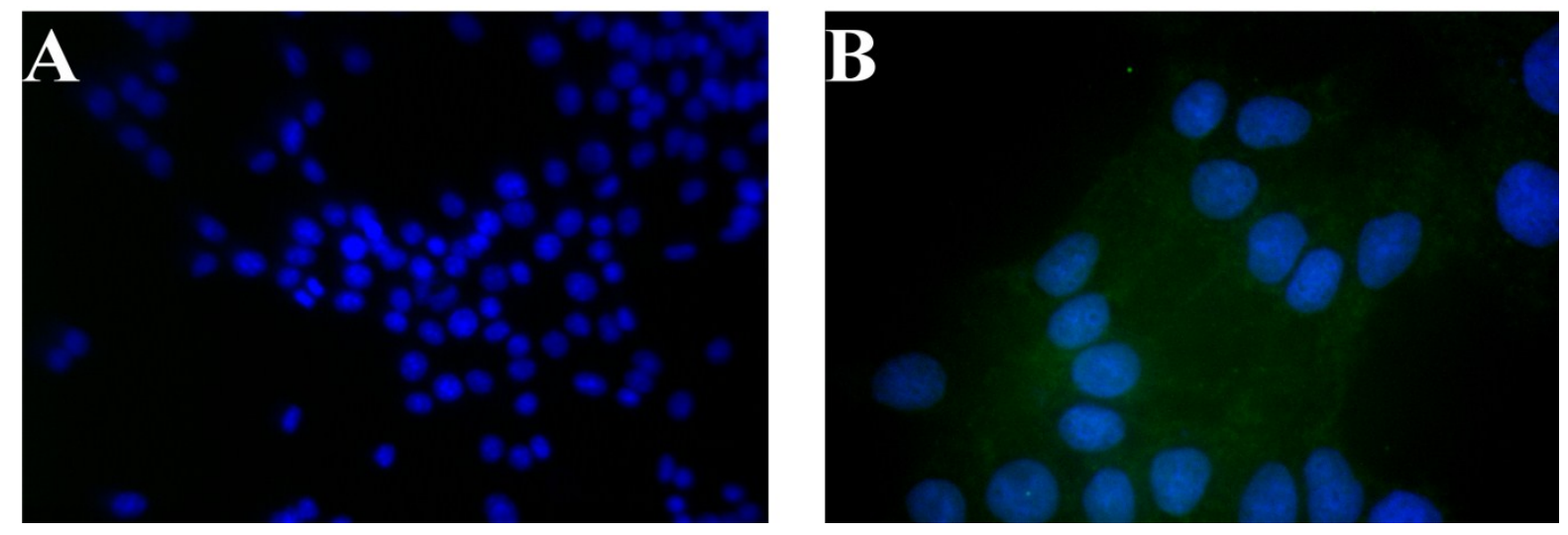

Abbildung 11: Immunhistochemische Färbung an distalen Tubulusepithelzellen (NP-1) auf Nestin. A: Negativkontrolle, Kernfärbung DAPI (400x) B: Zellprobe, die im Versuchsablauf keiner Stimulation mit TGF- $ß$ oder FGF-2 unterlag (1000x) 

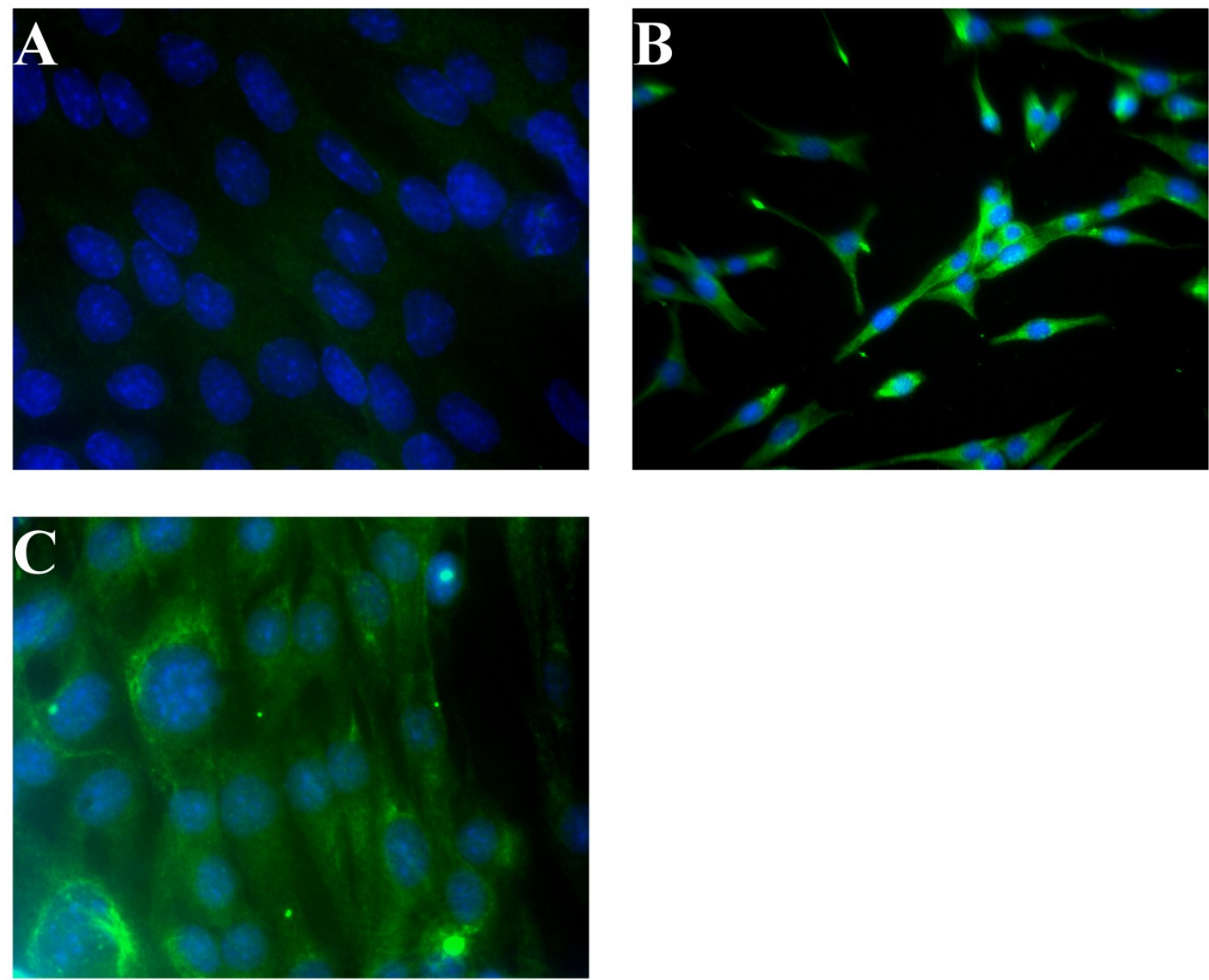

Abbildung 12: Immunhistochemische Färbung an distalen Tubulusepithelzellen (NP-1) auf Nestin nach TGF-ß-Behandlung. A: Stimulation mit TGF- $\beta$ in der Konzentration 0,1 ng/ml für $48 \mathrm{~h}(1000 \mathrm{x})$. B: Stimulation mit TGF- $\beta$ in der Konzentration $1 \mathrm{ng} / \mathrm{ml}$ für $48 \mathrm{~h}$ (400x). C: Stimulation mit TGF- $\beta$ in der Konzentration $10 \mathrm{ng} / \mathrm{ml}$ für $48 \mathrm{~h}$ (1000x). 

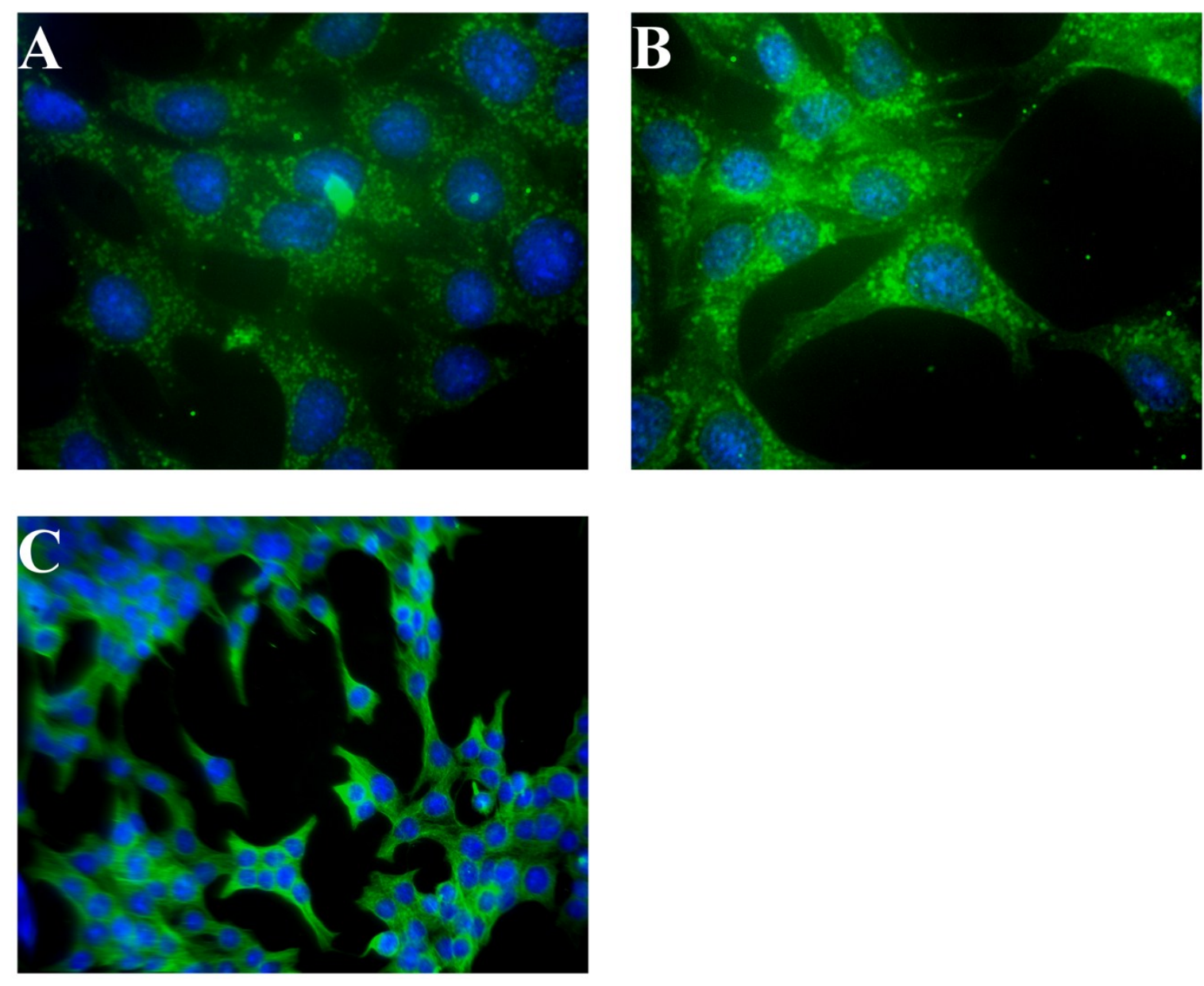

Abbildung 13: Immunhistochemische Färbung an distalen Tubulusepithelzellen (NP-1) auf Nestin nach FGF-2-Behandlung. A: Stimulation mit FGF-2 in der Konzentration 0,1 ng/ml für $48 \mathrm{~h}$ (1000x). B: Stimulation mit FGF-2 in der Konzentration $1 \mathrm{ng} / \mathrm{ml}$ für $48 \mathrm{~h}(1000 \mathrm{x})$. C: Stimulation mit FGF-2 in der Konzentration $10 \mathrm{ng} / \mathrm{ml}$ für $48 \mathrm{~h}(400 \mathrm{x})$.

An den Abbildungen der Versuchsreihe der distalen Tubulusepithelzellen fällt auf, dass auch in der Zellprobe, die keinen Kontakt zum stimulierenden Agens hatte, eine leicht positive FITC-Markierung von Nestin vorzufinden ist. Der Unterschied im Nestingehalt zwischen dieser unstimulierten Probe und der mit TGF- $\beta(0,1 \mathrm{ng} / \mathrm{ml})$ behandelten Probe ist nur geringfügig sichtbar. Sehr deutlich ist jedoch die gestreckte, spindelartige Zellform der mit TGF-ß (1 ng/ml) behandelten NP-1-Zellen zu erkennen, welche den Anschein machen, ihre phänotypisch epithelialen Charakteristika weitestgehend verloren $\mathrm{zu}$ haben. In den stark vergrößerten Aufnahmen (1000x) der Stimulation mit FGF-2 lässt sich die Ausbreitung von dem intermediären Filamentprotein Nestin besonders deutlich erkennen.

Bei den NP-1-Zellen erfolgte ebenfalls eine numerische Auswertung, um die Bildinformationen untereinander vergleichen und auswerten zu können. 


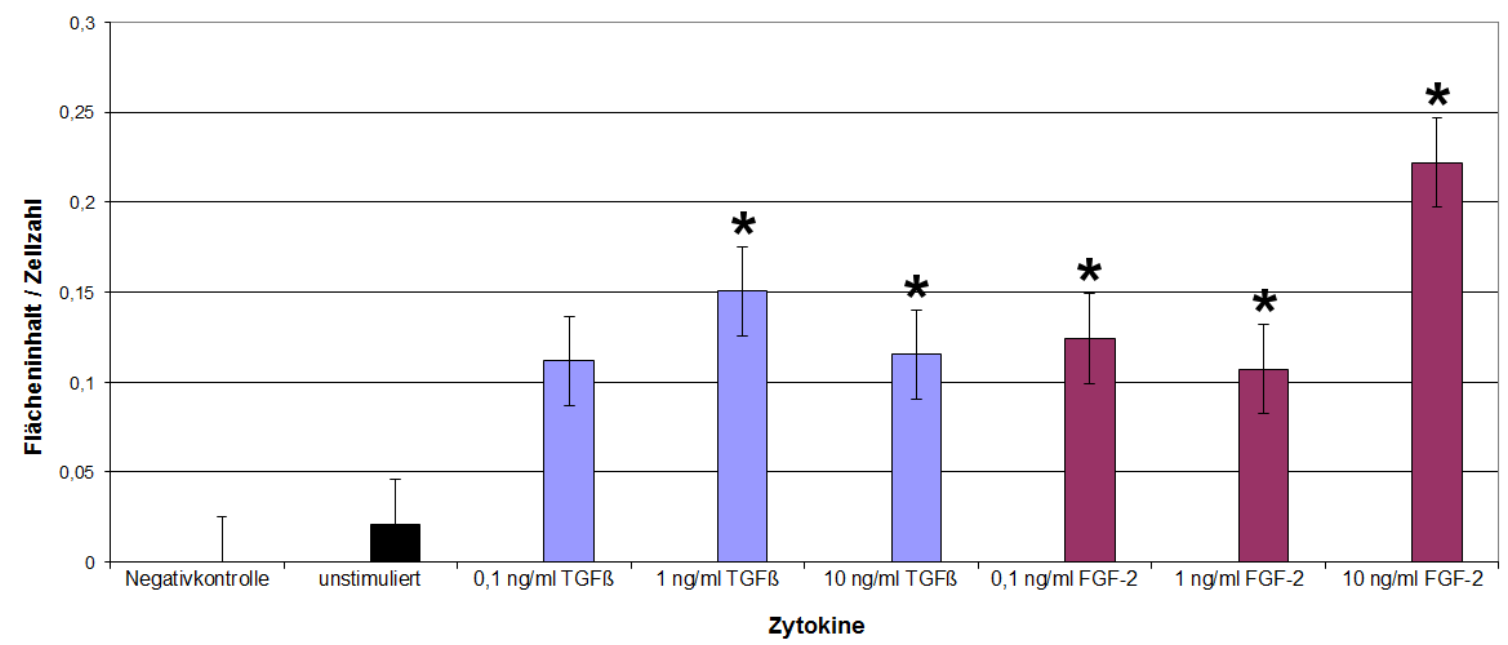

Abbildung 14: Zytokinstimulation von NP-1-Zellen mit TGF- $\beta$ und FGF-2 mit den Konzentrationen 0,1 ng/ml, $1 \mathrm{ng} / \mathrm{ml}$ und $10 \mathrm{ng} / \mathrm{ml}$ für 48 Stunden. Dargestellt sind die Mittelwerte des Quotienten Flächeninhalt (Nestin)/Zellzahl des jeweiligen Ausschnittes der Färbung sowie der Standardfehler. Signifikanzniveau $*=p<0,05$. Anmerkung: $*$ bezieht sich in dieser Abbildung auf den statistischen Vergleich der einzelnen Stimulationskonzentrationen mit der unstimulierten Probe.

\begin{tabular}{|l|l|l|l|}
\hline $\begin{array}{l}\text { TGF-B- } \\
\text { Zytokinbehandlung }\end{array}$ & p-Wert & $\begin{array}{l}\text { FGF-2- } \\
\text { Zytokinbehandlung }\end{array}$ & p-Wert \\
\hline Unstimuliert : $0,1 \mathrm{ng} / \mathrm{ml}$ & 0,0962 & Unstimuliert : 0,1 ng/ml & $\mathbf{0 , 0 0 4 4} *$ \\
\hline Unstimuliert : $1 \mathrm{ng} / \mathrm{ml}$ & $\mathbf{0 , 0 0 2 7} *$ & Unstimuliert : $1 \mathrm{ng} / \mathrm{ml}$ & $\mathbf{0 , 0 4 0 9 *}$ \\
\hline Unstimuliert : $10 \mathrm{ng} / \mathrm{ml}$ & $\mathbf{0 , 0 0 0 2} *$ & Unstimuliert : $10 \mathrm{ng} / \mathrm{ml}$ & $\mathbf{0 , 0 0 5 4} *$ \\
\hline
\end{tabular}

\begin{tabular}{|l|l|l|l|}
\hline $\begin{array}{l}\text { TGF-B- } \\
\text { Konzentrationsvergleich }\end{array}$ & p-Wert & $\begin{array}{l}\text { FGF-2- } \\
\text { Konzentrationsvergleich }\end{array}$ & p-Wert \\
\hline $0,1 \mathrm{ng} / \mathrm{ml}: 1 \mathrm{ng} / \mathrm{ml}$ & 0,3394 & $0,1 \mathrm{ng} / \mathrm{ml}: 1 \mathrm{ng} / \mathrm{ml}$ & 0,7798 \\
\hline $0,1 \mathrm{ng} / \mathrm{ml}: 10 \mathrm{ng} / \mathrm{ml}$ & 0,9454 & $0,1 \mathrm{ng} / \mathrm{ml}: 10 \mathrm{ng} / \mathrm{ml}$ & 0,0622 \\
\hline $1 \mathrm{ng} / \mathrm{ml}: 10 \mathrm{ng} / \mathrm{ml}$ & 0,3581 & $1 \mathrm{ng} / \mathrm{ml}: 10 \mathrm{ng} / \mathrm{ml}$ & 0,2090 \\
\hline
\end{tabular}

Tabelle 15: Statistische Ergebnisse des Quotienten Flächeninhalt (Nestin)/Zellzahl der Immunfluoreszenzfärbungen von NP-1-Zellen nach konzentrationsabhängiger Zytokinstimulation.

Die Grafik 14 zeigt die Zunahme des Nestingehalts in distalen Tubulusepithelzellen unter dem Einfluss von TGF- $\beta$ und FGF-2. Auffällig hierbei ist, dass bei TGF- $\beta$ ein induktiver Effekt erkennbar ist, der bei der Konzentration von $1 \mathrm{ng} / \mathrm{ml}$ am stärksten ausgeprägt ist. Erhöht man die Konzentration der Zytokinlösung auf $10 \mathrm{ng} / \mathrm{ml}$, kommt es zu einer Verringerung des Nestingehalts, was auf einen toxischen Effekt schließen lässt. Statistisch lässt sich dies im Vergleich zu der unstimulierten Probe bestätigen (siehe Tabelle 15). Ein 
konzentrationsabhängiger Effekt von TGF- $\beta$ auf die Nestinexpression in NP-1-Zellen ließ sich analog den Ergebnissen der Real-Time PCR statistisch nicht verifizieren.

Die Entwicklung des Nestingehalts unter Einflussnahme des Zytokins FGF-2 zeichnet sich durch eine starke Zunahme bei einer Konzentration von $10 \mathrm{ng} / \mathrm{ml}$ aus, wohingegen die Nestinwerte der niedrigeren Konzentrationen denen bei TGF- $\beta$ vorliegenden ähneln. Dies zeigt eine gewisse Parallelität zu der Ergebnistendenz, die bei der quantitativen Analyse der Real-Time PCR vorzufinden war mit dem maßgeblichen Unterschied, dass sich dies in der Immunfluoreszenz auch statistisch bestätigen lässt (siehe Tabelle 15). Hierbei ist allerdings wieder die Eventualität unspezifischer Bindungen des eingesetzten Antikörpers zu berücksichtigen, so dass den Ergebnissen der wesentlich sensitiveren Methode (Real-Time PCR) eine höhere Gewichtung zugeschrieben werden kann. Die Ergebnisse der Konzentrationsabhängigkeit bezüglich FGF-2 sind statistisch zu vernachlässigen und lassen sich einzig und allein in ihrer graphischen Tendenz mit einer maßgeblichen Steigerung mit zunehmender Konzentration ähnlich den Ergebnissen der Real-Time PCR beschreiben.

\subsection{Ergebnisse der Nestinanalyse mittels Western Blot}

Die Proteinanalyse der MCT- und NP-1-Zellen mittels Western Blot führte aufgrund von methodischen Problemen nicht zu verwertbaren Ergebnissen. Es stellte sich als sehr schwierig heraus, das Protein Nestin mit der laut Antikörperdatasheet zu erwartenden Größe von 176 Kilodalton mittels SDS-Gelelektrophorese deutlich darzustellen. Es wurden diverse Trenngele unterschiedlicher Porengröße gegossen $(12 \%, 10 \%, 7,5 \%, 5 \%)$, um eine deutlichere und verlässlichere Auftrennung von Nestin im Bereich von $200 \mathrm{kDa}$ zu erlangen, ohne jedoch den gewünschten Erfolg zu erzielen. Auch das Verwenden einer PVDF-Membran anstelle von Nitrozellulose blieb erfolglos.

Des Weiteren kam es zum Auftreten diverser unspezifischer Banden im Bereich von 45 und $30 \mathrm{kDa}$, die auch nach Wechseln des Primärantikörpers und des Sekundärantikörpers nicht ausblieben. Eine positive Aktinkontrolle zeigte, dass der Western Blot generell methodisch korrekt durchgeführt wurde, was zur Schlussfolgerung führte, dass die eingesetzten Antikörper den Kern der Problematik darstellten. Es wird Aufgabe weiterführender Forschungsarbeiten bleiben, obige Ergebnisse unter Verwendung spezifischer Antikörper mittels Western Blot zu bestätigen. 


\section{Diskussion}

In den letzten Jahren kam es zu einem starken Anstieg der Inzidenz der an chronischer Niereninsuffizienz erkrankten Patienten (Boor et al. 2010). Eine hohe Anzahl chronischer Nierenerkrankungen äußert sich in Form einer renalen tubulointerstitiellen Fibrose, welche eine fortschreitende Beeinträchtigung der Nierenfunktion nach sich zieht (Nangaku 2006). In den nächsten Jahren ist mit einem weiteren Anstieg der Prävalenz der terminalen Niereninsuffizienz zu rechnen (Pastan und Bailey 1998). Die bisher eingesetzten Therapieformen dieser Erkrankung können zwar das Fortschreiten der renalen Fibrose verlangsamen, jedoch besteht bis dato kein spezifischer therapeutischer Ansatz, der die Mechanismen der Fibroseentstehung selbst zum Ziel hat (Bascands et al. 2007).

Dies lenkte den wissenschaftlichen Fokus auf die Reparaturmechanismen der Niere. Ähnlich dem Wundheilungsprozess der Haut tritt an die Stelle des durch Krankheit beschädigten Nierengewebes ein aus extrazellulären Matrixkomponenten bestehendes Ersatzgewebe. Diese pathophysiologische Antwort auf einen Entzündungsreiz stellt einen Schutzmechanismus dar mit der Absicht, die strukturelle Integrität des Organs auch in Zeiten der Erkrankung aufrecht $\mathrm{zu}$ erhalten. Dieser vom Organ als Reparaturmechanismus durchgeführte Fibrosierungsprozess ist jedoch der Hauptgrund für die immer stärkere Beeinträchtigung der Nierenfunktion, da das überschießende, faserreiche Wundheilungsgewebe die komplexe Architektur der Niere keineswegs ersetzen kann und somit dem Organ bis hin zum Organversagen schadet (Kisseleva und Brenner 2008). Hierbei korreliert der Zerstörungsgrad des tubulointerstitiellen Gewebes stark mit der Beeinträchtigung der Nierenfunktion (Nath 1992; Nath 1998).

Diese Erkenntnis führte zu einer genaueren Betrachtung der renalen Fibrose, um durch eventuelle Therapiemittel ein Aufhalten oder sogar eine Umkehrung dieses progressiven Vorgangs zu finden. Um diese Fragestellung beantworten zu können, ist es notwendig, die verschiedenen Mechanismen, die einen Beitrag zur entstehenden Fibrose der Niere leisten, so genau wie möglich zu untersuchen. Die weitere Erforschung der Beteiligung der epithelialmesenchymalen Transition an der renalen Fibrogenese bildet einen bedeutsamen Baustein dieser Aufgabe. In den letzten Jahren hat diese phänotypische Veränderung von renalen Tubuluszellen eine wichtige Stellung im Fortschreiten einer tubulointerstitiellen Erkrankung und der daraus resultierenden Gewebeschädigung der Niere eingenommen, was eine genauere Betrachtung dieses Prozesses sinnvoll erscheinen lässt (Zoja et al. 2003; Mucsi und Rosivall 2007). 


\section{Der Einfluss des Zytokins TGF-ß auf die EMT}

Im Rahmen der epithelial-mesenchymalen Transition nimmt das Zytokin TGF- $\beta$ eine entscheidende Position ein. Die Umwandlung von Epithel $\mathrm{zu}$ Mesenchym ist kein eigenständig ablaufender Prozess, vielmehr unterliegt er der Kontrolle von Mediatoren. TGFß wird hierbei eine leitende Funktion zuteil, da dieser Mediator der am gründlichsten untersuchte Wachstumsfaktor ist, welcher in der Lage ist, eine vollständige Transition zu induzieren (Lee und Joo 1999). Charakteristisch für das Vollenden der epithelialen Transformation zu Mesenchym ist unter anderem der Verlust des epithelialen Markers ECadherin sowie die de-novo-Expression von alpha-Glattmuskelaktin in den veränderten Zellen (Yao et al. 2009).

Auch in dieser Arbeit ließ sich an proximalen und distalen Tubulusepithelzellen unter dem Einfluss von TGF-ß der gewünschte Effekt bezüglich Nestin im Rahmen der EMT signifikant nachweisen. Ein Grund dafür könnte sein, dass laut aktuellem Forschungsstand das Zytokin TGF- $ß$ den verlässlichsten Mediator darstellt, der bei alleinigem Einsatz die EMT induzieren kann. Laut Bani-Hani et al. ist es in vitro nur dem Zytokin TGF- $\beta$ und IL-18 möglich, eine vollständige Transformation von Epithel zu Mesenchym in Zellen zu bewirken (Bani-Hani et al. 2008). Den Arbeitsgruppen um Gauldie und Bates gelang es, zusätzlich noch den Tumornekrosefaktor alpha (TNF- $\alpha$ ) sowie Interleukin-1ß (IL-1ß) als Hauptfaktoren, die zur Induktion der EMT fähig sind, zu identifizieren (Gauldie et al. 2002; Bates et al. 2004).

Wachstumsfaktoren wie der epidermale Wachstumsfaktor EGF oder der Fibroblastenwachstumsfaktor FGF sind laut Strutz und Kollegen nicht in der Lage, den vollständigen Ablauf der EMT zu induzieren, zeigen jedoch einen additiven Effekt in Kombination mit TGF- $ß$ (Strutz et al. 2002). Eine sehr produktive Kombination zum Erreichen einer vollständigen Transformation scheint die gleichzeitige Stimulation von epithelialen Zellen mit TGF-ß und EGF zu sein (Okada et al. 1997).

TGF- $\beta$ konnte auch im Rahmen anderer fibrotischer Erkrankungen mit einer Induktion der EMT in Verbindung gebracht werden. So konnten zum Beispiel Kasai et al. zeigen, dass TGF- $\beta$ in einem Modell von humanem Alveolarepithel eine Transformation von Epithelzellen $\mathrm{zu}$ einem mesenchymalen Zelltyp über SMAD-2-vermittelte Signaltransduktion auslösen konnte (Kasai et al. 2005). Ebenso konnte für das Krankheitsbild der Leberfibrose eine Epitheltransformation zu einem Mesenchym mit Myofibroblasten-ähnlichem Charakter unter TGF-ß-Einfluss detektiert werden (Desmouliere et al. 2003). Auch in Zusammenhang mit nicht-fibrotischen Erkrankungen kann ein Einfluss von TGF- $\beta$ auf den Prozess der EMT nachgewiesen werden. Demnach konnte zum Beispiel auch eine phänotypische Veränderung 
von trachealen Mausepithelzellen zu Mesenchym-artigen Zellen unter Einfluss von TGF- $\beta$ festgestellt werden(Kuroishi et al. 2009).

Eine interessante Beobachtung unserer Untersuchungen stellt die signifikante Konzentrationsabhängigkeit der Behandlung proximaler Tubulusepithelzellen im Vergleich der Konzentrationen 0,1 ng/ml und 10 ng/ml mit TGF- 3 dar. Sowohl die Ergebnisse der RealTime PCR als auch die der Immunhistochemie zeigen, dass eine eindeutige Steigerung der Nestinexpression mit ansteigender Konzentration des Zytokins TGF- $\beta$ in MCT-Zellen vorliegt. Hierbei ist es aufschlussreich zu sehen, dass graphisch die Unterschiede zwischen den Konzentrationen $0,1 \mathrm{ng} / \mathrm{ml}$ und $1 \mathrm{ng} / \mathrm{ml}$ eher gering ausfallen, wohingegen sich das Ergebnis mit der Stimulationskonzentration von $10 \mathrm{ng} / \mathrm{ml} \mathrm{TGF-ß} \mathrm{deutlich} \mathrm{von} \mathrm{den} \mathrm{niedrigeren}$ Konzentrationen sowie der unstimulierten Probe abhebt. Auch statistisch lässt sich diese Tendenz bestätigen. Dies wirft die Frage, ob der wissenschaftlich untersuchte Effekt von TGF- $\beta$ auf renale Tubulusepithelzellen nur bei hohen Konzentrationen vollständig zu beobachten ist.

Fan und Kollegen gelang es, in einer in-vitro-Studie eine Konzentrationsabhängigkeit der Wirkung von TGF- $ß$ auf epitheliale Nierenzellen festzustellen. Des Weiteren kamen sie zu dem Schluss, dass eine Art Schwellenkonzentration existiert, ohne die das Erreichen einer vollständigen Transformation von Epithel zu Mesenchym nicht möglich zu sein scheint. Hierbei definierten sie eine TGF-ß-Konzentration von $10 \mathrm{ng} / \mathrm{ml}$ als notwendig, um auch eine ganzheitliche morphologische Umwandlung der Zellen zu bewirken und den Prozess der EMT als vollendet bezeichnen zu können (Fan et al. 1999). Somit kann auch bei den Ergebnissen dieses Forschungsprojektes davon ausgegangen werden, dass der vollständige Effekt der gesteigerten Nestinexpression bei der epithelial-mesenchymalen Transition allein bei einer Konzentration von $10 \mathrm{ng} / \mathrm{ml}$ TGF- $\beta$ zu beobachten war, da nur hier die Schwellenkonzentration im Versuchsablauf wirken konnte. Dies könnte auch eine Erklärung dafür darstellen, dass ein maßgeblicher Unterschied zwischen dem Effekt der höchsten Konzentration TGF- $\beta$ auf die Nestinproduktion im Vergleich zu den Konzentrationswerten $0,1 \mathrm{ng} / \mathrm{ml}$ und $1 \mathrm{ng} / \mathrm{ml}$ festzustellen war.

Die These der Schwellenkonzentration könnte auch als Erklärung für widersprüchliche Ergebnisse in der Literatur bezüglich des Effektes von TGF- $ß$ im Rahmen der EMT dienen. So konnten Creely und Kollegen bei einer Stimulationskonzentration von 3 ng/ml TGF- $\beta$ über fünf Tage keine maßgeblichen morphologischen Veränderungen proximaler Tubulusepithelzellen feststellen (Creely et al. 1992). Demgegenüber stehen Ergebnisse in der Literatur, die belegen, dass es bei kürzerer Stimulationsdauer und einer TGF-ß-Konzentration 
von $10 \mathrm{ng} / \mathrm{ml}$ sehr wohl möglich war, eine spindelförmige Transformation von proximalen Tubulusepithelzellen zu erreichen (Humes et al. 1991). Weiterführend wäre es interessant herauszufinden, ob der oben bereits erwähnte positive additive Effekt von TGF- $\beta$ und dem Wachstumsfaktor EGF auf die epithelial-mesenchymale Transition bei gesteigerter TGF-ßKonzentration ebenso evident wäre oder ob die Zugabe eines zusätzlichen Wachstumsfaktors bei einem TGF-ß-Konzentrationsniveau oberhalb der Schwelle keinen steigernden Effekt mehr hätte (Fan et al. 1999).

Von Interesse bezüglich der Wirkung von TGF- $\beta$ ist außerdem der Aspekt der Stimulationsdauer der Zellen mit dem Zytokin und der dadurch erzielten Resultate. Wie in den eben erwähnten Beispielen aus der Literatur zu sehen, scheint die Dauer der Einwirkung der Zytokine in ihrer Bedeutung und Auswirkung deutlich hinter der Konzentration zu stehen. Dies ließ sich auch in unseren Versuchsreihen bestätigen. An proximalen Tubulusepithelzellen nahm der expressionsfördernde Effekt mit zunehmender Stimulationsdauer von den Zytokinen ab, so dass bei einer Einwirkzeit von 4 Stunden graphisch der stärkste induktive Effekt auf die mRNA-Expression darstellbar war. Bei einer Stimulationsdauer von 24 Stunden sank die Nestinexpression auf Werte unterhalb des Calibratorniveaus, so dass toxische Effekte nicht auszuschließen sind. Auch statistisch ließ sich im direkten Vergleich der vierstündigen und der vierundzwanzigstündigen Stimulationsdauer ein knapp signifikanter Einfluss der Zeit auf die Nestinexpression feststellen.

Ergänzend ist $\mathrm{zu}$ erwähnen, dass in der Zeitversuchsreihe ausschließlich mit der Schwellenkonzentration von $10 \mathrm{ng} / \mathrm{ml}$ gearbeitet wurde, da mit dieser in den zuvor durchgeführten Konzentrationsversuchen unserer Arbeitsgruppe die besten Ergebniswerte erzielt werden konnten. Somit kann davon ausgegangen werden, dass die Konzentration in den Zeitversuchsreihen keinen limitierenden Faktor darstellte und demzufolge eine recht eindeutige Aussage bezüglich des Einflusses der Zeit auf die untersuchte Zellreihe getroffen werden kann.

An distalen Tubulusepithelzellen der Zellreihe NP-1 ließ sich keine zeitliche Signifikanz der Zytokinbehandlung detektieren, wobei sich graphisch ein eindeutiger Trend zum stärksten induktiven Effekt auf die mRNA-Expression von Nestin bei einer Stimulationsdauer von 8 Stunden feststellen ließ. Diese Tendenz ließe sich eventuell mit einer erhöhten Anzahl an Versuchsdurchläufen auch statistisch verifizieren. 


\section{Die Bedeutung des Zytokins FGF-2 im Zusammenhang mit der EMT}

Laut Courier und Kollegen kann dem Fibroblastenwachstumsfaktor FGF-2 eine wesentliche Rolle bei dem Entwicklungsprozess mesenchymaler Zellen zugeschrieben werden (Coulier et al. 1997). Ebenso ist es möglich, diesen Mediator mit der Regulation des Phänotyps primärer Epithelzellen in Zusammenhang $\mathrm{zu}$ bringen (Chen JK et al. 1994). Im Rahmen experimenteller Modelle fibrotischer Erkrankungen war eine verstärkte Expression von FGF2 vorzufinden, welche eine Vermutung auf Beteiligung dieses Zytokins an dem Prozess der EMT naheliegend erscheinen ließ. Der Arbeitsgruppe um Strutz gelang es, eine Hochregulation der Vimentin-, FSP-1 sowie $\alpha$-SMA-Expression in proximalen und distalen tubulären Zelllinien im Rahmen der EMT unter FGF-2-Einfluss nachzuweisen; zusätzlich konnte in der gleichen Versuchsreihe eine reduzierte Expression der epithelialen Marker ECadherin und Zytokeratin an mit FGF-2 behandelten Tubulusepithelzellen festgestellt werden. Interessanterweise konnten die Ergebnisse durch alleinige Anwendung des Fibroblastenwachstumsfaktors nicht an das Ausmaß des bereits bekannten Effektes des TGF$ß$ auf die EMT heranreichen. Dennoch ließ sich eine Steigerung der Wirkung von TGF- $\beta$ durch die zusätzliche FGF-2-Behandlung erzielen (Strutz et al. 2002).

Im Rahmen dieser Arbeit konnte eine leichte Steigerung der Nestinexpression in proximalen Tubulusepithelzellen (MCT-Zellen) unter Einfluss von FGF-2 mittels Real-Time PCR als statistisch signifikant detektiert werden. Immunhistochemisch konnte sowohl auf den fluoreszenzmikroskopischen Aufnahmen als auch in der numerischen Auswertung dieser eine Hochregulation des Nestingehalts an proximalen Tubulusepithelzellen unter FGF-2-Einfluss festgestellt werden. Graphisch erscheint dieser induktive Effekt jedoch weit ausgeprägter als bei der Real-Time PCR. Hierbei muss den Ergebnissen der wesentlich spezifischeren Methode der Real-Time PCR eine höhere Aussagekraft zugeordnet werden. Eine Konzentrationsabhängigkeit konnte bei keiner der eingesetzten Methoden graphisch oder statistisch festgehalten werden.

Deutlicher noch zeigt sich die erwähnte methodische Problematik bei den Ergebnissen der distalen Tubulusepithelzellreihe NP-1. Mittels Real-Time PCR ließen sich unter FGF-2Einfluss keine signifikanten Ergebnisse erzielen. Graphisch deutete sich eine Tendenz der Hochregulation der Nestinexpression mit steigender Konzentration an; dies ließ sich allerdings aufgrund der hohen Schwankungsbreite der Ergebnisse der dreifachen Versuchsdurchführung statistisch nicht verifizieren. Immunhistochemisch findet sich sowohl bildlich als auch graphisch dieselbe ansteigende Tendenz, welche sich hier auch statistisch 
bestätigen ließ. Es kann davon ausgegangen werden, dass eine gewisse Unspezifität bei einem sehr sensitiven Bindungsverhalten des eingesetzten Antikörpers hierfür verantwortlich ist. Man bedenke, dass auch bei der durchgeführten Western-Blot-Analyse die gewünschte Spezifität des Antikörpers ausblieb. In der distalen Zellreihe ließen sich ebenfalls weder mittels Real-Time PCR noch mit Hilfe der Immunfluoreszenzfärbungen Auswirkungen veränderter Stimulationskonzentrationen detektieren.

Ginge man nun rein hypothetisch davon aus, dass eine Steigerung der Nestinexpression unter Zytokineinfluss sich nur bei vollständig transformierten Zellen eindeutig zeigen ließe, so könnte man die Vermutung aufstellen, dass eine nicht ausreichende Menge Zellen der distalen Epithelversuchsreihe der Real-Time PCR unter FGF-2-Einfluss tatsächlich transformiert wurden und damit keine verlässlich messbare Steigerung der mRNA stattfand. Im Gegensatz dazu und somit im Einklang mit den Ergebnissen der Immunhistochemie stehen Ergebnisse der Arbeitsgruppe Strutz und Kollegen, die besonders an distalen Tubulusepithelzellen der Maus (NP-1-Zellen) in der Lage waren, die Effekte der Zytokine TGF-ß, FGF-2 und EGF auf die epithelial-mesenchymale Transition zu untersuchen (Strutz et al. 2002). Somit stellt sich die Frage: Liegt es eventuell an einer statistisch nicht verlässlich reproduzierbaren und ausreichenden Menge an Nestin, dass die Signifikanz in der Versuchsreihe der Real-Time PCR im distalen Tubulusepithel ausblieb? Hierbei ginge man davon aus, dass der Prozess der EMT auch in distalen renalen Epithelzellen durch Zytokinstimulation im in-vitro-Modell vollständig zu erreichen ist. Oder könnte ebenso als Grund in Erwägung gezogen werden, dass der Prozess der EMT generell mit größerem Erfolg an proximalem Nierenepithel untersucht wurde, so dass auch eine Unvollständigkeit der Transformation als Grund für statistisch nicht relevante Ergebnisse gesehen werden kann. Interessanterweise gelang es Sakairi und Kollegen, auch in distalem Nierenepithel eines einseitig obstruierten Uretermodells einen gewissen Grad an Nestinexpression zu detektieren; wenn auch weitaus schwächer als Ergebnisse der gleichen Versuchsreihe an proximalen Tubulusepithelzellen (Sakairi et al. 2007). Laut der Arbeitsgruppe Strutz und Zeisberg ist es Bestand aktueller Forschung, ob alle Arten des tubulären Nierenepithels zur EMT befähigt sind. Mit überwiegender Häufigkeit konnte bisher der Prozess jedoch an proximalen Tubulusepithelzellen ausgelöst werden (Strutz und Zeisberg 2006).

Naheliegend als Begründung für dieses Ereignis ist die Tatsache, dass in der Literatur bis dato nicht hinreichend geklärt ist, ob die epithelial-mesenchymale Transformation unter alleinigem Einfluss von FGF-2 vollständig zustande kommen kann. Wie oben bereits erwähnt scheint die ganzheitliche Transition nur unter Einfluss von TGF- $\beta$, IL-18 und TNF- $\alpha$ möglich zu sein, so 
dass davon ausgegangen werden kann, dass unter dem Einfluss von FGF-2 in unserer Versuchsreihe die Transition unter Umständen nicht vollendet werden konnte. Dies würde weiterführend eine Erklärung liefern, weshalb es bei der Stimulationsreihe mit TGF- $\beta$ signifikante Auswirkungen auf die Nestinexpression gab, die bei FGF-2-Behandlung in der Real-Time PCR der distalen Tubulusepithelzellreihe ausblieben. Immunhistochemisch lässt sich allerdings eine spindelzellartige Veränderung der Epithelzellen feststellen, was wiederum die Annahme unterstützen würde, dass die mesenchymale Umwandlung phänotypisch stattgefunden hat. Ebenso konnte durch den Fluoreszenzfarbstoff eine klare Veränderung des Nestingehalts an den mit FGF-2 behandelten Zellen im Vergleich zur unstimulierten Zellprobe festgestellt werden. Als bedeutungsvollste Eigenschaft von FGF-2 in Verbindung mit der EMT kristallisiert sich die durch dieses Zytokin gesteigerte Sekretion der Matrixmetalloproteinasen 2 und 9 heraus, welche entscheidend zur Disruption der Basalmembran von Epithelzellen beitragen und somit den Prozess der EMT fördern können (Strutz et al. 2002).

Interessanterweise konnte in unseren Untersuchungen eine Signifikanz der Stimulationsdauer mit dem Zytokin FGF-2 an proximalen und distalen Tubulusepithelzellen festgestellt werden. Bei den MCT-Zellen ließ sich ein eindeutig signifikanter Unterschied in der Einwirkungszeit der Zytokine zwischen 4 und 24 Stunden feststellen, wobei nach vierstündiger Stimulation ein induktiver Effekt auf die Nestinexpression verzeichnet werden kann. Bei acht und vierundzwanzigstündiger Stimulation kommt es zu einer Regression der Nestinexpression, so dass auch toxische Effekte nicht auszuschließen sind. Hierbei ist zu erwähnen, dass die konzentrationsabhängigen Untersuchungen der MCT-Zellen unter FGF-2-Einfluss mit einer Stimulationsdauer von acht Stunden durchgeführt wurden. Es galt in weiteren Studien zu überprüfen, inwiefern ein deutlicherer Effekt auf die Nestinexpression mit verschiedenen Konzentrationen bei einer Stimulationsdauer von vier Stunden bei MCT-Zellen zu erzielen ist.

Auch die distale Tubulusepithelzellreihe NP-1 weist eine Zeitabhängigkeit auf. Hier ist ebenso analog den Ergebnissen der proximalen Epithelien eine signifikante Differenz zwischen den Stimulationszeiten von 4 und 24 Stunden zu erkennen. Mit steigender Stimulationsdauer von FGF-2 zeichnet sich ein zunehmender Rückgang der gemessenen mRNA-Werte für Nestin ab. Auch hier wäre es von Bedeutung herauszufinden, ob eine veränderte Stimulationszeit von 8 auf 4 Stunden eventuell die Signifikanz der Ergebnisse der konzentrationsabhängigen Versuchsreihe beeinflussen könnte, da hierbei eine negative Beeinflussung mit etwaigem Zellzerfall nicht anzunehmen ist. 
Aus obigen Ausführungen wird deutlich, dass die Rolle von FGF-2 bei der epithelialmesenchymalen Transition noch nicht gesichert geklärt ist und hier noch weiterer Forschungsbedarf besteht. Auch in der Literatur finden sich gegensätzliche Thesen. So schreiben Perantoni und Kollegen FGF-2 eine Rolle in der embryonalen Entwicklung des renalen Tubulusepithels zu, welches im Widerspruch zur Unterstützung mesenchymaler Zellentwicklung, wie sie im Rahmen der EMT bestätigt wurde, steht (Perantoni et al. 1995). Ebenso beschreibt die Arbeitsgruppe um Tiede einen widersprüchlichen Effekt: Nestinpositive multipotente Progenitorzellen der Haut sollen durch Einfluss vom Fibroblastenwachstumsfaktor an ihrer Umwandlung zu Myofibroblasten gehindert und nicht stimuliert werden, was in Zukunft eventuell therapeutisch zur Verhinderung keloidhaltiger Hautnarben genutzt werden könnte (Tiede et al. 2009).

\section{Die renale Fibrose: Ein therapeutischer Ausblick}

In den letzten Jahren konnte durch zahlreiche Studien ein klarer Zusammenhang zwischen dem Ausprägungsgrad einer diabetischen Nephropathie und dem vermehrten Vorhandensein von TGF- $\beta$ festgestellt werden (Sharma und Ziyadeh 1995; Ziyadeh et al. 2000; Chen S et al. 2001). Auf molekularer Ebene ähnelt die Fibrose im Rahmen der diabetischen Form des Nierenleidens in ihrer Pathologie der Fibrose, wie sie auch aus zahlreichen anderen progressiven, renalen Erkrankungen bekannt ist. Ebenso kann ein enger Zusammenhang mit fibrotischen Krankheitsbildern anderer Organe festgestellt werden (Border und Noble 1994). All diesen Fibroseformen gemeinsam ist die Überexpression von TGF- $§$ (Border und Noble 1998). Effekte von Transforming Growth Factor $\beta$ stellen die renale Zellhypertrophie sowie die Akkumulation überschüssigen extrazellulären Matrixgewebes dar. Studien konnten zeigen, dass eben diese Auswirkungen auf einen erhöhten Blutzuckerspiegel zurückzuführen sind. Eine Erklärung könnte die direkte Einflussnahme des erhöhten Glukoselevels auf eine Steigerung der TGF-ß-Expression sein. Unterstützend zu dieser These konnte durch den invitro-Einsatz von TGF-ß-neutralisierendem Antikörper ein Aufhalten der exzessiven Matrixbildung erreicht, sowie ein Fortschreiten der nachlassenden Nierenfunktion verhindert werden (Chen S et al. 2003). Diese bedeutsame Erkenntnis bezüglich des Transforming Growth Factors lässt deutlich werden, dass nicht nur der Faktor selbst, sondern auch die von ihm beeinflussten Abläufe sehr wahrscheinlich einen wichtigen Angriffspunkt im therapeutischen Ansatz zur Bekämpfung des Nierenversagens darstellen. Zusätzlich wird 
deutlich, dass aufgrund der Gemeinsamkeiten der fibrotischen Krankheiten untereinander ein erfolgreicher Schritt in Richtung Therapie der renalen Fibrose auch eine entscheidende, therapeutische Erkenntnis für viele andere Krankheitsbilder bedeuten könnte (Border und Noble 1998).

Bahnbrechend im therapeutischen Fortschritt der chronischen Niereninsuffizienz war die Erkenntnis, dass BMP-7 (bone morphogenetic protein), ein homodimerisches Protein der TGF-ß-Superfamilie, eine Reversibilität bzw. Milderung des fibrotischen Nierenschadens herbeizuführen vermochte (Klahr et al. 2002; Xu Y et al. 2009). Dieses Protein ist befähigt, direkt in den durch TGF- $\beta$ ausgelösten Zyklus der EMT antagonistisch einzugreifen, indem es die Reexpression eines entscheidenden epithelialen Adhäsionsmoleküls, E-cadherin, bewirkt. Des Weiteren besitzt es die Fähigkeit, die Expression des zonula-occludens-Proteins, ZO-1, welches maßgeblich an der Bildung epithelialer tight junctions beteiligt ist, zu reaktivieren sowie den epithelialen Phänotyp der durch EMT veränderten Zellen wiederherzustellen (Cano et al. 2000; Zeisberg $\mathrm{M}$ et al. 2003). In den wissenschaftlichen Untersuchungen der Arbeitsgruppe um Zeisberg konnte so durch Einsatz von rekombinantem, humanen BMP-7 eine Wiederherstellung der Integrität stark zerstörter Epithelzellen der distalen Tubulusepithelzellreihe NP-1 in einem murinen Modell einer chronischen Nierenerkrankung bewirkt werden (Zeisberg $M$ et al. 2003).

Im Widerspruch hierzu stehen neuste Ergebnisse der wissenschaftlichen Forschung, die den reversiblen Effekt des BMP-7 an humanen proximalen Tubulusepithelzellen nicht bestätigen konnten (Dudas et al. 2009). Veerasamy und Kollegen konnten ebenfalls keine Reexpression von E-Cadherin feststellen und kamen zu dem Schluss, den anti-fibrotischen Effekt des Bone Morphogenetic Proteins 9 durch Inhibition der de-novo-Expression von alphaGlattmuskelaktin durch BMP-7 zu erklären (Veerasamy et al. 2009). Diese Widersprüche galt es zu klären, so dass sich weitere interessante Aspekte für die Forschung auf diesem Gebiet in den nächsten Jahren ergeben.

\section{Erhöhte Nestinexpression im in-vitro-Modell der EMT}

Die vorliegenden Ergebnisse zeigen einen signifikanten Anstieg der Nestinexpression in proximalen und distalen Tubulusepithelzellen der Maus unter Stimulation mit den Zytokinen TGF- 3 sowie FGF-2. Ursprünglich diente das Intermediärfilament Nestin als Marker für neurale Stamm- und Progenitorzellen (Cattaneo und McKay 1990; Michalczyk und Ziman 
2005). Wie vielfach wissenschaftlich bestätigt wurde, weist die herangereifte, gesunde Niere ausschließlich im Bereich der Podozyten die Expression des Proteins Nestin auf (Wagner et al. 2006; Zou et al. 2006). Erst der Arbeitsgruppe um Sakairi gelang es in einem Modell der fibrotisch erkrankten adulten Niere, Nestin außerhalb der Podozyten in tubuloepithelialen Zellen sowie in interstitiellen Myofibroblasten zu detektieren (Sakairi et al. 2007; Tomioka et al. 2010). Dies stellte den Anreiz für unsere Arbeitsgruppe dar, der Nestinexpression im Zusammenhang mit der EMT im renalen Tubulusepithel genauer nachzugehen.

Laut Ahn und Kollegen ließ sich Sakairis These bestätigen, dass Nestin-exprimierende Zellen zum Großteil im Medullabereich der Niere zu finden sind und in Richtung Kortex in ihrer Häufigkeit stark abnehmen. Des Weiteren konnten durch diese Arbeitsgruppe Zellen mit Nestingehalt im Bereich interstitieller Fibrose entdeckt werden. Daher lag die Vermutung nahe, dass die Anzahl an Nestin-exprimierenden Zellen in direktem Zusammenhang mit dem Ausmaß der renalen Fibrose stehen könnte (Ahn et al. 2008).

Kommt es zu einer Verletzung des Nierengewebes, so können Stammzellen den Prozess der Regeneration und Reparation unterstützen. Zum Beispiel ist es möglich, dass zerstörte Gewebsanteile mit Hilfe von infiltrierenden oder residenten Stammzellen ersetzt werden (Haller et al. 2005). In diesem Zusammenhang konnte ein erneuter Anstieg des Proteins Nestin in den versehrten Zellen einiger Gewebe festgestellt werden (Wiese et al. 2004). Dieses Phänomen könnte auch eine Erklärung für das vermehrte Vorhandensein eines eigentlich Stammzellen zuzuordnenden Proteins in der fibrotisch erkrankten Niere sein, da der Prozess der EMT maßgeblich an der Wundheilung des versehrten renalen Gewebes beteiligt ist. In einem experimentellen Modell des Myokardinfarktes konnten ebenso Nestinexprimierende Zellen im verletzten Myokard gefunden werden, was bestätigt, dass Zellen, die Nestin exprimieren, in Zusammenhang mit einem zu reparierenden Gewebeschaden stehen (Marvin et al. 1998). Diese Reexpression in Zusammenhang mit einer Gewebsverletzung scheint auf einen Zustand der Remodellierung des betroffenen Organs sowie einen Rückgang zu einem schwächer entwickelten Phänotyp hinzuweisen (Tomioka et al. 2010). Auch Zou und Kollegen gelang es, das Auftreten von Nestin in Verbindung mit krankheitsbedingten Beeinträchtigungen von Podozyten nachzuweisen (Zou et al. 2006).

Der Prozess der Rückentwicklung von verletzten epithelialen Zellen zu einem mesenchymalen Phänotyp lässt sich mit eben dieser wichtigen Rolle von Stamm- und Progenitorzellen im Wundheilungsprozess in Zusammenhang bringen. Der dabei durch die EMT entstandene mesenchymale Zelltyp kann seinen Teil zur reparativen Fibrose beitragen, um so die Gewebewundheilung der Niere unterstützen (Abbattista und Schena 2004). Nestin 
und auch Intermediärfilamenten generell wird eine wichtige Rolle in der Stabilisation des Phänotyps einer Zelle zugeordnet (Zou et al. 2006). Dies lässt die Vermutung zu, dass Nestin den neu entstandenen mesenchymalen Zelltyp in seinem Aufbau stärkt und somit erhält.

Paradoxerweise führt jedoch der Reparaturprozess der Narbenbildung, also die Fibrosierung, im Fall der Niere zu einem verschlechterten Heilungsvorgang des Organs, da durch das überschüssige Ersatzgewebe und die ausbleibende Wiederherstellung der komplexen Nierenarchitektur die Nierenfunktion stark beeinträchtigt wird. Laut Chen und Kollegen kann Nestin ein häufiges Vorkommen in Bereichen der Regeneration zugeschrieben werden. Somit kann auch in unseren Experimenten davon ausgegangen werden kann, dass Nestin aufgrund der maßgeblichen Beteiligung der EMT an der renalen Fibrose auch in einem in-vitro-Modell dieses Prozesses vorzufinden sein müsste (Chen J et al. 2006). Auch die Arbeitsgruppe um Sakairi konnte das Auftreten von Nestin im Rahmen von Gewebsverletzungen im ZNS, der Leber, des Pankreases sowie den Zähnen bestätigen (Sakairi et al. 2007).

Des Weiteren ist es interessant zu sehen, dass in dieser Arbeit mittels Real-Time PCR die deutlichste Signifikanz der Nestinexpression proximalen Tubulusepithelzellen unter TGF-ßStimulation zugeschrieben werden konnte. Das Vorkommen von Nestin in der embryonalen Entwicklung der Niere ist ebenfalls größtenteils im proximalen Anteil der Tubuli sowie in den Progenitorzellen der glomerulären Endothelialzellen bekannt (Mokry und Nemecek 1998). Die persistierende Expression des intermediären Filamentproteins Nestin ist in der gesunden adulten Niere bis dato einzig und allein für Podozyten nachgewiesen worden. Embryologisch gesehen ist Nestin nur in Strukturen aufzufinden, die aus dem metanephrischen Mesenchym hervorgegangen sind. Nierengewebe, welches über die Vorläuferstruktur der Ureterknospe entstanden ist, ist jedoch Nestin-frei (Chen $J$ et al. 2006). Hier lässt sich die Vermutung aufstellen, dass epitheliale Strukturen, die embryologisch mesenchymalen Ursprunges sind, verstärkt die Fähigkeit besitzen, mittels epithelial-mesenchymaler Transition die Rückentwicklung zum Mesenchym durchzuführen. Des Weiteren scheinen es eben diese Anteile des renalen Gewebes zu sein, bei denen im Rahmen der EMT das Protein Nestin am deutlichsten zum Vorschein kommt.

Auch in distalen Tubulusepithelzellen war es im Rahmen dieses Projektes möglich Nestin nachzuweisen. Übereinstimmend mit diesen Ergebnissen gelang es auch der Arbeitsgruppe um Sakairi zu zeigen, dass der Nestingehalt im Rahmen der tubulointerstitiellen Verletzung zwar in proximalen Tubulusepithelzellen am stärksten ausgeprägt ist, jedoch auch in distalen Tubulusepithelzellen und in Anteilen der Henle-Schleife zu finden ist. In Sammelrohren konnte im Rahmen der Untersuchung eines Modells der einseitigen Harnleiterverlegung keine 
Expression von Nestin festgestellt werden (Sakairi et al. 2007). Diese Erkenntnis lässt sich mit der embryonalen Herkunft des Sammelrohrs aus der Ureterknospe in Verbindung bringen, da es naheliegend scheint, dass an Orten, an denen im Rahmen der Entwicklung kein Nestin $\mathrm{zu}$ finden war, auch in Zeiten der Regeneration und Reparation keine wieder aufgenommene Nestinexpression zu detektieren ist.

Kritisch an den Ergebnissen dieses Forschungsprojektes ist die Tatsache zu sehen, dass in den immunhistochemischen Untersuchungen ein gewisser Grundgehalt an Nestin-positivem Signal in den unstimulierten tubulären Zellen zu erkennen ist. In der Literatur ist Nestin sowohl in murinem als auch in humanem ausgereiften gesunden Nierengewebe nur in Podozyten wiederholt beschrieben worden (Ishizaki et al. 2006; Su et al. 2007; Su et al. 2008). Nur in Zusammenhang mit renalen Erkrankungen, wie etwa der renalen Fibrose, scheint Nestin im adulten Nierengewebe auch außerhalb der Podozyten zu existieren (Sakairi et al. 2007; Ahn et al. 2008). Hierbei muss erneut betont werden, dass der eingesetzte Antikörper unter Umständen nicht die gewünschte Selektivität bezüglich Nestin besitzt und es eventuell zur unspezifischen Bindung anderer Proteine gekommen ist. Somit kann den Ergebnissen der Immunfluoreszenz nicht die gleiche Gewichtung wie der äußerst sensiblen Methode der PCR zugeschrieben werden.

\section{Nestin als prognostischer Marker der renalen Fibrose?}

In Bezug auf die Myofibroblasten, deren Vorhandensein stark mit einer fortgeschrittenen renalen Fibrose in Verbindung gebracht wird, gelang es Tomioka et al. festzustellen, dass eine Nestinexpression in der fibrotischen Niere nicht alle $\alpha$-SMA-positiven Myofibroblasten betraf (Tomioka et al. 2010) Dies lässt die Schlussfolgerung zu, dass Myofibroblasten unterschiedliche Charakteristika aufweisen (Strutz et al. 2000; Qi et al. 2006). Bis dato sind bereits vielfältige Entstehungsquellen der renalen Myofibroblasten bekannt: 1. Die Aktivierung residenter nephrogener Fibroblasten 2. die Infiltration über den Blutweg und 3. die Prozesse der endothelial- und epithelial-mesenchymalen Transition (Strutz und Müller 2006; Zeisberg EM et al. 2008). Die Ergebnisse dieser Arbeit erlauben die Hypothese, dass die Nestinexpression in Myofibroblasten einen Indikator für den Entstehungsort der Myofibroblasten darstellt. Hierbei ist es denkbar, dass die sich durch Nestinexpression auszeichnenden Myofibroblasten durch epithelial-mesenchymale und endothelialmesenchymale Transitionsvorgänge entstanden sind, da die epithelialen und endothelialen 
Progenitorzellen bereits Nestin aufwiesen und sich so von anders generierten Myofibroblasten unterscheiden.

Intermediärfilamenten kommen wichtige Aufgaben im Bereich der Zellfunktionen wie Beeinflussung der Zellform und Beweglichkeit, die Kontrolle des Zellzyklus sowie der Signaltransduktion zu (Chang und Goldman 2004; Omary et al. 2004). Dies lässt die Vermutung $\mathrm{zu}$, dass das Intermediärfilament Nestin sich nicht nur als Indikator zur Differenzierung verschiedener Myofibroblasten eignet, sondern auch eventuelle funktionelle Aufgaben im Rahmen der tubulointerstitiellen Fibrose übernimmt. Wie Kleeberger et al. herausfinden konnten, bewirkt eine Veränderung von Nestin auf RNA-Ebene eine Verringerung des Migrations- und Invasionspotentials von Krebszellen (Kleeberger et al. 2007). Auch in dem Formationsprozess der Podozytenfortsätze scheint Nestin eine entscheidende Rolle einzunehmen, da bei Beeinflussung der Nestin-RNA mittels silencing eine reduzierte Ausführung dieses Ablaufes zu finden war (Chen J et al. 2006). Demnach kann man davon ausgehen, dass Nestin auch funktionelle Aufgaben in renalen Myofibroblasten übernimmt.

Anhand der Ergebnisse dieser Arbeit kann nun auch eine Aussage für Nestin bezüglich des therapeutischen Ausblicks für die Zukunft getroffen werden. Da der Anstieg des Nestingehalts in Tubulusepithelzellen mit verlässlicher Signifikanz in Korrelation mit der erhöhten TGF-ß-Konzentration im Rahmen der renalen Fibrose zu sehen ist, kann folgende Vermutung geäußert werden: Da Nestin in gesundem renalen Gewebe allein in Podozyten zu finden ist, kann es daher bei Vorkommen anderenorts in der Niere in direkten Zusammenhang mit dem verstärkten Ablauf der epithelial-mesenchymalen Transition gebracht werden; so ist möglicherweise ein neuer Indikator zur Feststellung der Progression der fibrotischen Nierenerkrankung definiert worden (Chen J et al. 2006). Laut Sakairi et al. korreliert der Grad der Nestinexpression stark mit der Ausbreitung der tubulointerstitiellen Beeinträchtigung (Sakairi et al. 2007). Weiterführend bedeutete dies, dass hierdurch eventuell eine neue Möglichkeit gefunden wurde, mit deren Hilfe sich der Grad der Fibrose der Niere im Rahmen renaler oder systemischer Erkrankungen feststellen ließe, so dass ein zeitnahes therapeutisches Einschreiten erreicht werden könnte. Da laut Literatur ein nicht unmaßgeblicher Anteil des fibrotisch veränderten Gewebes auf den durch TGF- $\beta$ induzierten Prozess der EMT zurückzuführen ist, könnte durch eine Beeinflussung dieses Zweiges eine Verlangsamung beziehungsweise ein teilweises Aufhalten der fortschreitenden Niereninsuffizienz erzielt werden. Verwendet man den TGF-ß-Spiegel direkt als Indikator, ist hierbei nicht gesichert, dass dieser unmittelbar mit der bereits geschehenen EMT korreliert. 
Wie oben bereits erwähnt kann TGF- $\beta$ von diversen Körperzellen produziert werden und somit vielerlei Aufgaben und Wirkorten zugeordnet werden, so dass man mit der Bestimmung des erhöhten TGF- $ß$ allein keine sichere Aussage bezüglich des Grades der durch EMT fibrotisch veränderten Nierenzellen treffen kann (Blobe et al. 2000; Hill et al. 2000). Allerdings muss eingeräumt werden, dass durch die Ergebnisse unserer Arbeitsgruppe sowie vieler anderer Forschungsgruppen bei einem erhöhten TGF-ß-Spiegel in der Niere mit sehr hoher Wahrscheinlichkeit von einem bereits fortgeschrittenen fibrotischen Prozess ausgegangen werden kann.

Ein weiterer interessanter Aspekt der Nestinexpression in Myofibroblasten ist, dass in Untersuchungen anderer Arbeitsgruppen nicht alle $\alpha$-SMA-positiven interstitiellen Zellen auch Nestin-positiv waren (Sakairi et al. 2007). Dies lässt die Vermutung zu, dass durch Nestin ein neuer Marker tubulointerstitieller Erkrankungen entdeckt wurde, der getrennt von den konventionellen Markern wie Vimentin und $\alpha$-SMA zu sehen ist. Hierdurch könnte man annehmen, dass zwei verschiedene Gruppen von Myofibroblasten existieren: Die Nestinpositiven und die Nestin-negativen Zellen. Weist dies jedoch nur auf den oben erwähnten unterschiedlichen Entstehungsort der Myofibroblasten hin oder kann man auch einen Unterschied in der Funktion dieser Zellen feststellen (Bascands et al. 2007)? Denkbar wäre zum Beispiel, dass die Nestin-positiven Zellen aufgrund des ursprünglichen Vorkommens von Nestin in Progenitorzellen eher dazu geneigt sind, an einer potentiellen Reversibilität des chronisch fibrotischen Prozesses teilzunehmen (Wiese et al. 2004). Hierbei könnte der Umkehrprozess der EMT, also die mesenchymal-epitheliale Transition der Nestin-positiven Zellen zurück zum renalen Tubulusepithel, eine regenerative Funktion übernehmen. Es wäre äußerst interessant festzustellen, ob diese reversiblen Fähigkeiten nur Nestin-positiven Myofibroblasten zuzuordnen sind und die Nestin-negativen Myofibroblasten kein regeneratives Potential aufweisen. Dieser Aspekt muss dringend in der Tiefe untersucht werden in Anbetracht der Tatsache, dass schon über viele Jahre eine mögliche Reversion der tubulointerstitiellen Fibrose diskutiert wird und durch die Entdeckung von Nestin im Zusammenhang mit der renalen EMT ein entscheidender neuer Denkansatz entstanden ist (Maschio et al. 1991).

Demgegenüber steht eine kontroverse These: Ist das Vorhandensein des Intermediärfilamentes Nestin in Myofibroblasten der Niere eher mit einer Verschlechterung des Erkrankungszustandes in Verbindung $\mathrm{zu}$ bringen statt eine reversible Funktion einzunehmen? Die generellen Eigenschaften von Intermediärfilamenten wie zum Beispiel die Aufrechterhaltung der zytoskelettalen Strukturen einer Zelle könnten vielmehr für eine 
Stabilisation und Unterstützung der Myofibroblasten in ihrer fibrotischen Aktivität sprechen. Hierbei wäre daher Nestin ein positiver Effektor der weiteren Vernarbung des Organs und würde somit durch ein schnelleres Erlangen des sogenannten point of no return der chronischen Niereninsuffizienz $\mathrm{zu}$ einer maßgeblichen Verschlechterung des Erkrankungszustandes des Patienten führen (Bascands et al. 2007). Dieser faszinierenden Gegensätzlichkeit möglicher Funktionen von Nestin im Rahmen der renalen epithelialmesenchymalen Transition gilt es in weiteren Studien auf den Grund zu gehen. 


\section{Zusammenfassung}

Der Prozess der epithelial-mesenchymalen Transition (EMT) ist schon seit längerem als einer der möglichen Hauptfaktoren der Entstehung fibrotischen Gewebes bekannt. Im Rahmen dieser Arbeit wurde anhand von quantitativen und immunhistochemischen Verfahren der Zusammenhang zwischen dem intermediären Filamentprotein Nestin und der EMT untersucht. Durch Stimulation mit Zytokinen (TGF- $\beta$ und FGF-2) wurde an murinen Tubulusepithelzellen der Umwandlungsprozess von Epithel zu Mesenchym nachgestellt und die Expression von Nestin, das in gesunden Nieren nur in Podozyten zu detektieren ist, untersucht. Hierbei konnte mittels Real-Time PCR eine Induktion von Nestin durch Stimulation mit TGF- $\beta$ in proximalen Tubulusepithelzellen (MCT) nachgewiesen werden (Zytokinbehandlung: $\mathrm{p}$-Wert $=0,0114$ ). Auch eine FGF-2-Behandlung führte zu einer signifikanten Expressionssteigerung (Zytokinbehandlung: p-Wert $=0,0398$ ). Mit Hilfe der Immunhistochemie konnte ein statistisch signifikanter Einfluss der Konzentration von TGF- $\beta$ und FGF-2 auf den Nestingehalt der untersuchten Zellen gezeigt werden. Ebenso konnte die phänotypische Veränderung der Epithelzellen zum mesenchymalen Zelltyp beobachtet werden. Eine Untersuchung der Zeitabhängigkeit der Nestinexpression zeigte einen zytotoxischen Effekt von TGF- $\beta$ und FGF-2 mit Rückgang der Nestinexpression nach $24 \mathrm{~h}$ $($ TGF-ß $(4 \mathrm{~h}: 24$ h) p-Wert $=0,0545$, FGF-2 (4 h : 24 h) p-Wert =0,0230).

In der distalen murinen Tubulusepithelzellreihe NP-1 zeigte die Real-Time PCR eine signifikante Steigerung der Nestinexpression unter TGF- 3 ( $p$-Wert $=0,0417$ ), bei FGF-2Stimulation wurde das Signifikanzniveau nicht erreicht. Beide Zytokine zeigten jedoch einen induktiven Effekt auf den Nestingehalt der Zellen in der Immunhistochemie sowie eine phänotypische, spindelförmige Zellveränderung. Ein signifikanter Einfluss steigender Stimulationskonzentrationen auf diesen Effekt konnte trotz graphisch zunehmender Tendenz der Ergebnisse beim Einsatz höherer Konzentrationen statistisch weder für TGF- $\beta$ noch für FGF-2 bestätigt werden. Eine Expressionsminderung nach hoher Stimulationsdauer konnte für FGF-2 gezeigt werden (FGF-2 (4 h : $24 \mathrm{~h}) \mathrm{p}$-Wert = 0,0015).

Zusammenfassend lässt sich sagen, dass durch die Ergebnisse dieser Arbeit das im ursprünglichen Sinne als neuroepithelialer Stammzellmarker entdeckte intermediäre Filamentprotein Nestin im Rahmen der Transition von renalen proximalen und distalen Epithelzellen zu Mesenchym nachgewiesen werden konnte. Das Vorkommen von Nestin im Prozess der EMT ist abhängig von den Konzentrationen von TGF- $\beta$ und FGF-2, die bei Erkrankungen fibrotischer Natur erhöht sind. Dies lässt die Vermutung zu, dass sich Nestin in 
Zukunft als Marker für die im Rahmen einer renalen Erkrankung erfolgten fibrotischen Veränderungen des Organs, die direkt auf den Prozess der epithelial-mesenchymalen Transition zurückzuführen sind, einsetzen lässt, um eventuell frühzeitig in dieses pathologische Geschehen eingreifen zu können. Weiterführend muss hierbei untersucht werden, inwiefern das Vorhandensein von Nestin eine potentielle Reversibilität des fibrotischen Prozesses durch Retransformation Nestin-positiver Myofibroblasten zurück zu epithelialen Zellen in sich birgt oder aber ob Nestin als stabilisierender Faktor der progressiven Fibrose durch unterstützende Wirkung auf die Myofibroblasten gesehen werden muss. Eine weitergehende detaillierte wissenschaftliche Analyse ist wünschenswert, um den tatsächlichen klinischen Nutzen dieser Erkenntnisse bewerten $\mathrm{zu}$ können. 


\section{Literaturverzeichnis}

Abbattista MR, Schena FP (2004): Stem cells and kidney diseases. Minerva Med 95: 411-8.

Ahn KO, Li C, Lim SW, Song HK, Ghee JY, Kim SH, Kim JY, Yoon HE, Cha JH, Kim J, Yang CW (2008): Infiltration of nestin-expressing cells in interstitial fibrosis in chronic cyclosporine nephropathy. Transplantation $\underline{86}$ : 571-7.

Alvarez RJ, Sun MJ, Haverty TP, Iozzo RV, Myers JC, Neilson EG (1992): Biosynthetic and proliferative characteristics of tubulointerstitial fibroblasts probed with paracrine cytokines. Kidney Int 41: 14-23.

Bani-Hani AH, Campbell MT, Meldrum DR, Meldrum KK (2008): Cytokines in epithelialmesenchymal transition: a new insight into obstructive nephropathy. J Urol 180: 4618.

Bascands JL, Klein J, Schanstra JP (2007): A nest in renal fibrosis? Kidney Int 72: 242-4.

Bates RC, DeLeo MJ, 3rd, Mercurio AM (2004): The epithelial-mesenchymal transition of colon carcinoma involves expression of IL-8 and CXCR-1-mediated chemotaxis. Exp Cell Res 299: 315-24.

Bertelli E, Regoli M, Fonzi L, Occhini R, Mannucci S, Ermini L, Toti P (2007): Nestin expression in adult and developing human kidney. J Histochem Cytochem 55: 411-21.

Blobe GC, Schiemann WP, Lodish HF (2000): Role of transforming growth factor beta in human disease. N Engl J Med 342: 1350-8.

Bohle A, Bader R, Grund KE, Mackensen S, Neunhoeffer (1977): Serum creatinine concentration and renal interstitial volume. Analysis of correlations in endocapillary (acute) glomerulonephritis and in moderately severe mesangioproliferative glomerulonephritis. Virchows Arch A Pathol Anat Histol 375: 87-96. 
Bohle A, Wehrmann M, Bogenschutz O, Batz C, Vogl W, Schmitt H, Muller CA, Muller GA (1992): The long-term prognosis of the primary glomerulonephritides. A morphological and clinical analysis of 1747 cases. Pathol Res Pract 188: 908-24.

Boor P, Ostendorf T, Floege J (2010): Renal fibrosis: novel insights into mechanisms and therapeutic targets. Nat Rev Nephrol 6: 643-56.

Border WA, Noble NA (1994): Transforming growth factor beta in tissue fibrosis. N Engl J Med 331: 1286-92.

Border WA, Noble NA (1998): Evidence that TGF-beta should be a therapeutic target in diabetic nephropathy. Kidney Int 54: 1390-1.

Boyer B, Valles AM, Edme N (2000): Induction and regulation of epithelial-mesenchymal transitions. Biochem Pharmacol 60: 1091-9.

Cano A, Perez-Moreno MA, Rodrigo I, Locascio A, Blanco MJ, del Barrio MG, Portillo F, Nieto MA (2000): The transcription factor snail controls epithelial-mesenchymal transitions by repressing E-cadherin expression. Nat Cell Biol 2: 76-83.

Cattaneo E, McKay R (1990): Proliferation and differentiation of neuronal stem cells regulated by nerve growth factor. Nature $\underline{347}$ : 762-5.

Chang L, Goldman RD (2004): Intermediate filaments mediate cytoskeletal crosstalk. Nat Rev Mol Cell Biol 5: 601-13.

Chen J, Boyle S, Zhao M, Su W, Takahashi K, Davis L, Decaestecker M, Takahashi T, Breyer MD, Hao CM (2006): Differential expression of the intermediate filament protein nestin during renal development and its localization in adult podocytes. $\mathrm{J}$ Am Soc Nephrol 17: 1283-91.

Chen JK, Shen LS, Chao HH (1994): Correlation of transformation from epithelial to mesenchymal-like morphology and endogenous bFGF levels in human nasopharyngeal carcinoma cells. J Cell Physiol 160: 401-8. 
Chen S, Jim B, Ziyadeh FN (2003): Diabetic nephropathy and transforming growth factorbeta: transforming our view of glomerulosclerosis and fibrosis build-up. Semin Nephrol 23: 532-43.

Chen S, Hong SW, Iglesias-de la Cruz MC, Isono M, Casaretto A, Ziyadeh FN (2001): The key role of the transforming growth factor-beta system in the pathogenesis of diabetic nephropathy. Ren Fail 23: 471-81.

Coulier F, Pontarotti P, Roubin R, Hartung H, Goldfarb M, Birnbaum D (1997): Of worms and men: an evolutionary perspective on the fibroblast growth factor (FGF) and FGF receptor families. J Mol Evol $\underline{44}$ : 43-56.

Creely JJ, DiMari SJ, Howe AM, Haralson MA (1992): Effects of transforming growth factor-beta on collagen synthesis by normal rat kidney epithelial cells. Am J Pathol 140: 45-55.

Daniel C, Albrecht H, Ludke A, Hugo C (2008): Nestin expression in repopulating mesangial cells promotes their proliferation. Lab Invest $\underline{88}$ : 387-97.

Davies JA, Perera AD, Walker CL (1999): Mechanisms of epithelial development and neoplasia in the metanephric kidney. Int J Dev Biol 43: 473-8.

Derynck R, Akhurst RJ, Balmain A (2001): TGF-beta signaling in tumor suppression and cancer progression. Nat Genet 29: 117-29.

Desmouliere A, Darby IA, Gabbiani G (2003): Normal and pathologic soft tissue remodeling: role of the myofibroblast, with special emphasis on liver and kidney fibrosis. Lab Invest $\underline{83}$ : 1689-707.

Dudas PL, Argentieri RL, Farrell FX (2009): BMP-7 fails to attenuate TGF-beta1-induced epithelial-to-mesenchymal transition in human proximal tubule epithelial cells. Nephrol Dial Transplant 24: 1406-16. 
Fan JM, Ng YY, Hill PA, Nikolic-Paterson DJ, Mu W, Atkins RC, Lan HY (1999):

Transforming growth factor-beta regulates tubular epithelial-myofibroblast transdifferentiation in vitro. Kidney Int 56: 1455-67.

Frei U, Schober-Halstenberg HJ (1999): Annual Report of the German Renal Registry 1998. QuaSi-Niere Task Group for Quality Assurance in Renal Replacement Therapy. Nephrol Dial Transplant 14: 1085-90.

Frei U, Schober-Halstenberg HJ (2008): Nierenersatztherapie in Deutschland, Bericht über Dialysebehandlung und Nierentransplantation in Deutschland 2006/2007. http://www.bundesverband-niere.de/files/QuaSi-Niere-Bericht_2006-2007.pdf (aufgerufen am 12.9.2010).

Gauldie J, Kolb M, Sime PJ (2002): A new direction in the pathogenesis of idiopathic pulmonary fibrosis? Respir Res $\underline{3}: 1$.

Greenburg G, Hay ED (1982): Epithelia suspended in collagen gels can lose polarity and express characteristics of migrating mesenchymal cells. J Cell Biol 95: 333-9.

Haller H, de Groot K, Bahlmann F, Elger M, Fliser D (2005): Stem cells and progenitor cells in renal disease. Kidney Int $\underline{68}$ : 1932-6.

Haverty TP, Kelly CJ, Hines WH, Amenta PS, Watanabe M, Harper RA, Kefalides NA, Neilson EG (1988): Characterization of a renal tubular epithelial cell line which secretes the autologous target antigen of autoimmune experimental interstitial nephritis. J Cell Biol 107: 1359-68.

Healy E, Brady HR (1998): Role of tubule epithelial cells in the pathogenesis of tubulointerstitial fibrosis induced by glomerular disease. Curr Opin Nephrol Hypertens 7: $525-30$.

Hewitson TD (2009): Renal tubulointerstitial fibrosis: common but never simple. Am J Physiol Renal Physiol 296: F1239-44. 
Hill C, Flyvbjerg A, Gronbaek H, Petrik J, Hill DJ, Thomas CR, Sheppard MC, Logan A (2000): The renal expression of transforming growth factor-beta isoforms and their receptors in acute and chronic experimental diabetes in rats. Endocrinology 141: 1196208.

Humes HD, Beals TF, Cieslinski DA, Sanchez IO, Page TP (1991): Effects of transforming growth factor-beta, transforming growth factor-alpha, and other growth factors on renal proximal tubule cells. Lab Invest 64: 538-45.

Ibelgaufts: Lexikon Zytokine. Medikon Verlag. München (1992).

Ishizaki M, Ishiwata T, Adachi A, Tamura N, Ghazizadeh M, Kitamura H, Sugisaki Y, Yamanaka N, Naito Z, Fukuda Y (2006): Expression of nestin in rat and human glomerular podocytes. J Submicrosc Cytol Pathol 38: 193-200.

Iwano M, Plieth D, Danoff TM, Xue C, Okada H, Neilson EG (2002): Evidence that fibroblasts derive from epithelium during tissue fibrosis. J Clin Invest 110: 341-50.

Jakic M, Jakic M, Zibar L, Mihaljevic D, Stipanic S, Teskera T (2009): [Diabetic nephropathy and prevention of diabetic nephropathy caused chronic renal insufficiency]. Lijec Vjesn 131: 218-25.

Kasai H, Allen JT, Mason RM, Kamimura T, Zhang Z (2005): TGF-beta1 induces human alveolar epithelial to mesenchymal cell transition (EMT). Respir Res $\underline{6}: 56$.

Kishaba Y, Matsubara D, Niki T (2010): Heterogeneous expression of nestin in myofibroblasts of various human tissues. Pathol Int $\underline{60}$ : 378-85.

Kisseleva T, Brenner DA (2008): Mechanisms of fibrogenesis. Exp Biol Med (Maywood) 233: 109-22.

Klahr S, Morrissey J, Hruska K, Wang S, Chen Q (2002): New approaches to delay the progression of chronic renal failure. Kidney Int Suppl 82: S23-26. 
Kleeberger W, Bova GS, Nielsen ME, Herawi M, Chuang AY, Epstein JI, Berman DM (2007): Roles for the stem cell associated intermediate filament Nestin in prostate cancer migration and metastasis. Cancer Res 67: 9199-206.

Kuroishi S, Suda T, Fujisawa T, Ide K, Inui N, Nakamura Y, Nakamura H, Chida K (2009): Epithelial-mesenchymal transition induced by transforming growth factor-beta1 in mouse tracheal epithelial cells. Respirology 14: 828-37.

Lechleider R, Roberts A: Transforming growth factor- $\beta$; in: The Cytokine Network and Immune Functions. Oxford University Press. New York (1999): 104-9.

Lechner MS, Dressler GR (1997): The molecular basis of embryonic kidney development. Mech Dev 62: 105-20.

Lee EH, Joo CK (1999): Role of transforming growth factor-beta in transdifferentiation and fibrosis of lens epithelial cells. Invest Ophthalmol Vis Sci 40: 2025-32.

Lendahl U, Zimmerman LB, McKay RD (1990): CNS stem cells express a new class of intermediate filament protein. Cell $\underline{60}$ : 585-95.

Lin Y, Zhang S, Tuukkanen J, Peltoketo H, Pihlajaniemi T, Vainio S (2003): Patterning parameters associated with the branching of the ureteric bud regulated by epithelialmesenchymal interactions. Int J Dev Biol 47: 3-13.

Liu Y (2004): Epithelial to mesenchymal transition in renal fibrogenesis: pathologic significance, molecular mechanism, and therapeutic intervention. J Am Soc Nephrol 15: $1-12$.

Marshall MR, Byrne BG, Kerr PG, McDonald SP (2006): Associations of hemodialysis dose and session length with mortality risk in Australian and New Zealand patients. Kidney Int 69: 1229-36. 
Marvin MJ, Dahlstrand J, Lendahl U, McKay RD (1998): A rod end deletion in the intermediate filament protein nestin alters its subcellular localization in neuroepithelial cells of transgenic mice. J Cell Sci 111 ( Pt 14): 1951-61.

Maschio G, Oldrizzi L, Rugiu C (1991): Is there a "point of no return" in progressive renal disease? J Am Soc Nephrol 2: 832-40.

Massague J (1998): TGF-beta signal transduction. Annu Rev Biochem 67: 753-91.

Michalczyk K, Ziman M (2005): Nestin structure and predicted function in cellular cytoskeletal organisation. Histol Histopathol 20: 665-71.

Misseri R, Rink RC, Meldrum DR, Meldrum KK (2004): Inflammatory mediators and growth factors in obstructive renal injury. J Surg Res 119: 149-59.

Mokry J, Nemecek S (1998): Angiogenesis of extra- and intraembryonic blood vessels is associated with expression of nestin in endothelial cells. Folia Biol (Praha) 44: 155-61.

Mucsi I, Rosivall L (2007): Epithelial-mesenchymal transition in renal tubular cells in the pathogenesis of progressive tubulo-interstitial fibrosis. Acta Physiol Hung 94: 117-31.

Nangaku M (2006): Chronic hypoxia and tubulointerstitial injury: a final common pathway to end-stage renal failure. J Am Soc Nephrol 17: 17-25.

Nath KA (1998): The tubulointerstitium in progressive renal disease. Kidney Int 54: 992-4.

Nath KA (1992): Tubulointerstitial changes as a major determinant in the progression of renal damage. Am J Kidney Dis 20: 1-17.

Okada H, Danoff TM, Kalluri R, Neilson EG (1997): Early role of Fsp1 in epithelialmesenchymal transformation. Am J Physiol 273: F563-74. 
Okada H, Inoue T, Suzuki H, Strutz F, Neilson EG (2000): Epithelial-mesenchymal transformation of renal tubular epithelial cells in vitro and in vivo. Nephrol Dial Transplant 15 Suppl 6: 44-6.

Omary MB, Coulombe PA, McLean WH (2004): Intermediate filament proteins and their associated diseases. N Engl J Med 351: 2087-100.

Owen WF, Jr. (2003): Patterns of care for patients with chronic kidney disease in the United States: dying for improvement. J Am Soc Nephrol 14: S76-80.

Pastan S, Bailey J (1998): Dialysis therapy. N Engl J Med 338: 1428-37.

Perantoni AO, Dove LF, Karavanova I (1995): Basic fibroblast growth factor can mediate the early inductive events in renal development. Proc Natl Acad Sci U S A 92: 4696-700.

Perry J, Ho M, Viero S, Zheng K, Jacobs R, Thorner PS (2007): The intermediate filament nestin is highly expressed in normal human podocytes and podocytes in glomerular disease. Pediatr Dev Pathol 10: 369-82.

Plisov SY, Ivanov SV, Yoshino K, Dove LF, Plisova TM, Higinbotham KG, Karavanova I, Lerman M, Perantoni AO (2000): Mesenchymal-epithelial transition in the developing metanephric kidney: gene expression study by differential display. Genesis 27: 22-31.

Qi W, Chen X, Poronnik P, Pollock CA (2006): The renal cortical fibroblast in renal tubulointerstitial fibrosis. Int J Biochem Cell Biol $\underline{38}$ : 1-5.

Reibman J, Meixler S, Lee TC, Gold LI, Cronstein BN, Haines KA, Kolasinski SL, Weissmann G (1991): Transforming growth factor beta 1, a potent chemoattractant for human neutrophils, bypasses classic signal-transduction pathways. Proc Natl Acad Sci U S A $\underline{88}$ : 6805-9.

Sakairi T, Hiromura K, Yamashita S, Takeuchi S, Tomioka M, Ideura H, Maeshima A, Kaneko Y, Kuroiwa T, Nangaku M, Takeuchi T, Nojima Y (2007): Nestin expression in the kidney with an obstructed ureter. Kidney Int 72: 307-18. 
Schiffer M, von Gersdorff G, Bitzer M, Susztak K, Bottinger EP (2000): Smad proteins and transforming growth factor-beta signaling. Kidney Int Suppl 77: S45-52.

Sharma K, Ziyadeh FN (1995): Hyperglycemia and diabetic kidney disease. The case for transforming growth factor-beta as a key mediator. Diabetes $\underline{44}$ : 1139-46.

Shull MM, Ormsby I, Kier AB, Pawlowski S, Diebold RJ, Yin M, Allen R, Sidman C, Proetzel G, Calvin D, et al. (1992): Targeted disruption of the mouse transforming growth factor-beta 1 gene results in multifocal inflammatory disease. Nature 359: 6939.

Solhaug MJ, Bolger PM, Jose PA (2004): The developing kidney and environmental toxins. Pediatrics 113: 1084-91.

Steinert PM, Chou YH, Prahlad V, Parry DA, Marekov LN, Wu KC, Jang SI, Goldman RD (1999): A high molecular weight intermediate filament-associated protein in BHK-21 cells is nestin, a type VI intermediate filament protein. Limited co-assembly in vitro to form heteropolymers with type III vimentin and type IV alpha-internexin. J Biol Chem 274: 9881-90.

Strutz F, Müller GA (2006): Renal fibrosis and the origin of the renal fibroblast. Nephrol Dial Transplant 21: 3368-70.

Strutz F, Neilson EG (2003): New insights into mechanisms of fibrosis in immune renal injury. Springer Semin Immunopathol 24: 459-76.

Strutz F, Zeisberg M (2006): Renal fibroblasts and myofibroblasts in chronic kidney disease. J Am Soc Nephrol 17: 2992-8.

Strutz F, Okada H, Lo CW, Danoff T, Carone RL, Tomaszewski JE, Neilson EG (1995): Identification and characterization of a fibroblast marker: FSP1. J Cell Biol 130: 393405. 
Strutz F, Zeisberg M, Hemmerlein B, Sattler B, Hummel K, Becker V, Muller GA (2000):

Basic fibroblast growth factor expression is increased in human renal fibrogenesis and may mediate autocrine fibroblast proliferation. Kidney Int 57: 1521-38.

Strutz F, Zeisberg M, Ziyadeh FN, Yang CQ, Kalluri R, Muller GA, Neilson EG (2002): Role of basic fibroblast growth factor-2 in epithelial-mesenchymal transformation. Kidney Int $\underline{61}: 1714-28$.

Su W, Chen J, Yang H, You L, Xu L, Wang X, Li R, Gao L, Gu Y, Lin S, Xu H, Breyer MD, Hao CM (2007): Expression of nestin in the podocytes of normal and diseased human kidneys. Am J Physiol Regul Integr Comp Physiol 292: R1761-7.

Su W, Fang C, Yang HC, Gu Y, Hao CM (2008): [Expression of nestin in human kidney and its clinical significance]. Zhonghua Bing Li Xue Za Zhi 37: 309-12.

Tiede S, Ernst N, Bayat A, Paus R, Tronnier V, Zechel C (2009): Basic fibroblast growth factor: a potential new therapeutic tool for the treatment of hypertrophic and keloid scars. Ann Anat 191: 33-44.

Tomasek JJ, Gabbiani G, Hinz B, Chaponnier C, Brown RA (2002): Myofibroblasts and mechano-regulation of connective tissue remodelling. Nat Rev Mol Cell Biol $\underline{3}:$ 34963.

Tomioka M, Hiromura K, Sakairi T, Takeuchi S, Maeshima A, Kaneko Y, Kuroiwa T, Takeuchi T, Nojima Y (2010): Nestin is a novel marker for renal tubulointerstitial injury in immunoglobulin A nephropathy. Nephrology (Carlton) 15: 568-74.

Underwood JCE: General and Systematic Pathology. Churchill Livingstone. Edinburgh (1992).

van Kooten C, Daha MR, van Es LA (1999): Tubular epithelial cells: A critical cell type in the regulation of renal inflammatory processes. Exp Nephrol 7: 429-37. 
Veerasamy M, Nguyen TQ, Motazed R, Pearson AL, Goldschmeding R, Dockrell M (2009): Differential regulation of E-cadherin and \{alpha\}-Smooth Muscle Actin by BMP 7 in human renal proximal tubule epithelial cells and its implication in renal fibrosis. Am $\mathrm{J}$ Physiol Renal Physiol.

Venkataraman G, Raman R, Sasisekharan V, Sasisekharan R (1999): Molecular characteristics of fibroblast growth factor-fibroblast growth factor receptor-heparinlike glycosaminoglycan complex. Proc Natl Acad Sci U S A $\underline{96}$ : 3658-63.

Wagner N, Wagner KD, Scholz H, Kirschner KM, Schedl A (2006): Intermediate filament protein nestin is expressed in developing kidney and heart and might be regulated by the Wilms' tumor suppressor Wt1. Am J Physiol Regul Integr Comp Physiol 291: R779-87.

Wallner EI, Yang Q, Peterson DR, Wada J, Kanwar YS (1998): Relevance of extracellular matrix, its receptors, and cell adhesion molecules in mammalian nephrogenesis. Am J Physiol 275: F467-77.

Wiese C, Rolletschek A, Kania G, Blyszczuk P, Tarasov KV, Tarasova Y, Wersto RP, Boheler KR, Wobus AM (2004): Nestin expression--a property of multi-lineage progenitor cells? Cell Mol Life Sci 61: 2510-22.

Xu J, Lamouille S, Derynck R (2009): TGF-beta-induced epithelial to mesenchymal transition. Cell Res 19: 156-72.

Xu Y, Wan J, Jiang D, Wu X (2009): BMP-7 counteracts TGF-beta1-induced epithelial-tomesenchymal transition in human renal proximal tubular epithelial cells. J Nephrol 22 : 403-10.

Yamashita T, Yoshioka M, Itoh N (2000): Identification of a novel fibroblast growth factor, FGF-23, preferentially expressed in the ventrolateral thalamic nucleus of the brain. Biochem Biophys Res Commun 277: 494-8. 
Yang J, Liu Y (2001): Dissection of key events in tubular epithelial to myofibroblast transition and its implications in renal interstitial fibrosis. Am J Pathol 159: 1465-75.

Yao G, Xu L, Wu X, Xu L, Yang J, Chen H (2009): Preventive effects of salvianolic acid B on transforming growth factor-beta1-induced epithelial-to-mesenchymal transition of human kidney cells. Biol Pharm Bull 32: 882-6.

Zeisberg EM, Potenta SE, Sugimoto H, Zeisberg M, Kalluri R (2008): Fibroblasts in kidney fibrosis emerge via endothelial-to-mesenchymal transition. J Am Soc Nephrol 19: 2282-7.

Zeisberg M, Hanai J, Sugimoto H, Mammoto T, Charytan D, Strutz F, Kalluri R (2003): BMP-7 counteracts TGF-betal-induced epithelial-to-mesenchymal transition and reverses chronic renal injury. Nat Med 9: 964-8.

Zhang YE (2009): Non-Smad pathways in TGF-beta signaling. Cell Res 19: 128-39.

Ziyadeh FN, Hoffman BB, Han DC, Iglesias-De La Cruz MC, Hong SW, Isono M, Chen S, McGowan TA, Sharma K (2000): Long-term prevention of renal insufficiency, excess matrix gene expression, and glomerular mesangial matrix expansion by treatment with monoclonal antitransforming growth factor-beta antibody in $\mathrm{db} / \mathrm{db}$ diabetic mice. Proc Natl Acad Sci U S A 97: 8015-20.

Zoja C, Morigi M, Remuzzi G (2003): Proteinuria and phenotypic change of proximal tubular cells. J Am Soc Nephrol 14 Suppl 1: S36-41.

Zou J, Yaoita E, Watanabe Y, Yoshida Y, Nameta M, Li H, Qu Z, Yamamoto T (2006): Upregulation of nestin, vimentin, and desmin in rat podocytes in response to injury. Virchows Arch 448: 485-92.

Zukowski M, Bohatyrewicz R, Biernawska J, Kotfis K, Zegan M, Knap R, Janeczek M, Zietek Z (2009): Risk factors for septic complications in kidney transplant recipients. Transplant Proc 41: 3043-5. 


\section{Danksagungen}

Mein Dank geht an Herrn Prof. Dr. med. Frank Strutz, der mir im Jahr 2007 freundlicherweise dieses Thema überließ. Eine gute Einführung in das Thema und eine umfassende, stets freundliche Betreuung bei wichtigen Fragen im Zusammenhang mit dieser Arbeit zeichneten ihn aus. Insbesondere bedanke ich mich für die Möglichkeit, diese Arbeit zu beenden, obwohl Herr Prof. Dr. Strutz die Abteilung Nephrologie und Rheumatologie in Göttingen im Jahr 2009 verließ.

Außerdem gilt mein Dank den Mitarbeitern des Labors: Den medizinisch-technischen Assistentinnen Frau Christina Stanischa, Frau Swantje Wehn, Frau Fatima Agdas und Frau Anika Krüger. Sie standen stets mit Rat und Tat zur Seite und waren eine äußerst freundliche, hilfsbereite und kompetente Unterstützung bei der Durchführung der Experimente und deren Auswertungen. Des Weiteren bedanke ich mich bei meinen Mitdoktoranden Sebastian, Katharina, Tanja, Varenja, Marcel, Benjamin, Björn und Desiree für die gute Zusammenarbeit.

Für die statistische Beratung im Rahmen der Doktorandensprechstunde der Abteilung medizinische Statistik der Universität Göttingen bedanke ich mich in aller Form bei Herrn Dr. Klaus Jung. 


\section{Curriculum vitae}

Als Tochter von Dr. Klaus Udo Lotzkat, Zahnarzt, und Dr. Marion Ingeborg Lotzkat, Zahnärztin, wurde ich am 16. August 1983 in Hannover geboren.

In den Jahren 1990-1994 besuchte ich die Grundschule Brüder-Grimm in Hannover mit anschließendem Übergang zur Orientierungsstufe Lüerstrasse in den Jahren 1994-1996. Als Schülerin des Kaiser-Wilhelm- und Ratsgymnasiums erhielt ich im Jahre 2003 mein Abitur.

Den Zeitraum von 2000 bis 2001 verbrachte ich als Austauschschülerin an der Bishop's School in San Diego, Kalifornien. Dort erwarb ich meinen amerikanischen High-SchoolAbschluss.

Im Wintersemester 2003 begann ich das Studium der Zahnmedizin an der Georg-August Universität Göttingen. Im Sommer 2004 absolvierte ich die naturwissenschaftliche Vorprüfung, im Frühjahr 2006 die zahnmedizinische Vorprüfung und im Winter 2008 die zahnärztliche Prüfung. Im Dezember 2008 erhielt ich meine Approbation.

In dem Zeitraum vom Sommer 2007 bis Sommer 2009 arbeitete ich als Doktorandin in der Abteilung Nephrologie und Rheumatologie der Universität Göttingen unter der Leitung von Herrn Prof. Dr. med. Frank Strutz.

Im August 2009 trat ich eine Stelle als Vorbereitungsassistentin in der zahnärztlichen Gemeinschaftspraxis Dres. Lotzkat in Hannover an. Nach Abschluss des allgemeinzahnärztlichen Jahres begann ich im September 2010 die fachzahnärztliche Weiterbildung zur Kieferorthopädin in der Praxis Dr. Eva Rohde in Witzenhausen. 